Check for updates

Cite this: Chem. Soc. Rev., 2021, 50, 5952

Received 25th August 2020

DOI: $10.1039 / \mathrm{d0cs00540a}$

rsc.li/chem-soc-rev

\section{Racemases and epimerases operating through a 1,1-proton transfer mechanism: reactivity, mechanism and inhibition}

\author{
Matthew D. Lloyd, (D)*a Maksims Yevglevskis, ${ }^{\text {ab }}$ Amit Nathubhai, ${ }^{\text {ac }}$ \\ Tony D. James, (D) de Michael D. Threadgill ${ }^{\text {af }}$ and Timothy J. Woodman ${ }^{\text {a }}$
}

\begin{abstract}
Racemases and epimerases catalyse changes in the stereochemical configurations of chiral centres and are of interest as model enzymes and as biotechnological tools. They also occupy pivotal positions within metabolic pathways and, hence, many of them are important drug targets. This review summarises the catalytic mechanisms of PLP-dependent, enolase family and cofactor-independent racemases and epimerases operating by a deprotonation/reprotonation (1,1-proton transfer) mechanism and methods for measuring their catalytic activity. Strategies for inhibiting these enzymes are reviewed, as are specific examples of inhibitors. Rational design of inhibitors based on substrates has been extensively explored but there is considerable scope for development of transition-state mimics and covalent inhibitors and for the identification of inhibitors by high-throughput, fragment and virtual screening approaches. The increasing availability of enzyme structures obtained using X-ray crystallography will facilitate development of inhibitors by rational design and fragment screening, whilst protein models will facilitate development of transition-state mimics.
\end{abstract}

${ }^{a}$ Drug \& Target Discovery, Department of Pharmacy \& Pharmacology, University of Bath, Claverton Down, Bath BA2 7AY, UK. E-mail: M.D.Lloyd@bath.ac.uk; Fax: +44-(0)1225-386786

${ }^{b}$ CatSci Ltd., CBTC2, Capital Business Park, Wentloog, Cardiff, CF3 2PX, UK

${ }^{c}$ University of Sunderland, School of Pharmacy \& Pharmaceutical Sciences, Sciences Complex, Sunderland SR1 3SD, UK

${ }^{d}$ Department of Chemistry, University of Bath, Claverton Down, Bath BA2 $7 A Y, U K$

${ }^{e}$ School of Chemistry and Chemical Engineering, Henan Normal University, Xinxiang 453007, People's Republic of China

${ }^{f}$ Institute of Biological, Environmental \& Rural Sciences, Aberystwyth University, Aberystwyth SY23 3BY, UK

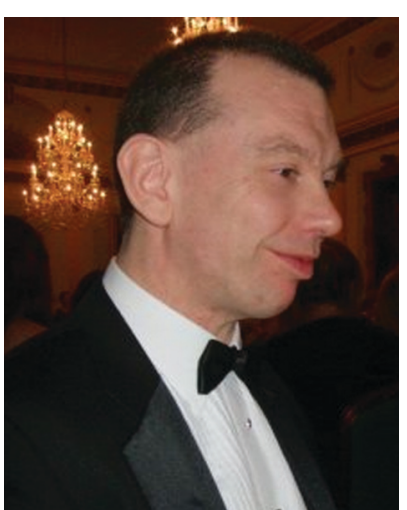

Matthew D. Lloyd
Matthew D. Lloyd obtained his BSc (Hons) in Biological Chemistry at the University of Leicester, and a DPhil at the University of Oxford with the late Professor Sir Jack E. Baldwin FRS and Professor Chris Schofield FRS. Following postdoctoral research at Brown University and oxford, he joined the Department of Pharmacy \& Pharmacology at the University of Bath in 2002 and is a Senior Lecturer and Fellow of the Royal Society of Biology, undertaking research in chemical biology, lipid metabolism, enzymes and inhibitors as new treatments for cancer and other diseases. He is 4th Degree Black Belt in Ch'ang-Hon Taekwon-Do.

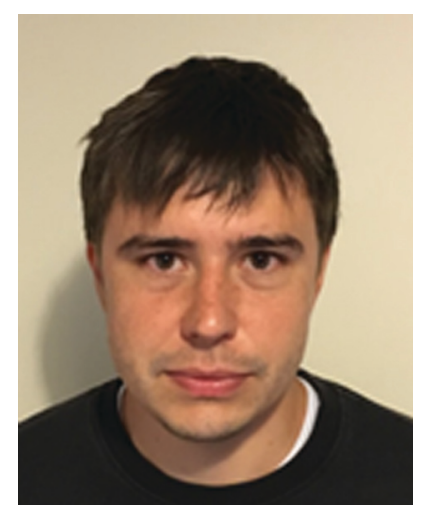

Maksims Yevglevskis
Maksims Yevglevskis obtained his $B S c$ in Chemical Engineering from Riga Technical University (Latvia) in 2009 and MRes in Chemical Research from University of Bath in 2011. He then joined Matthew Lloyd's group at the University of Bath, where he obtained a PhD in 2015 working on developing assays and inhibitors of $\alpha$-methylacylCoA racemase (AMACR). This was followed by a three-year PDRA position on the same project. He is currently working at CatSci Ltd in Cardiff and has an interest in enzymes as drug targets and biomarkers. 


\section{Introduction}

Chirality is at the very heart of Chemical Biology. Proteins, nucleic acids, carbohydrates and many lipids are all chiral molecules, as are the overwhelming majority of their monomer precursors. In addition, many cellular metabolites also contain chiral centres. It is well-known that, for most chiral biomolecules, one particular configuration is preferred; thus proteins contain predominantly chiral amino-acids with L-configuration ${ }^{1,2}$ ( $S$-configuration in the Cahn-Ingold-Prelog system $^{3}$ except for $R$-cysteine and achiral glycine). Similarly, carbohydrates are or contain predominantly D-sugars, with L-ascorbic acid (vitamin C) being a well-known exception. An important consequence of the chiral nature of proteins is that, when they interact with other chiral molecules, a diastereomeric situation arises; thus, most proteins will be highly

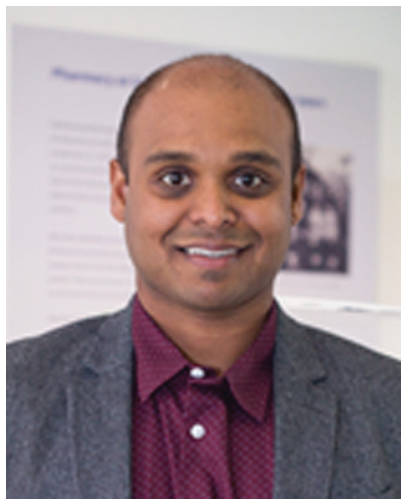

Amit Nathubhai

Amit Nathubhai obtained his BSc (hons) and $\mathrm{MSc}$ in Biological Chemistry from the University of Leicester and a PhD from the University of Bath with $\mathrm{Dr}$ Ian Eggleston. Amit performed postdoctoral studies in Medicinal Chemistry, Biochemistry and in vitro Cell Biology at the University of Bath. He is currently a Senior Lecturer at the University of Sunderland. His research interests lie at the chemistry and biology interface and emphasises development of chemical tools and drug-like molecules to dissect biological mechanisms involved in cancer, fibrosis, diabetes and obesity. He has a keen interest in fresh-water aquatics, and writing and playing music.

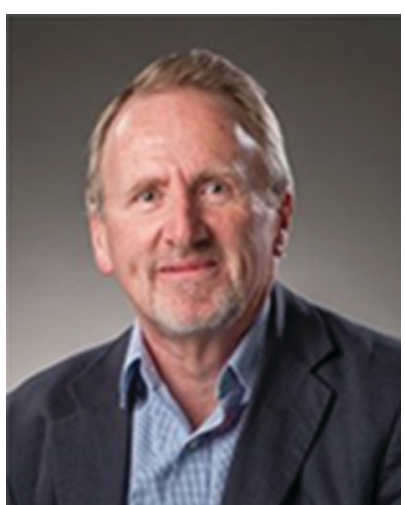

Michael D. Threadgill
Michael D. Threadgill is Emeritus Professor of Medicinal Chemistry at the University of Bath and Visiting Professor at Aberystwyth University. He obtained MA and $\mathrm{PhD}$ from the University of Cambridge (PhD under the supervision of Prof. Sir Alan $R$. Battersby FRS), PGCE from the University of Durham and DSc from the University of Bath and is a Fellow of the Royal Society of Chemistry. His research interests include developing inhibitors of the PARP superfamily of enzymes, tumour-selective delivery of drugs, identification of natural products and BNCT. He is also a keen cricketer and umpire. selective for a particular configuration of their interacting partners (substrate, inhibitor, allosteric effector). An important consequence of this is that different stereoisomers of chiral drugs are effectively different drugs, which will generally have different protein targets (enzyme, receptors etc.) and different pharmacokinetics. ${ }^{4,5}$ Finally, many drugs are known to undergo metabolic changes of chiral configuration in vivo, ${ }^{4,5}$ e.g. ibuprofen and related 'profens' (reviewed in ref. 6-8) and mandelic acid.,10 In addition the 2-(aryloxy)propanoic acid herbicides undergo changes in chiral configuration which are mediated by soil bacteria. $^{11-13}$

Notwithstanding the fact that most biological molecules exist overwhelmingly in one stereochemical configuration, there are many examples where minor stereoisomers play an essential role. The most well-known example of this is proteinogenic amino-acids such as alanine and glutamate, which are

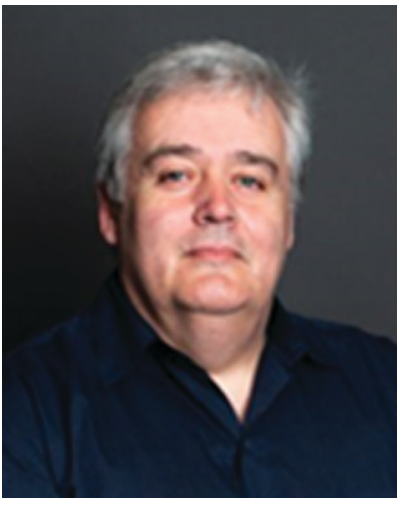

Tony D. James
Tony D. James obtained his BSc from the University of East Anglia (1986), PhD from the University of Victoria, Canada (1991), and undertook Postdoctoral Research with Seiji Shinkai (1991-95). He was a Royal Society University Research Fellow at the University of Birmingham (1995-2000) before moving to the University of Bath (2001) where he is a Professor and holds a prestigious Royal Society Wolfson Research Merit Award (20172022). He was awarded the Daiwa-Adrian Prize (2013), the inaugural CASE Prize (2015) and the MSMLG Czarnik Award (2018). He has $>363$ papers on molecular recognition and sensor design and a h-index of 72 .

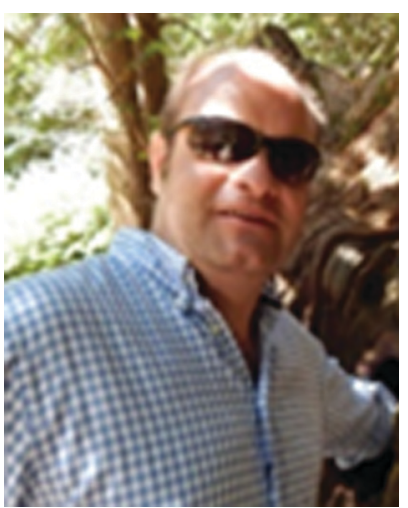

Timothy J. Woodman
Timothy J. Woodman obtained a BSc (hons) in Chemistry from the University of Warwick (1994) and a PhD in organometallic chemistry from the same institution in 1999, studying under Dr Gerald Willey. Following a year in New Zealand as a Royal Society Fellow, he joined the research group of Professor Manfred Bochmann, initially at the University of Leeds and subsequently at the University of East Anglia. He joined the University of Bath in 2005 and is currently a Senior NMR Spectroscopist, with interests in prostate cancer and the science of chillies. Outside the University, his main interest is cricket. 
found in their $\mathrm{D}$-configuration ( $R$-configuration) within bacterial peptidoglycan. ${ }^{14-17}$ In most cases, these minor stereoisomers are not biosynthesised de novo but are obtained by changing the stereochemical configuration of the most abundant isomer into that of the less abundant isomer.

The enzymes which perform these changes in stereochemical configuration are known as racemases and epimerases, which have been shown to have a pivotal position in metabolism, and thus have gained significant interest as drug targets for diseases such as bacterial infections, ${ }^{14,18-25}$ Chagas disease, ${ }^{26-28}$ cancer, ${ }^{6,7,18,29}$ Alzheimer's disease and other dementias, ${ }^{1,2,30-32}$ formation of cataracts ${ }^{1,33}$ and diabetic retinopathy; ${ }^{34}$ racemase levels are also a marker of ischaemic stroke. ${ }^{35}$ Inhibition of diaminopimelate epimerase activity also potentiates cephem antibiotic activity by compromising the integrity of the bacterial cell wall. ${ }^{36}$

Low activity or concentrations of racemases/epimerases (AMACR $^{37}$ methylmalonyl-CoA epimerase ${ }^{38}$ ) are associated with inherited errors in metabolism and may also be associated with stroke and dementia ${ }^{39}$ and neurodegenerative diseases, ${ }^{40}$ such as Amyotrophic Lateral Sclerosis (ALS, a.k.a. motor neurone disease, Lou Gehrig's disease). Increased methylmalonic acid levels in the aging population (resulting from a decrease in methylmalonyl-CoA epimerase activity) is suggested to promote an aggressive cancer phenotype by upregulation of the SOX4 transcription factor. ${ }^{41}$ Increased levels of aspartate/ glutamate racemases protect Salmonella enterica from aminoacrylate metabolic stress. ${ }^{42}$ Increased activity of the bifunctional enzyme UDP- $N$-acetylglucosamine 2-epimerase/ $N$-acetylmannosamine kinase results in sialuria, an extremely rare genetic disorder, while knockout of the corresponding gene is lethal in mice. ${ }^{43,44}$ Mutations in this epimerase are linked to hereditary inclusion body myopathy (HIBM). ${ }^{44,45}$ In addition, $O$-ureidoserine racemase is involved in the biosynthesis of the antibiotic D-cycloserine ${ }^{46}$ while a peptide epimerase is found in funnel web spider (Agelenopsis aperta) venom which interconverts two 48 aminoacid peptides differing only in the configuration at a single serine residue (Ser-46). ${ }^{47}$ Finally, racemases and epimerases are used in dynamic kinetic resolutions and other biotechnological applications. $^{48-54}$

Racemases and epimerases use several different strategies to bring about changes in stereochemical configuration of their substrates, including the use of radical reactions, ${ }^{55-60}$ elimination and re-addition of nucleotides ${ }^{20,61}$ and the use of redox cofactors. ${ }^{18,19,62-64}$ An important example of a 'epimerase' utilising redox cofactors is decaprenylphosphoryl- $\beta$-D-ribose epimerase (DprE); however, this is not a true epimerase reaction as the oxidative and reductive reactions are catalysed by separate enzymes (DprE1 and 2, respectively) using different cofactors [flavin adenine dinucleotide (oxidised) and nicotinamide adenine dinucleotide (reduced)]. ${ }^{65-68}$

By far the most common mechanism used by racemases and epimerases is the deprotonation/reprotonation ${ }^{14,18,20,63}(1,1-$ proton transfer) reaction. These enzymes fall into three classes: those which are pyridoxal 5' -phosphate (PLP)-dependent; ${ }^{5,50,69,70}$ those which use metal ions (enolase enzymes ${ }^{14,49,71,72}$ ); and those which are cofactor-independent (Scheme 1). ${ }^{6,7,18,20,63}$ The PLP-dependent enzymes (Scheme 1A) catalyse exchange between PLP in the internal aldimine 1 (catalytic Lys sidechain) and the external aldimine 2 (substrate $\alpha$-amino group). Deprotonation $^{69,70}$ of 2 results in the ylide intermediate 3 which is subsequently reprotonated from the other face to produce the external aldimine $\mathbf{4}$ with opposite configuration. In contrast, the metal-dependent enzymes, e.g. mandelate racemase, apparently perform a concerted reaction (Scheme 1B; 5-7). Solvent isotope experiments show that label is incorporated into product with little incorporation into recovered substrate, ${ }^{73,74}$ which is consistent with a concerted mechanism. However, kinetic isotope effect measurements on mandelate racemase are consistent with a stepwise reaction and a discrete deprotonated intermediate. ${ }^{75}$ Finally, most cofactor-independent racemases/ epimerases utilise a concerted mechanism, ${ }^{5,76-78}$ as illustrated by glutamate racemase (Scheme $1 \mathrm{C} ; \mathbf{8 - 1 0}$ ). However, some cofactor-independent enzymes using substrates with acidic $\alpha$-protons perform their reactions with a stepwise mechanism via a discrete enolate intermediate (e.g. $\alpha$-methylacyl-CoA racemase $\mathrm{ra-81}^{79}$.

Enzymes which use metal ions as Lewis acids (enolase family enzymes) or are cofactor-independent are of particular interest, since they are able to perform the apparently simple 1,1-proton transfer using active site amino-acid residues and thus are model systems for understanding enzymatic reactions in general. Several of these enzymes are also important as drug targets, ${ }^{6,7,20-23}$ potential drug targets, ${ }^{84}$ or are used in biotechnological applications. ${ }^{48,49,51}$ This review will consider racemases/ epimerases utilising deprotonation and deprotonation mechanisms, their reactivity and the strategies used to inhibit them.

\section{Reactivity of racemases and epimerases}

\section{Racemisation and epimerisation reactions}

On the face of it, the reaction catalysed by racemases and epimerases operating through a 1,1-proton transfer mechanism is deceptively simple, consisting of only deprotonation and deprotonation (Scheme 1). In the case of the PLP-dependent enzymes, e.g. alanine racemase, the active site is situated at the interface between two dimer subunits. ${ }^{69}$ Formation of the external aldimine between the PLP cofactor and substrate considerably enhances the acidity of the $\mathrm{C}_{\alpha}-\mathrm{H}^{5,18,20,69}$ Stabilisation of the developing negative charge in PLP-dependent enzyme reactions requires that the broken bond is perpendicular to the PLP $\pi$-system. ${ }^{69,70,85}$

The imine nitrogen between the amino-acid substrate and the PLP cofactor is thought to be protonated ${ }^{5}$ and this enhances the acidity of the $\mathrm{C}_{\alpha}-\mathrm{H}$. This effect is illustrated by chemical systems which show that the $\mathrm{p} K_{\mathrm{a}}$ of zwitterionic glycine is 28.9 whilst the corresponding $\mathrm{p} K_{\mathrm{a}}$ for the zwitterionic imine between glycine and acetone is $22 .{ }^{86}$ Model studies using the glycine aldimine of pyridoxal suggest a $\mathrm{C}_{\alpha}-\mathrm{H}$ p $K_{\mathrm{a}}$ value of 11 and 17 for when the pyridoxal aromatic hydroxy group is 

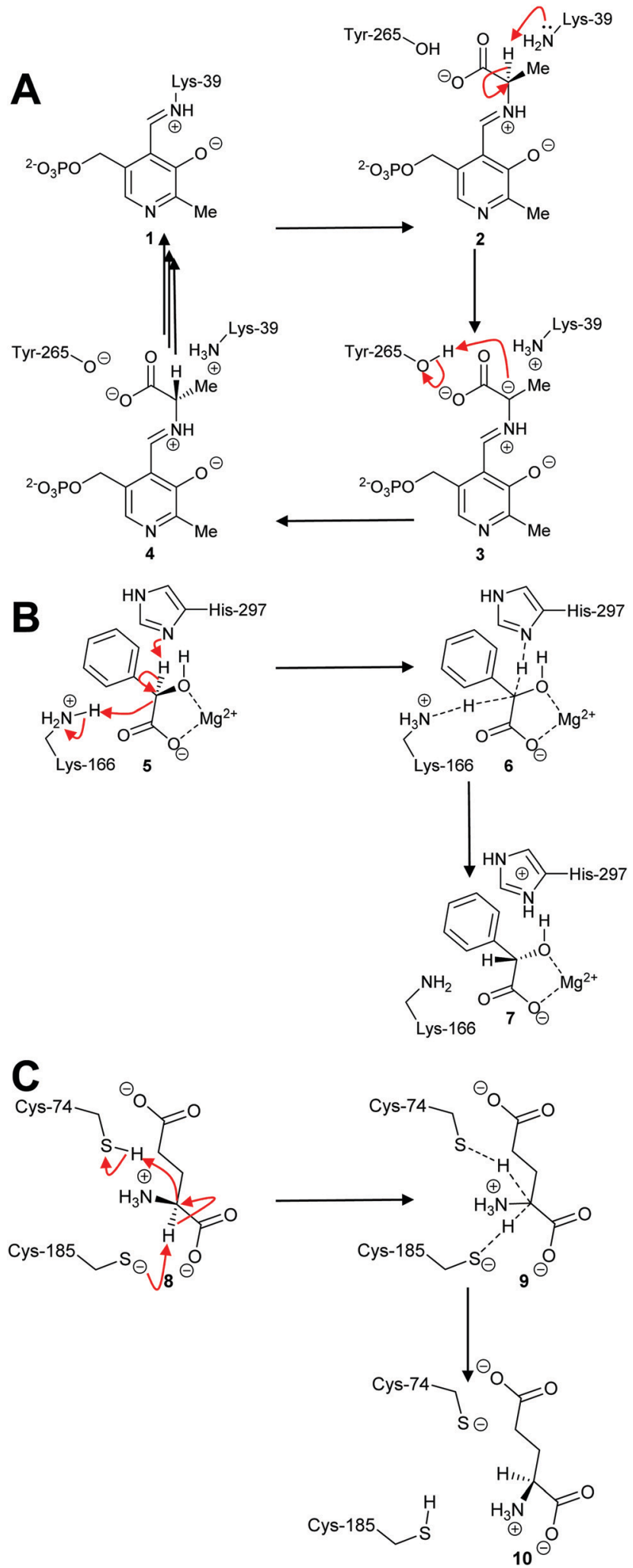

Scheme 1 Example mechanisms of racemases and epimerases operating by a 1,1-proton transfer mechanism. (A) PLP-dependent amino acid racemases, as shown by alanine racemase; ${ }^{5,69}$ (B) Metal-dependent (enolase) enzymes, as shown by mandelate racemase, ${ }^{74,75}$ (C) Cofactorindependent racemases as shown by glutamate racemase. ${ }^{63,82,83}$ Dashed lines show bonds being broken or formed in the transition state.

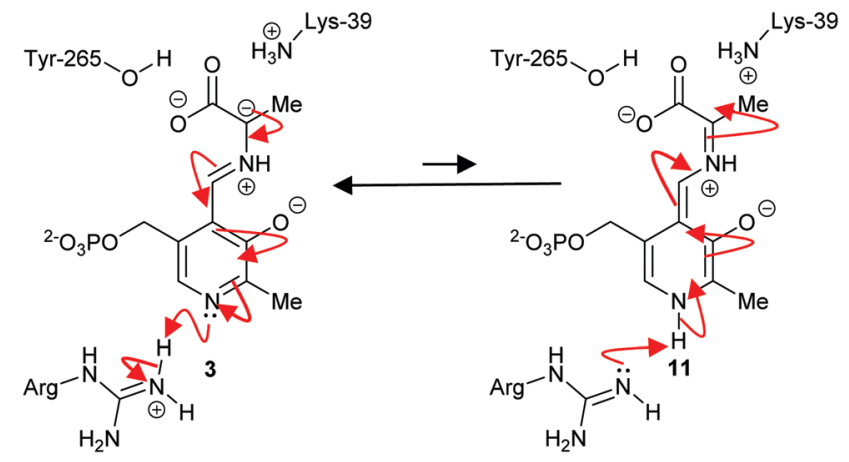

Scheme 2 Carbanion 3 and quinoid $\mathbf{1 1}$ intermediates in the alanine racemase reaction. ${ }^{69}$

protonated and deprotonated, respectively. ${ }^{5}$ These studies also show that protonation of the amino-acid carboxylate further decreases the $\mathrm{C}_{\alpha}-\mathrm{H}$ p $K_{\mathrm{a}}$ value to 6 but crystal structures suggest that this does not occur during the enzyme catalytic cycle. This is contrast to the situation in cofactor-independent racemases/ epimerases, where substrate carboxylate groups are held within a hydrogen-bonding network ${ }^{20}$ or transiently protonated during the reaction. ${ }^{21}$ The $\mathrm{p} K_{\mathrm{a}}$ of the external aldimine $\mathrm{C}_{\alpha}-\mathrm{H}$ in the alanine racemase reaction is estimated to be 9 , which is intermediate between those for the catalytic bases, Tyr-265 and Lys-39. ${ }^{69}$

The mechanism of some PLP-dependent enzymes, e.g. ornithine decarboxylase, is thought to go via a quinoid intermediate $^{69,70}$ resulting from protonation of the pyridoxal nitrogen by a glutamic acid residue. The equivalent residue in alanine racemase is an arginine and the pyridoxal nitrogen is not extensively protonated ${ }^{69,70}$ (Scheme 2). Therefore, alanine racemase is thought to catalyse its reaction via a carbanion 3 not a quinoid 11 intermediate. ${ }^{69}$ Kinetic isotope effect experiments on alanine racemase are consistent with a carbanion rather than quinoid intermediate. ${ }^{70,87}$

The situation is different for enolase-family racemases and epimerases and those which are cofactor-independent. The fundamental problem for these enzymes is how to deprotonate a substrate carbon acid (typical $\mathrm{p} K_{\mathrm{a}}=\sim 21-23^{86,88,89}$ ) using active site bases with $\mathrm{p} K_{\mathrm{a}}$ values in the range 6-9 without the enhancement afforded by a PLP cofactor. Many racemase/ epimerase substrates possess carboxylic acids ( $\left.K_{\mathrm{a}} 2-5\right)$, which are deprotonated to the negatively charged carboxylate (e.g. substrates of amino-acid racemases/epimerases ${ }^{20}$ and methylmalonyl-CoA epimerase ${ }^{90}$ ). Consequently, the apparent $\mathrm{p} K_{\mathrm{a}}$ of the $\mathrm{C}_{\alpha}-\mathrm{H}$ for these substrates will be $\sim 29^{20,86}$ This effect is illustrated by chemical systems, which show that the $\mathrm{p} K_{\mathrm{a}}$ for the $\mathrm{C}_{\alpha}-\mathrm{H}$ of glycine in water is 28.9 , while the corresponding $\mathrm{p} K_{\mathrm{a}}$ for glycine methyl ester is $21.0 .^{86}$

Racemases and epimerases utilising a negatively charged substrate generally hold the carboxylate group within a hydrogen-bonding network or ion pair to disperse the negative charge. ${ }^{20}$ In some cases, the enzyme also transfers the incoming proton onto the substrate carboxylate group before it is transferred onto the $\mathrm{C}_{\alpha}$ of the product (e.g. glutamate racemase ${ }^{21}$ ). 
Exceptions to this strategy are seen with methylmalonyl-CoA epimerase $^{90}$ and mandelate racemase, ${ }^{91,92}$ where the carboxylate group is ligated to the active site $\mathrm{Co}^{2+}$ or $\mathrm{Mg}^{2+}$ ion which acts as a Lewis acid and diminishes the $\mathrm{p} K_{\mathrm{a}}$ of the $\mathrm{C}_{\alpha}-\mathrm{H}{ }^{21}$ Typically the carboxylate group is also held within a hydrogen-bonding network with active-site residues. ${ }^{5}$ Some racemase/epimerase substrates also contain further destabilising groups, such as ammonium groups (amino-acid racemases/epimerases), ${ }^{18,20}$ amide carbonyl groups ( $N$-succinylamino acid racemases, dipeptide epimerases and other enolase family enzymes ${ }^{18,49}$ ) and $\mathrm{OH}$ (mandelate racemase, ${ }^{18,91}$ various sugar epimerases ${ }^{18}$ ). Both ammonium and $\mathrm{OH}$ groups are more easily deprotonated than the $\mathrm{C}_{\alpha}-\mathrm{H}$. Chemical models ${ }^{86,93}$ show that the $\mathrm{p} K_{\mathrm{a}}$ of the $\mathrm{C}_{\alpha}-\mathrm{H}$ is diminished by 9-15 units by protonation of an adjacent amine and a number of amino-acid racemases/epimerases, ${ }^{20,94}$ including diaminopimelate epimerase and glutamate racemase, appear to protonate the amine of the substrate during the reaction. In the case of mandelate racemase $\mathrm{e}^{18,91}$ and $\mathrm{N}$-succinylaminoacid racemases, ${ }^{49}$ the $\mathrm{OH}$ or amide carbonyl groups are ligated to active-site metals such as $\mathrm{Mg}^{2+}$ (mandelate racemase ${ }^{18,91,92}$ ) or $\mathrm{Co}^{2+}, \mathrm{Mn}^{2+}$ or, occasionally, $\mathrm{Mg}^{2+}(N$-succinylamino-acid racemases $\left.{ }^{49}\right)$. The rates of proton transfer for the deprotonation and reprotonation steps are generally high, with rate constants of the order of $5 \times 10^{9}$ to $100 \times 10^{9} \mathrm{M}^{-1} \mathrm{~s}^{-1}$. $^{86}$

Recent analysis ${ }^{18}$ of racemase/epimerase crystal structures, obtained in the presence of ligands, suggests that the vast majority of enzymes bind the two substrate stereoisomers using 'mirror-image packing', that is functional groups are held within the same position with the $\mathrm{C}_{\alpha}-\mathrm{H}$ on opposite sides in the different stereoisomers. In some cases, e.g. amino-acid racemases/epimerases, ${ }^{20}$ the positions of the substrate sidechain and functional groups show remarkably small differences in their positions between the stereoisomers. In other cases, e.g. AMACR/MCR ${ }^{6,7,18,95}$ which utilises substrates with large hydrophobic side-chains, the different epimers are accommodated by fixing two of the function groups (the methyl group and acyl-CoA moiety in this case) whilst the side-chain is accommodated in discrete binding sites on a hydrophobic surface at the entrance of the active site.

The active-site bases sit immediately adjacent to the $\mathrm{C}_{\alpha}-\mathrm{H}$. In the vast majority of cases, the active-site bases are located on both sides of the substrate (the so called 'two-base enzymes'), while, in a few cases (the 'one-base' enzymes), a single activesite base mediates catalysis. ${ }^{18,20,96}$ Many racemases/epimerases are dimers, with the active site located at the dimer interface and active-site bases contributed by both subunits; ${ }^{18,20,95}$ binding of substrate often triggers movement of the subunits from an 'open' to a 'closed' conformation, moving the active-site bases into position and desolvating the active site..$^{20,94,97,98}$ In some enzymes (e.g. glutamate racemase $\mathrm{e}^{21}$ ), this conformational change triggers a change in the conformation of the deprotonating activesite base as part of the pre-activation step which results in protonation of the substrate carboxylate group. It has also been suggested that conformational changes by 'capping domains', which result in the closed form of the racemase, activate the enzyme for catalysis, are important, e.g. in mandelate racemase. ${ }^{94}$
In other cases, little or no conformational changes are observed in the protein upon binding of substrate and the enzyme active site is substantially desolvated in the unbound state. ${ }^{20,95}$

\section{Active-site bases}

PLP-dependent enzymes use several different active-site bases. In alanine racemase, these are generally thought to be Tyr-265 and Lys-39 (Fig. 1). 5,69,70,99 Chemical models suggest that the $\mathrm{p} K_{\mathrm{a}}$ of these active-site bases are increased to $\sim 21$ (Lys) and $\sim 28$ (Tyr), respectively, in the hydrophobic active site. ${ }^{100}$ This is considerably higher than the experimentally-determined $\mathrm{C}_{\alpha}-\mathrm{H} \mathrm{p} K_{\mathrm{a}}$ value of $11^{101}$ and $9.94 .{ }^{87}$ Hence, deprotonation of the substrate is expected to be facile. In serine racemase, the corresponding active-site bases are Lys-57 and Ser-82 ${ }^{69}$ and the experimentally determined external aldimine $\mathrm{C}_{\alpha}-\mathrm{H} K_{\mathrm{a}}$ value is 9.26. ${ }^{87}$ Chemical models suggest that their active site base $\mathrm{p} K_{\mathrm{a}}$ values will be $\sim 21$ and $33-39,{ }^{100}$ the latter being extremely high. These $\mathrm{p} K_{\mathrm{a}}$ values will be modified by hydrogen-bonding networks within the active site, to allow deprotonation of the active-site residues and reprotonation of the carbanionic intermediate (vide supra, Schemes 1 and 2, 3).

The $N$-succinylamino acid racemases and related enolase enzymes, e.g. $O$-succinylbenzoate synthase, ${ }^{102,103}$ utilise a pair of lysine residues as catalytic bases ${ }^{49,104}$ (Fig. 2). Chemical models ${ }^{100}$ suggest that the $\mathrm{p} K_{\mathrm{a}}$ for these lysine residues within the active site will be $\sim 21$. The $\mathrm{C}_{\alpha}-\mathrm{H}$ p $K_{\mathrm{a}}$ for these substrates

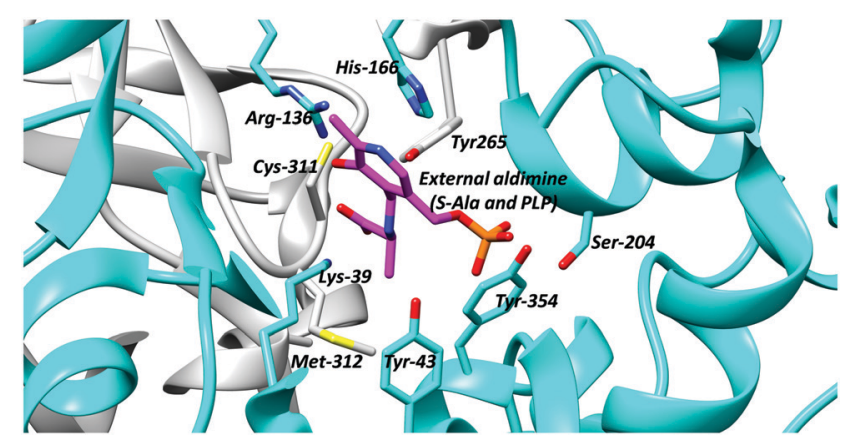

Fig. 1 Active site residues of $B$. stearothermophilus alanine racemase showing the external aldimine (alanine conjugated to PLP) and active site bases Lys-39 and Tyr-265 (PDB: 1L6F). ${ }^{99}$

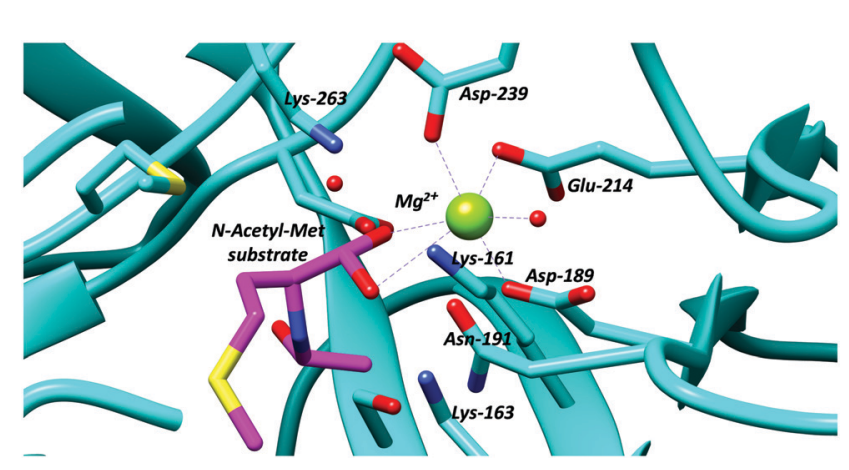

Fig. 2 Active site residues of an $\mathrm{N}$-acetyl-amino-acid racemase, showing binding of $N$-acetyl-methionine substrate (PDB: 4A6G). ${ }^{104}$ 


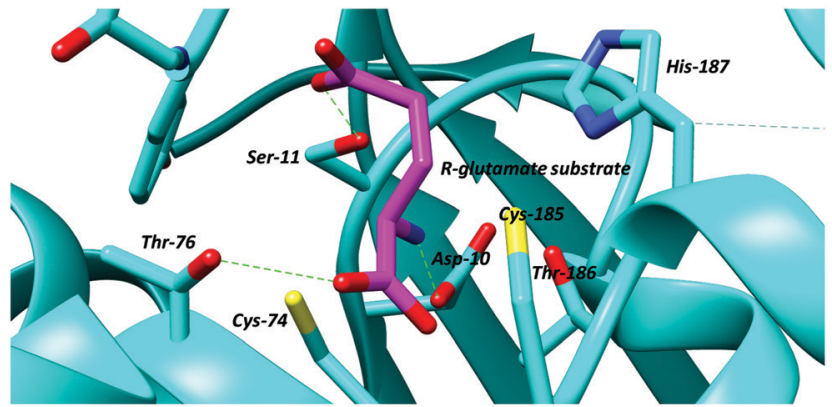

Fig. 3 Active site of glutamate racemase from B. subtilis showing bound $R$-glutamate substrate and active site bases, the cysteine residues, Cys-74 and Cys-185 (PDB: 1ZUW). ${ }^{105}$ Hydrogen bonds are shown as green dashed lines.

ligated to active-site metals appears not to have been calculated, though studies on other metal-dependent enzymes (mandelate racemase) ${ }^{101}$ suggests that this will be $\sim 15$.

Several different active-site bases are used by the cofactorindependent racemases and epimerases. In most amino-acid racemases/epimerases, both active-site bases are Cys, which act as a thiolate base/thiol acid pair, catalysing deprotonation and deprotonation, ${ }^{18,20}$ e.g. Cys-74 and Cys-185 in B. subtilis glutamate racemase ${ }^{105}$ (Fig. 3). Cys is favoured as an active-site base in amino-acid racemases and epimerases because it is more easily desolvated and has a lower $\mathrm{p} K_{\mathrm{a}}$ than Ser or Thr. ${ }^{106}$ Chemical models suggest that desolvation raises the $\mathrm{p} K_{\mathrm{a}}$ of the Cys residue thiol to thiolate conversion to $\sim 28,{ }^{100}$ matching the expected $\mathrm{p} K_{\mathrm{a}}$ of the $\mathrm{C}_{\alpha}-\mathrm{H}$ of $\sim 29 .^{20,86}$ This allows deprotonation of the $\mathrm{C}_{\alpha}-\mathrm{H}$ by the Cys thiolate. In contrast, the $\mathrm{p} K_{\mathrm{a}}$ values of the active-site Cys residues acting as an acid appear to be $\sim 6-7$ to enable protonation from the opposite side. This change in $\mathrm{p} K_{\mathrm{a}}$ appears to be mediated by a dipole on the $\alpha$-helices bearing the Cys thiol (at least in diaminopimelate epimerase $\left.^{20,107}\right)$. Exceptions to this rule include aspartate/ glutamate racemase from a pathogenic E. coli strain (Ecl-DER), in which one of the catalytic Cys is replaced by Thr. This enzyme catalyses irreversible conversion of $S$-Asp to $R$-Asp, which arises partly because of differences in the $\mathrm{p} K_{\mathrm{a}}$ values of the Cys and Thr side-chains and partly because of differences in the distance between the $\mathrm{C}_{\alpha}-\mathrm{H}$ and the catalytic bases on either side of the substrate. ${ }^{20,108,109}$ Similarly, MMP0739 aspartate/glutamate racemase from Methanococcus maripaludis possesses active-site Cys and Thr residues and is predicted to catalyse unidirectional enantiomerisation $^{42}$ (the opposite catalytic base is replaced compared to the aspartate/glutamate racemase exception noted above $\left.^{20}\right)$. The $H$. sapiens trans-3-hydroxy-S-proline epimerase ${ }^{110}$ also possesses an equivalent Cys-to-Thr substitution to that in MMP0739. ${ }^{42}$ However, biochemical analysis shows that this Cysto-Thr substitution converts the latter enzyme from an epimerase into a dehydratase, ${ }^{110}$ i.e. the enzyme catalyses elimination rather than racemisation/epimerisation (vide infra).

Other racemases and epimerases use a variety of active-site bases, including Cys/Cys (allantoin racemase ${ }^{71}$ ), His/Lys (mandelate racemase $^{71}$ ), Glu/Glu or Asp/Asp (several different epimerases acting on sugar substrates ${ }^{71}$ ), Glu/Glu (methylmalonyl-CoA epimerase $^{90}$ ), Tyr/Glu (heparin sulfate D-glucuronosyl C-5 epimerase $^{71}$ ), Glu/His or Tyr/His (various sugar mutarotatases ${ }^{71}$ ), Lys/Lys (various $N$-succinylamino-acid racemases and enolase family racemases ${ }^{18,49}$ ), an Asp/His pair and Tyr (dTDPdiphosphate-4-keto-6-deoxyglucose 3,5-epimerase a.k.a. RmlC), ${ }^{111}$ and a Glu/His pair and Asp (AMACR and $\mathrm{MCR}^{71,81,95,112}$ ). $\mathrm{N}$-Acetylmannosamine-6-phosphate 2-epimerase appears to be an exception to this rule, as only one active site base/acid (Lys) has been identified. ${ }^{18,96}$

The active sites of these other racemases and epimerases also exclude bulk solvent. ${ }^{95}$ Chemical models ${ }^{100}$ again suggest that the $\mathrm{p} K_{\mathrm{a}}$ of these active-site bases are correspondingly increased to $\sim 29$ (His), $\sim 21$ (Lys), $\sim 22$ (Asp and Glu), and $\sim 28$ (Tyr), again matching approximately the expected $\mathrm{p} K_{\mathrm{a}}$ values of the substrate $\mathrm{C}_{\alpha}-\mathrm{H}$. Each of these bases participates in a hydrogen-bonding network with other active site residues and, in some cases, active-site ordered waters.

An often-overlooked consideration in the catalytic mechanism is the hydrogen bonding between the electron-deficient $\mathrm{C}_{\alpha}-\mathrm{H}$ (which are activated by adjacent carbonyl groups) and active-site bases. This is of relevance for all proteins, since all protein amino-acid residues are capable of forming such bonds. ${ }^{113}$ These hydrogen bonds tend to be moderately weak ( 8 to $10.6 \mathrm{~kJ} \mathrm{~mol}^{-1}$ when bonding to water compared to $18.9 \mathrm{~kJ} \mathrm{~mol}^{-1}$ for an 'typical' intra-molecular bond ${ }^{114}$ ). In addition, amino-acids and other racemase/epimerase substrates will also be able to form such bonds. The case of the $\mathrm{C}_{\alpha}-\mathrm{H} / \mathrm{His} /$ Glu hydrogen bond in AMACR/MCR is particularly interesting in this regard (Fig. 4), as the hydrogen bond resembles that in the catalytic triad of chymotrypsin and related hydrolytic enzymes which has been studied in detail. ${ }^{115}$

\section{Concerted versus stepwise reactions}

The PLP-dependent enzymes have been extensively studied and a series of mechanistic and computational studies show the

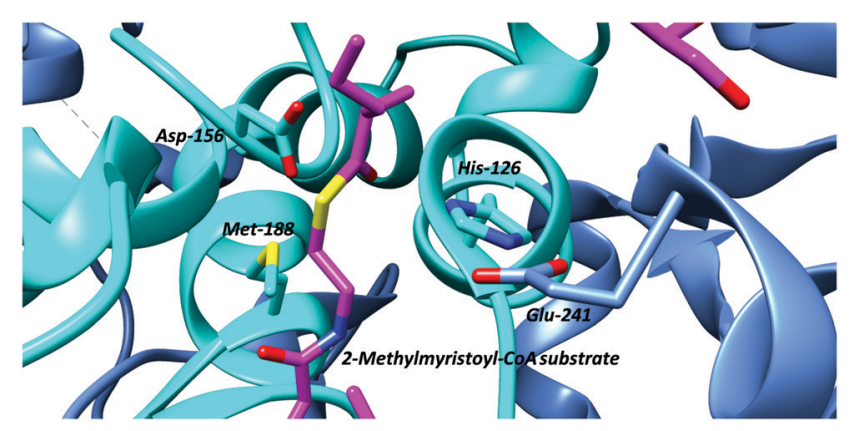

Fig. 4 Active-site arrangement of $\alpha$-methylacyl-CoA racemase (MCR) from $M$. tuberculosis showing binding of binding of 2-methyltetradecanoyl-CoA substrate (PDB: 2GCl). ${ }^{95}$ Active site bases include Asp-156 and the His-126/Glu-241 pair, with Glu-241 contributed by the second monomer subunit. The His-126/Glu-241 pair removes the $\alpha$-proton of the S-2-methylacyl-CoA substrate whilst Asp-156 protonates the enolate intermediate. 6,7,81,95 The roles of these residues are reversed for the $R$-2-methylacyl-CoA substrate. Met-188 stabilises formation of the enolate intermediate. 
presence of a carbanionic intermediate (vide supra, Schemes 1 and 2, 3), 5,50,69,70,101 indicating a step-wise reaction. Kinetic isotope effect studies on alanine racemase are also consistent with a carbanionic intermediate. ${ }^{87}$ Alanine racemase catalyses $\mathrm{C}_{\alpha}-\mathrm{H}$ exchange but the stereochemical course of this reaction was not determined, ${ }^{116}$ although non-stereoselective incorporation of label into substrate is expected because of the stability of the carbanionic intermediate.

Studies investigating isotopic incorporation from solvent into substrates have been particularly informative about the concertedness of mechanism in other enzymes. For the majority of enolase family and cofactor-independent racemases and epimerases, isotopic incorporation is observed into the product but very little incorporation is observed into the substrate, e.g. glutamate racemase, ${ }^{78}$ proline racemase, ${ }^{77}$ mandelate racemase, ${ }^{74} 2$-methylmalonyl-CoA epimerase ${ }^{73}$ and a racemase mediating post-translational modification of peptides. ${ }^{117}$ This is consistent with a concerted reaction. Monitoring the progress of the reaction by these enzymes in isotopically labelled solvent using circular dichroism typically results in an overshoot of the equilibrium position, e.g. as has been observed for mandelate racemase. ${ }^{74}$ This results from isotopic incorporation into product only with a significant kinetic deuterium isotope effect affecting the reverse reaction. These results further support a mechanism in which two-base enzymes catalyse a microscopic enantiomerisation reaction, with asynchronously concerted deprotonation and reprotonation. ${ }^{76}$ Such a mechanism minimises the formation of a highly unstable doubly deprotonated intermediate and hence partly overcomes the effect of destabilising groups adjacent to the $\mathrm{C}_{\alpha}-\mathrm{H}$ (i.e. the carboxylate).

In contrast to the above is the observation that incubation of substrates with AMACR in ${ }^{2} \mathrm{H}_{2} \mathrm{O}$ results in a near $1: 1$ incorporation of deuterium into substrate and product. This has been interpreted as formation of a discrete deprotonated intermediate followed by deuteration from either side. ${ }^{79,80}$ Analysis of the crystal structure of the M. tuberculosis homologue, MCR, shows catalytic residues on both sides of the substrate (the His-126/Glu-241 pair and Asp-156; Fig. 4) and are consistent with the formation of an enolate intermediate. $^{81,95,112}$ Thus, AMACR and MCR fundamentally differ in their mechanisms from most other cofactorindependent racemases and epimerases, in that they catalyse microscopic racemisation rather than epimerisation. ${ }^{8,79,80}$ Incorporation of deuterium from solvent is also catalysed by hydantoin racemase via an enolate intermediate ${ }^{118}$ and is expected to be non-stereoselective but this has not yet been verified.

The above results can be rationalised based on the $\mathrm{p} K_{\mathrm{a}}$ values for the deprotonation of the substrate. The $\mathrm{p} K_{\mathrm{a}}$ of $\mathrm{C}_{\alpha}-\mathrm{H}$ for a thioester is $21,{ }^{86,88}$ while the $\mathrm{p} K_{\mathrm{a}}$ values for $\mathrm{C}_{\alpha}-\mathrm{H}$ for amino-acid zwitterions is $29,{ }^{20,86}$ for simple carboxylates is 33 and for simple amides $28.4 .^{86}$ Therefore, concerted reactions occur with substrates containing relatively unactivated $\mathrm{C}_{\alpha}-\mathrm{H}$ (high $\mathrm{p} K_{\mathrm{a}}$ values), with consequent asymmetrical isotopic incorporation. This explains the behaviour of peptide epimerases, ${ }^{117}$ which are observed to undergo concerted reactions. These peptide substrates have $\mathrm{p} K_{\mathrm{a}}$ values of $\sim 26-31$ for $\mathrm{C}_{\alpha}-\mathrm{H}$, although these values are dependent on both $N$ - and $C$-substituents and the protonation status of amine groups. ${ }^{86}$ This model also allows prediction of enzymatic behaviour for uncharacterised racemases/ epimerases, e.g. hydantoin racemase, ${ }^{118}$ based on $\mathrm{p} K_{\mathrm{a}}$ values for $\mathrm{C}_{\alpha}-\mathrm{H}$. The proposed model also casts doubt on the use of isotopic labelling studies to differentiate between 'two-base' and 'one-base' enzymes (reviewed in ref. 92). It has previously been proposed that near-symmetrical isotopic incorporation into substrate and product is indicative of 'internal return', i.e. a 'one-base' mechanism. The results on $\mathrm{AMACR}^{79,80}$ (reviewed in ref. 6 and 7) show that this behaviour is also observed with 'two-base' enzymes with activated $\mathrm{C}_{\alpha}-\mathrm{H}$, as it is known that AMACR/MCR possesses appropriate active-site bases on both sides of the substrate.

\section{Elimination reactions}

Several racemases/epimerases catalyse elimination reactions, in addition to racemisation/epimerisation. With the exception of the 'mutant' $H$. sapiens trans-3-hydroxy-S-proline epimerase containing a Cys-to-Thr substitution noted above ${ }^{110}$ giving rise to dehydratase activity, and the Labrenzia aggregata cis-3hydroxy-S-proline racemase/dehydratase (IAM 12614) ${ }^{119}$ (vide infra), all of the known elimination reactions take place with unnatural substrates. The vast majority of these unnatural substrates are halogen derivatives, ${ }^{20,47,63,82,120-126}$ with only a few exceptions. ${ }^{63,119,124,127,128}$ The deprotonation step in the elimination reaction is highly similar to that described for racemisation/epimerisation (vide supra).

Several PLP-dependent racemases catalyse elimination reactions. $^{129-133}$ The classic example is alanine racemase (Scheme 3) which $\beta$-eliminates halogens from 3-fluoroalanine 12 and 3-chloroalanine $13 .^{132} O$-Carbamoyl- $R$-serine $14 R$ and $O$-acetyl- $R$-serine $\mathbf{1 5 R}$ act as irreversible inhibitors whilst $O$-carbamoyl-S-serine $\mathbf{1 4 S}$ and $O$-acetyl- $S$-serine $\mathbf{1 5 S}$ are reversible competitive inhibitors. ${ }^{132}$ 3-Fluoroalanine 12 is a potent inactivator of alanine racemase. 3-Chloroalanine 13 and $O$-carbamoyl- $S$-serine 14 and $O$-acetyl- $S$-serine 15 also act as substrates. These substrates result in the formation of 2-aminoacrylate $\mathbf{1 6}$, which tautomerises to pyruvate $\mathbf{1 7}$ with a

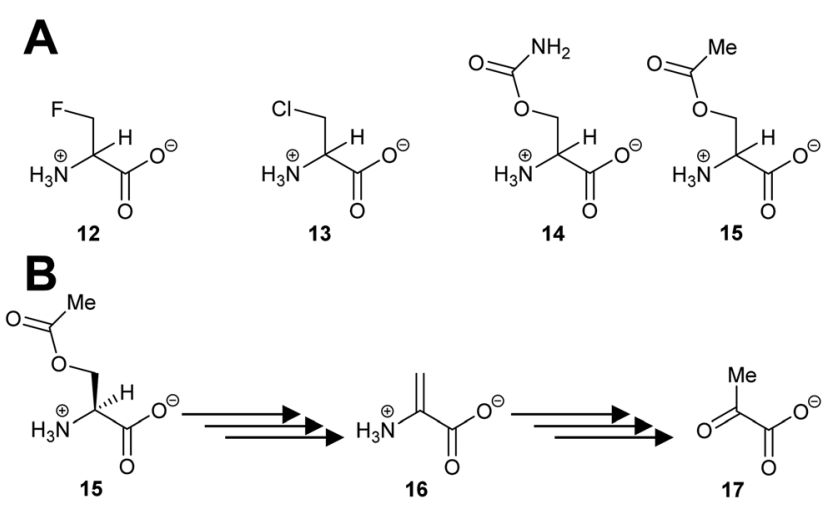

Scheme 3 (A) Structures of eliminating inhibitors and substrates of $E$. coli alanine racemase; (B) conversion of $O$-acetyl-S-serine $15 S$ to pyruvate 17 by alanine racemase. ${ }^{132}$ 
partition coefficient of between 790 and 920 to 1 (catalytic conversion/inactivation).

There have also been several studies on the elimination reaction catalysed by $H$. sapiens serine racemase. ${ }^{129-131,133}$ The wild-type enzyme has a $c a$. 4-fold preference for $\beta$-elimination over racemisation of $S$-serine. ${ }^{129,131}$ Other substrates can also undergo $\beta$-elimination, including $S$-serine- $O$-sulfate and $S$-threo-hydroxyaspartate. ${ }^{131}$ The enzyme is allosterically activated by divalent metal ions (with $\mathrm{Mn}^{2+}$ being the strongest) and ATP ${ }^{129,133}$ and activity is potentiated by halide anions. ${ }^{130}$ The elimination reaction catalysed by serine racemase is thought to control levels of $R$-serine in neurons ${ }^{133}$ and, hence, modulate the activity of NMDA receptors; ${ }^{129,131,133}$ over-activation of the NMDA receptor has been shown to result in neuronal cell death. ${ }^{133}$ This is, however, at the expense of producing highly electrophilic 2-aminoacrylate $16 .^{129,131,133}$

Enolase family enzymes, such as $P$. putida mandelate racemase $^{126}$ and L. aggregata cis-3-hydroxy-S-proline racemase/ dehydratase (IAM 12614), ${ }^{119}$ are also able to catalyse elimination reactions. Mandelate racemase was able to catalyse elimination of chlorine from 3-chlorolactate 18 to give pyruvate 19 (Scheme 4A). ${ }^{126}$ The mechanistic details of the reaction was not determined but it is assumed to occur by E2 anti-elimination to give the enol 20 followed by tautomerisation. ${ }^{126}$ However, the possibility of a E1cb-type mechanism via an enediolate type intermediate cannot be discounted. The elimination of chlorine from 3-chlorolactate $\mathbf{1 8}$ by mandelate racemase is reminiscent of the elimination of $\mathrm{HCl}$ from 3-chloroalanine $\mathbf{1 3}$ by glutamate racemase, which also gives pyruvate $\mathbf{1 7}$ as a product (vide infra, Scheme 12). ${ }^{134}$ This result contrasts with the earlier observation on $P$. putida mandelate racemase with 3,3,3-trifluorolactate 21, which undergoes racemisation. $\beta$-Elimination to give 22 is not observed (Scheme 4B). ${ }^{91}$

L. aggregata cis-3-hydroxy-S-proline racemase/dehydratase $(\text { IAM } 12614)^{119}$ catalyses both racemisation and $\beta$-elimination
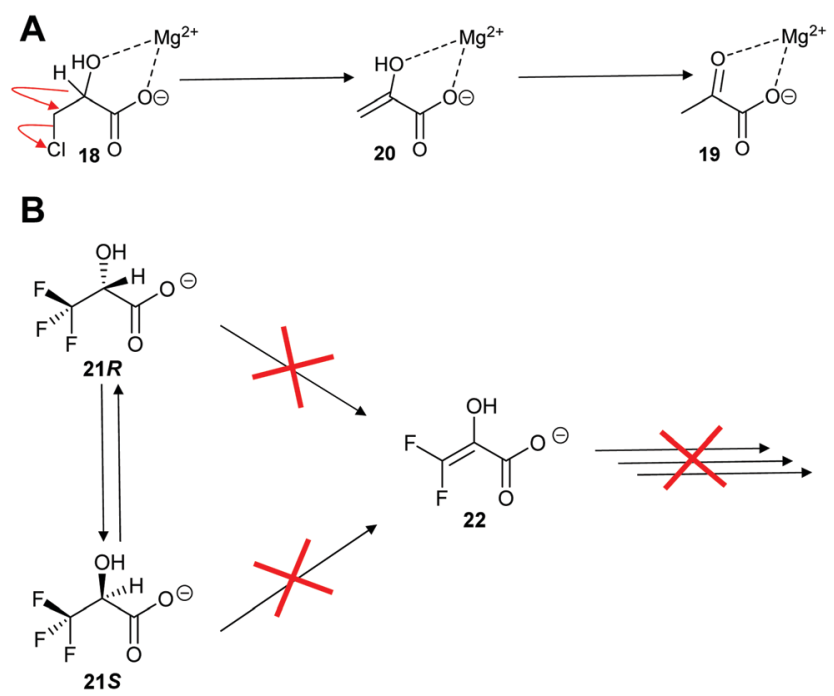

Scheme 4 Reaction of halogen substrates with $P$. putida mandelate racemase. ${ }^{91,126}$ (A) Elimination of chlorine from 3-chlorolactate $18^{-126}$ (B) expected elimination of 3,3,3-trifluorolactate 21 to give $22 .{ }^{91}$

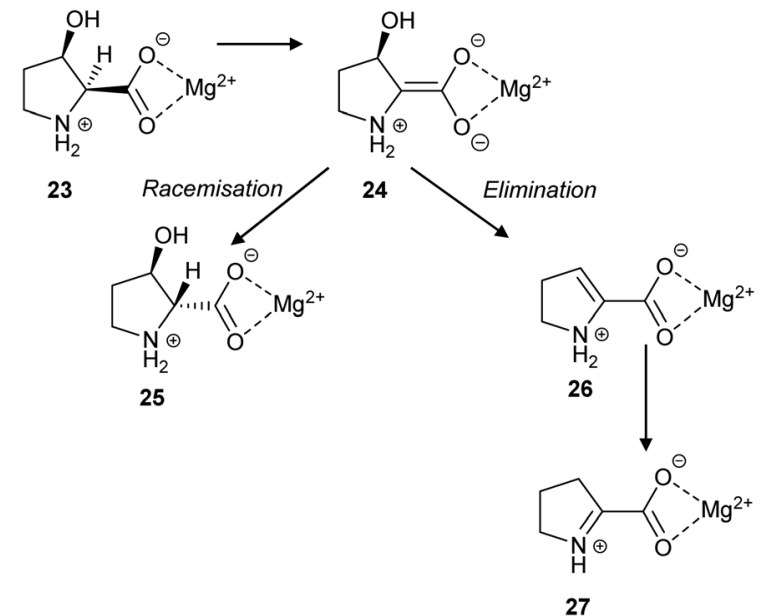

Scheme 5 The racemisation and elimination reactions catalysed by cis-3-hydroxy-S-proline racemase/dehydratase. ${ }^{119}$

reactions with its substrate 23 , in a 3 to 2 ratio (Scheme 5). The $\beta$-elimination reaction is proposed to go via an enediolate intermediate 24, although it may be a more concerted E2-like reaction. The cis substrate allows for anti-elimination of the hydroxy group to give the enamine product 26, which subsequently tautomerises to $\Delta$-pyrroline-2-carboxylate 27 (Scheme 5). Alternatively, epimerisation to give 25 can occur. It is notable that $\mathbf{2 7}$ is a known inhibitor of $T$. cruzi proline racemase. ${ }^{135}$

The cofactor-independent enzymes diaminopimelate epimerase $^{124}$ and glutamate racemase ${ }^{128}$ are able to eliminate $N$-hydroxy substrates. In the case of glutamate racemase, deprotonation of substrate $\mathbf{2 8}$ results in elimination of hydroxide or water with formation of imine $\mathbf{2 9}$, which is hydrolysed to 2-oxoglutarate 30 (Scheme 6).

With aliphatic substrates containing $\beta$-fluorine or $\beta$-chlorine, the presence of the halogen increases the acidity of the $\mathrm{C}_{\alpha}-\mathrm{H},{ }^{120,136}$ and, hence, these elimination substrates tend to be converted with somewhat higher efficiency than their

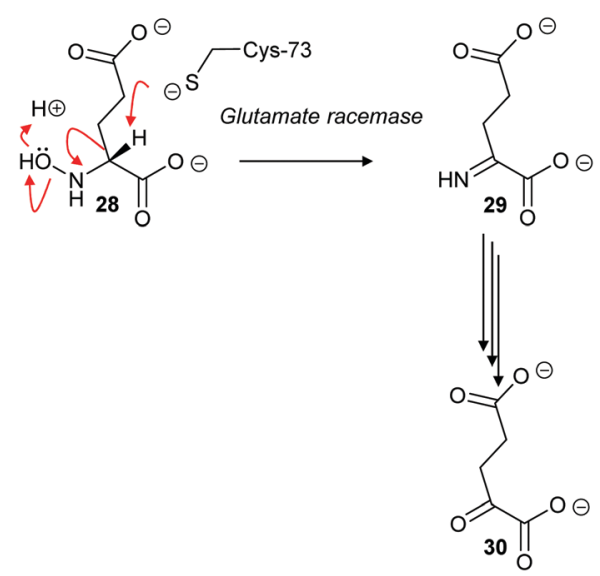

Scheme 6 Elimination of $N$-hydroxy- $R$-glutamate 28 by an E2 mechanism followed by hydrolysis of imine $\mathbf{2 9}$ to form 2-oxoglutarate $\mathbf{3 0}{ }^{128}$ 

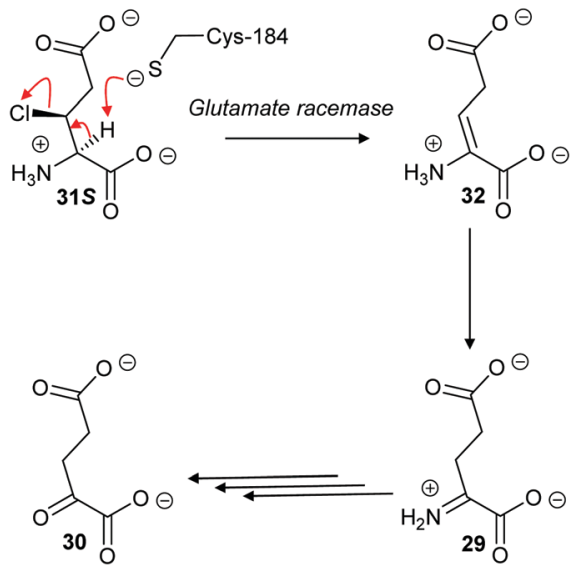

Scheme $7 \quad \beta$-Elimination of 2S,3S-3-chloroglutamate 315 by Lactobacillus glutamate racemase to give enamine $\mathbf{3 2}$. Tautomerisation to imine $\mathbf{2 9}$ followed by hydrolysis gives the resulting 2 -oxoglutarate $30 .^{82}$

racemisation/epimerisation equivalents. ${ }^{120}$ With diaminopimelate epimerase, ${ }^{121}$ only stereoisomers allowing an antiperiplanar conformation between the $\mathrm{C}_{\alpha}-\mathrm{H}$ and the fluorine underwent elimination, with substrates not allowing an antiperiplanar conformation undergoing epimerisation instead. Similarly, mutant glutamate racemases (in which the active-site Cys bases were mutated to Ser) eliminated either $2 R, 3 R$ - or $2 S, 3 S-3$ chloroglutamate stereoisomers $31 R$ and $31 S$ with antielimination (Scheme 7), depending on which active site Cys residue was still present. ${ }^{82}$ The resulting enamine 32 tautomerises to imine 29, which is hydrolysed to 2-oxoglutarate $\mathbf{3 0}$. These results are consistent with a substantially concerted (E2) mechanism. ${ }^{137}$

The above results contrast with those observed with AMACR, in which epimeric substrates $\mathbf{3 3}$ and $\mathbf{3 4}$ were eliminated to the same product $35,{ }^{120}$ consistent with an E1cb mechanism through the enolate intermediate 36 (Scheme 8). ${ }^{137}$ These results are inconsistent with an E2-elimination because the substrate requires a conformation in which the $\alpha-\mathrm{H}$ and the fluorine are anti-; epimer 33 can adopt such a conformation but epimer 34 cannot. Interestingly, compounds closely related to 33 and 34 were synthesised ${ }^{136}$ and tested as inhibitors of native rat AMACR and no elimination of fluoride was observed. ${ }^{136}$ These inhibitors ${ }^{136}$ had the same configuration as $\mathbf{3 4}$ (and its epimer with opposite C2 and C3 configurations) but, in view of the subsequent report, ${ }^{120}$ this is a surprising observation.

However, this is not the only example where an expected elimination reaction did not take place. Nagar et al. investigated trifluorolactate (2-hydroxy-3,3,3-trifluoropropanoate) $\mathbf{9 R}$ and $9 \boldsymbol{S}$ as substrates for mandelate racemase (vide supra, Scheme 4). ${ }^{91}$ Kinetic analysis showed that $K_{\mathrm{m}}$ values for trifluorolactate 9 were unexpectedly similar to the natural substrate, mandelate (1.2-1.74 $\mathrm{mM}$ and 1.0-1.2 $\mathrm{mM}$, respectively) and lower than the predicted $K_{\mathrm{m}}$ value of $\sim 10 \mathrm{mM}$. In contrast, $k_{\text {cat }}$ values were reduced by $\sim 318$-fold, with $k_{\text {cat }} / K_{\mathrm{m}}$ reduced by $\sim 430$-fold. ${ }^{19} \mathrm{~F}$ NMR analysis showed that no fluoride was eliminated during the reaction and, hence, $\mathbf{1 0}$ was not formed. ${ }^{91}$ The lack of a $\beta$-elimination reaction is unexpected, because the

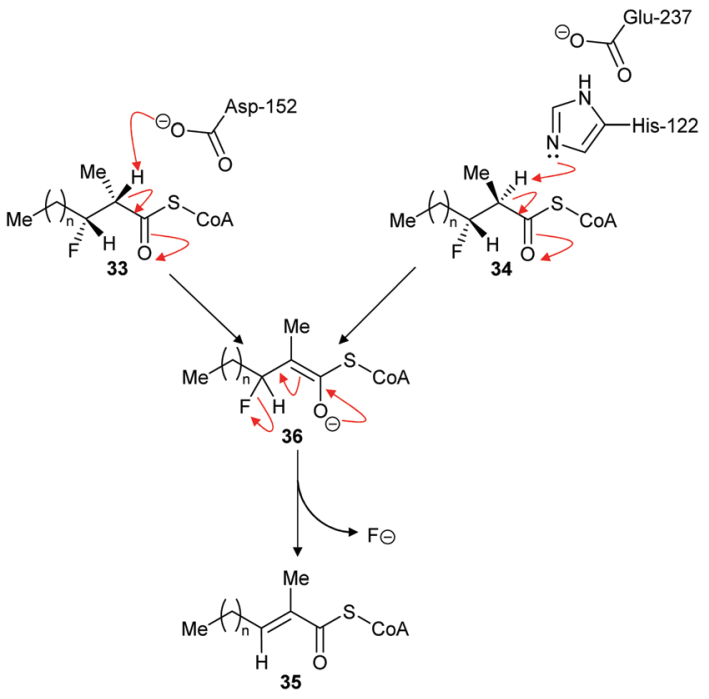

Scheme 8 Elimination of fluoride from substrates by $\alpha$-methylacyl-CoA racemase. ${ }^{120}$ For substrates 33 and $34, n=6$. For inhibitors (34 and its epimer with opposite $\mathrm{C} 2$ and $\mathrm{C} 3$ configuration) tested on native rat enzyme reported not to eliminate ${ }^{136} n=12$. Enzyme catalytic residue numbers are those for human AMACR. ${ }^{6,7}$

trifluorolactate $\mathbf{9}$ is able to take up the required anti-conformation for an E2 reaction when in a staggered conformation. Clearly, the mandelate racemase-catalysed racemisation of trifluorolactate is faster than the elimination reaction. The reasons for this are unclear but it could be related to the presence of multiple fluorine atoms within the substrate. ${ }^{138}$ If loss of fluoride is asynchronous with abstraction of the $\mathrm{C}_{\alpha}-\mathrm{H}$, this will result in generation of a positive charge on the $\beta$-carbon. The presence of two additional fluorine atoms will destabilise formation of this transition state. However, it is notable that E. coli dipeptide epimerase (YcjG) eliminates fluoride from $S$-alanyl- $R, S$-difluoroalanine in preference to epimerisation, ${ }^{125}$ suggesting that other factors are also at play such as the extent of $\delta+$ charge stabilisation in the transition state.

\section{Methods for determining racemase and epimerase activity}

Racemases and epimerases are simple enzymes, in the sense that they only have one substrate and product (a uni-uni reaction), which is a characteristic they share with other isomerases. A consequence of racemases and epimerases accepting both stereochemical configurations of their substrates is that their reaction will, in most cases, be readily reversible and $k_{\text {cat }} / K_{\mathrm{m}}$ values are likely to be similar for the reactions in both directions (which is required by the Haldane relationship $^{79,80,139}$ for an equilibrium constant of $\sim 1$ ). Hence the rate for the reverse reaction when determining initial rates is likely to be significant and this must be corrected for in any kinetic study, such as the determination of inhibitor potency.

Several different assays exist for measuring racemase/ epimerase activity (Table 1). One approach is to measure rates 


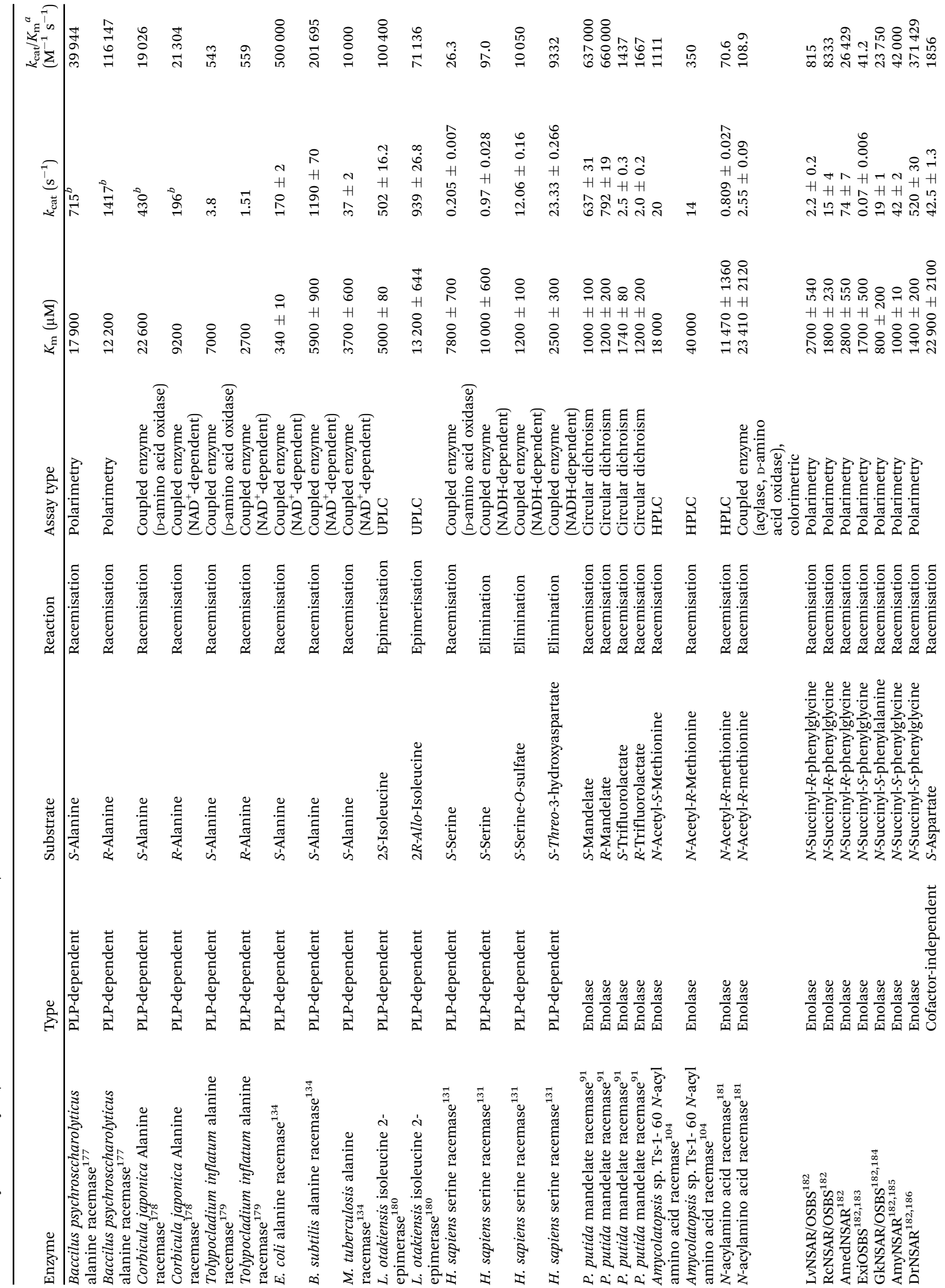


at very early time points where the reverse reaction will have less impact. Typically, the enzyme reaction is followed using techniques such as optical rotation ${ }^{46,140-145}$ or circular dichroism, ${ }^{23,91,107,146-150}$ allowing a time-course to be determined. These assays are ideal, in that they allow much more accurate determination of initial rates, ${ }^{151}$ although correction for the reverse reaction should still be performed. Indeed, circular dichroism is by far the most common method of detecting enzymatic activity (Table 1), although it is noted that these are kinetic studies designed to measure $K_{\mathrm{m}}, k_{\text {cat }}$ and $k_{\text {cat }} / K_{\mathrm{m}}$ (vide infra).

A second alternative when analysing substrates undergoing racemisation or epimerisation is to use HPLC of a diastereoisomeric substrate/product mixture at a fixed time point, ${ }^{37,136}$ although the differences in energies between diastereoisomers means that these substrates may behave differently from natural enantiomeric substrates. Alternatively, a product containing one chiral centre can be derivatised using a chiral reagent and analysed by HPLC, GC or NMR. ${ }^{8,79,80}$ The latter approach is time-consuming, as several time-points for each reaction should be analysed and can be technically challenging, especially when working with the low amounts of product typically obtained from enzymatic reactions. Chiral HPLC is an option for separating enantiomeric substrates, although there appear to be no examples of this having been used.

A second approach is to measure exchange of the $\alpha$-proton with isotopically labelled substrates ${ }^{82,95,152-154}$ or solvent, ${ }^{8,73,78-80,107}$ measuring reaction extent by scintillation counting, mass spectrometry or NMR. Such approaches will introduce significant kinetic isotope effects ${ }^{155-158}$ and deprotonation and reprotonation rates will be markedly different from each other although the extent of this will depend on levels of conversion of substrate and whether the transition states are early or late. ${ }^{107}$ Consequently, careful design of experiments is needed, especially where precise rate measurements are required. These approaches are often used in mechanistic studies where isotopic distribution in substrate and product is measured (vide supra).

A third approach is to make the enzymatic reaction irreversible. This can be achieved using an irreversible coupled enzyme to remove the reaction product. ${ }^{107,159,160}$ There are a number of examples of the use of coupling enzymes in kinetic studies determining $K_{\mathrm{m}}$ and $k_{\text {cat }}$ values (Table 1 ). The most common coupling enzymes used are D-amino acid oxidase and NAD-dependent oxidoreductases. Coupled enzyme assays are the second most common method of assessing enzymatic activity. Similarly, an unnatural substrate which undergoes an irreversible elimination reaction ${ }^{82,83,120,127,161}$ can also be used. Typical examples of eliminated groups include water (from amino-acid hydroxamate derivatives ${ }^{83,162}$ ), bromide, $^{122,123}$ chloride $\mathrm{e}^{47,82,124}$ and fluoride $\mathrm{e}^{120,121,124,125,161}$ as described above. The products from these elimination reactions often need to be assayed using coupling enzymes ${ }^{83,121}$ or low-throughput spectroscopic techniques such as NMR. ${ }^{120,121,161}$ Attempts to use fluoride sensors to measure enzymatic activity with substrates eliminating fluorine has met with limited success. ${ }^{161}$ A notable

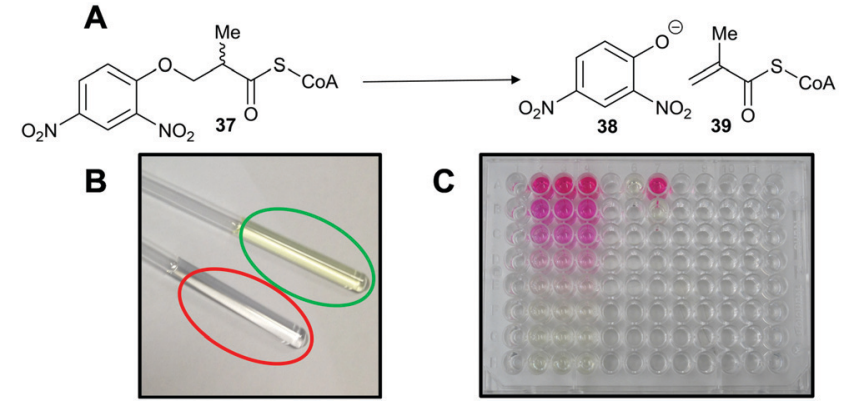

Scheme 9 Colorimetric assay for $\alpha$-methylacyl-CoA racemase (AMACR) based on elimination of 2,4-dinitrophenolate 38 from the acyl-CoA substrate $37 .{ }^{127}$ (A) Reaction catalysed by AMACR; (B) assay samples showing reaction with heat-inactivated enzyme (red circle) and active enzyme (green circle) showing absorbance at $354 \mathrm{~nm}^{, 127}$ (C) measurement of dose-response curve for Rose Bengal (a known inhibitor of $A M A C R^{127,152}$ ) using the colorimetric assay. Schemes $9 B$ and $C$ have been reproduced from Yevglevskis et al., $2017^{127}$ with permission from the Royal Society of Chemistry.

example of this approach is the elimination reaction of an unnatural acyl-CoA substrate 37 by AMACR to give 2,4dinitrophenoxide 38 and acyl-CoA 39 (Scheme 9); ${ }^{127}$ this assay was used in a high-throughput screening campaign of 20387 compounds which identified novel pyrazoloquinolines and pyrazolopyrimidines as inhibitors ${ }^{163}$ and also in the first extensive inhibitor structure-activity relationship studies on any racemase/epimerase (vide infra). ${ }^{164,165}$

\section{Catalytic efficiency of racemases and epimerases}

Kinetic parameters for racemases/epimerases can vary quite widely (Table 1). $K_{\mathrm{m}}$ values for amino-acid racemases tend to be in the low $\mathrm{mM}$ range, although there are several examples where much higher $K_{\mathrm{m}}$ values have been measured. Typical examples include Fusobacterium nucleatum and B. subtilis glutamate racemase, which have $K_{\mathrm{m}}$ values of 1.04 and $1.07 \mathrm{mM}$ and 14 and $1.24 \mathrm{mM}$, respectively. ${ }^{166}$ In contrast, $O$-ureidoserine racemase which has reported $K_{\mathrm{m}}$ values $^{46}$ of 12 and $32 \mathrm{mM}$ for $S$ - and $R$-O-ureidoserine, respectively. In contrast, the $K_{\mathrm{m}}$ for $S, S$-diaminopimelate (2,6-diaminoheptanedioic acid) for M. tuberculosis diaminopimelate epimerase is only $166 \mu \mathrm{M},{ }^{167}$ significantly lower than the $K_{\mathrm{m}}$ values for other amino-acid racemases/epimerases. The relatively high $K_{\mathrm{m}}$ values for most amino-acid racemases/epimerases are undoubtedly a consequence of these enzymes converting small and relatively unfunctionalised substrates. The same trend is observed for mandelate racemase, which has $K_{\mathrm{m}}$ values of 1.0 and $1.2 \mathrm{mM}$ for $S$ - and $R$-mandelate (2-hydroxyphenylacetate), respectively. ${ }^{91}$ Racemases/epimerases with larger substrates tend to have lower $K_{\mathrm{m}}$ values, as there is more opportunity for binding interactions. For example, human AMACR has a $K_{\mathrm{m}}$ value of $\sim 86 \mu \mathrm{M}$ for pristanoyl-CoA, ${ }^{152}$ while $K_{\mathrm{m}}$ values for $S$ - and $R$-ibuprofenoyl-CoA are 86 and $48 \mu \mathrm{M}$ for the M. tuberculosis 
homologue. ${ }^{146}$ These lower $K_{\mathrm{m}}$ values are generally accompanied by lower $k_{\text {cat }}$ values (Table 1 ).

Catalytic efficiency is quantified using $k_{\text {cat }} / K_{\mathrm{m}}$ values (Table 1). Again, these can vary quite widely but many racemases/epimerases have relatively modest efficiencies. For example, $O$-ureidoserine racemase is quite efficient, with reported $k_{\text {cat }} / K_{\mathrm{m}}$ values $^{46}$ of 39583 and $45312 \mathrm{M}^{-1} \mathrm{~s}^{-1}$. Similarly, $k_{\text {cat }} / K_{\mathrm{m}}$ is reported to be 16730 and $15294 \mathrm{M}^{-1} \mathrm{~s}^{-1}$ for $F$. nucleatum glutamate racemase for $S$ - and $R$-Glu, while the corresponding values are 3000 and $3806 \mathrm{M}^{-1} \mathrm{~s}^{-1}$ for the $B$. subtilis enzyme. ${ }^{166}$ In contrast, $M$. tuberculosis diaminopimelate epimerase $^{167}$ has a very modest $k_{\text {cat }} / K_{\mathrm{m}}$ of $883 \mathrm{M}^{-1} \mathrm{~s}^{-1}$. On the other hand, $\operatorname{RacX}^{168}$ has extremely low $k_{\text {cat }} / K_{\mathrm{m}}$ values of 2.86 and $3.23 \mathrm{M}^{-1} \mathrm{~s}^{-1}$ for $S$ - and $R$-Lys, while $\mathrm{YgeA}^{168}$ has $k_{\text {cat }} / K_{\mathrm{m}}$ values of 45.8 and $45.8 \mathrm{M}^{-1} \mathrm{~S}^{-1}$ for $S$ - and $R$-His.

$k_{\text {cat }} / K_{\mathrm{m}}$ values for other racemases and epimerases tend to be higher and this is often related to the lower $K_{\mathrm{m}}$ values observed for these larger substrates. For example, mandelate racemase (6.2 and $6.5 \times 10^{5} \mathrm{M}^{-1} \mathrm{~s}^{-1}$ for $S$ - and $R$-mandelate ${ }^{91}$ ) and the M. tuberculosis homologue of AMACR $\left(5.23 \times 10^{6}\right.$ and $6.0 \times 10^{6} \mathrm{M}^{-1} \mathrm{~S}^{-1}$ for $S$ - and $R$-ibuprofenoyl-CoA, ${ }^{146}$ respectively). Finally, $N$-succinylamino acid racemases and $N$-acetylamino acid racemases exhibit highly variable $k_{\text {cat }} / K_{\mathrm{m}}$ values (Table 1 ).

It is noteworthy that even the most efficient racemases/ epimerases have $k_{\text {cat }} / K_{\mathrm{m}}$ values well below the theoretical diffusion-controlled maximum of $\sim 1 \times 10^{9} \mathrm{M}^{-1} \mathrm{~s}^{-1} .^{169}$ As proton-transfer reactions are extremely fast (between $5 \times$ $10^{9}$ and $\left.1 \times 10^{11} \mathrm{M}^{-1} \mathrm{~s}^{-1}\right),{ }^{86}$ rates may be limited by binding of substrate, release of product or conformational changes in the protein. A survey of $k_{\text {cat }} / K_{\mathrm{m}}$ values for various enzymes ${ }^{169}$ shows that, for most enzymes, they are around $10^{5}$ to $10^{9} \mathrm{M}^{-1} \mathrm{~s}^{-1}$, with the most efficient enzyme (superoxide dismutase) having a $k_{\text {cat }} / K_{\mathrm{m}}$ of $7 \times 10^{9} \mathrm{M}^{-1} \mathrm{~s}^{-1}$. Moreover, $k_{\text {cat }} / K_{\mathrm{m}}$ values for most enzyme-catalysed reactions appear to be diffusion-limited. ${ }^{169}$ There have been few detailed kinetic studies on racemases/ epimerases but studies on mandelate racemase using mandelate as a substrate show that both $k_{\text {cat }}$ and $k_{\text {cat }} / K_{\mathrm{m}}$ are affected by increasing the viscosity of the solvent. ${ }^{170,171}$ This indicates that both binding of substrate and release of product are partly rate-limiting, although the effects on $k_{\text {cat }}$ are more extensive than those on $k_{\text {cat }} / K_{\mathrm{m}}$ indicating that that release of product is more sensitive to solvent viscosity than binding of substrate. ${ }^{172}$ In contrast, poorer substrates of mandelate racemase ${ }^{91}$ or less active mutants of the enzyme ${ }^{173}$ tend to be unaffected by increasing solvent viscosity, suggesting that rates are limited by the chemical reaction or other processes, e.g. conformational changes in the protein. Although the $k_{\text {cat }} / K_{\mathrm{m}}$ values for mandelate racemisation is relatively modest $\left(6.2 \text { and } 6.5 \times 10^{5} \mathrm{M}^{-1} \mathrm{~s}^{-1}\right)^{91}$ compared to these other enzymes, it should be noted that racemisation of mandelate is a 'difficult' reaction as judged by the estimated half-life for the spontaneous uncatalysed reaction of $9.8 \times 10^{4}$ year. $^{169}$ Thus, mandelate racemase is providing a considerable enhancement (an effective molarity of $\sim 4.87 \times 10^{6} \mathrm{M}$ ). It is unclear whether racemases/ epimerases with lower $k_{\text {cat }} / K_{\mathrm{m}}$ values are limited by diffusion, chemical reactivity or other processes, or whether these low efficiencies result from a low amount of active enzyme within the enzyme preparation.

\section{Drug design strategies for inhibiting racemases and epimerases}

As noted above, many racemases and epimerases are drug targets for various diseases. The following is a survey of different strategies for the development of inhibitors.

\section{Substrate/product analogues}

Exploiting the differences in side-chain conformation of different racemase/epimerase substrate stereochemical isomers can be a particularly fruitful strategy for the development of inhibitors. A significant advantage of these inhibitors is that they are achiral when identical sidechains are used. The substrate/product analogue approach works particularly well for racemases/epimerases possessing discrete side-chain-binding pockets for the different stereoisomers, e.g. mandelate racemase ${ }^{139}$ and M. tuberculosis $\alpha$-methylacyl-CoA racemase (MCR). ${ }^{149}$ It can also work for enzymes with more subtle changes in side-chain conformation, e.g. aspartate racemase ${ }^{174}$ and glutamate racemase, ${ }^{175}$ although the potency of inhibition tends to be more modest. In many respects, substrate/product analogues are the equivalent of bisubstrate inhibitors of other enzymes, ${ }^{176}$ which often give rise to potent inhibition.

Several substrate/product analogues have been reported as inhibitors of amino-acid racemases (Fig. 5). For example, citrate 40 was shown by X-ray crystallography to bind as a substrate/ product analogue to aspartate racemase. ${ }^{174}$ Citrate 40 behaves as a competitive inhibitor, although the potency was very low ( $K_{\mathrm{i}}=7.4 \mathrm{mM}$ vs. $K_{\mathrm{m}}=0.74 \mathrm{mM}$ for L-aspartate). Pal et al. designed cyclic inhibitors of glutamate racemase, in which the ring mimicked the side-chain positions for the different stereoisomers of glutamate, including compound $\mathbf{4 1}^{175}$ This proved to be a partial non-competitive inhibitor, although potency was modest $\left(K_{\mathrm{i}}=3.1 \mathrm{mM}\right.$ vs. $K_{\mathrm{m}}=1.41 \mathrm{mM}$ for
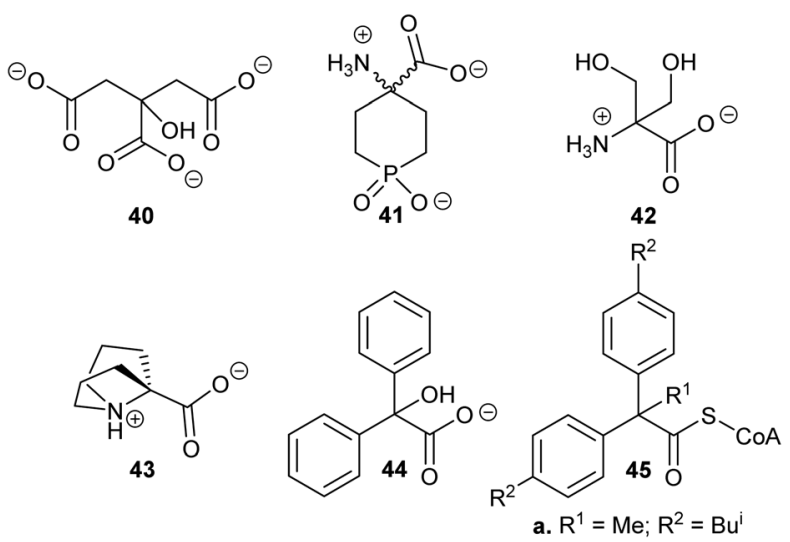

Fig. 5 Structures of representative substrate-product analogues which are inhibitors of aspartate racemase $(\mathbf{4 0}),{ }^{174}$ glutamate racemase $(\mathbf{4 1}),{ }^{175}$ serine racemase (42), ${ }^{188}$ proline racemase $(\mathbf{4 3}){ }^{188}$ mandelate racemase $(\mathbf{4 4})^{139}$ and M. tuberculosis $\alpha$-methylacyl-CoA racemase (MCR) (45). ${ }^{149}$ 
substrate $S$-glutamate). ${ }^{175}$ In contrast, substrate/product analogues were poor inhibitors of serine racemase (e.g. 42, mixed competitive inhibition; $K_{\mathrm{i}}=167 \mathrm{mM}$ and $K_{\mathrm{i}}{ }^{\prime}=661 \mathrm{mM} v s$. $\left.K_{\mathrm{m}}=19 \mathrm{mM}\right)^{188}$ and proline racemase (e.g. 43, non-competitive inhibition; $K_{\mathrm{i}}=111 \mathrm{mM}$ vs. $\left.K_{\mathrm{m}}=5.7 \mathrm{mM}\right) .{ }^{188}$ Proline racemase is known to have an extremely confined active site in the 'closed form' of the enzyme, ${ }^{26,27}$ which binds substrates and inhibitors.

There have only been two substrate/product analogue studies on non-amino-acid racemases. Mandelate racemase substrate/product analogues ${ }^{139}$ bind with similar affinity to the substrate [e.g. benzilate (2,2-diphenyl-2-hydroxyacetate) $\mathbf{4 4}, K_{\mathrm{i}}=$ $0.67 \mathrm{mM}$ vs. $K_{\mathrm{m}}=0.70$ and $0.54 \mathrm{mM}$ for $R$ - and $S$-mandelate, respectively $\left.{ }^{139}\right]$. Similarly, a substrate-product analogue of ibuprofenoyl-CoA (Fig. 5, 45a) was a competitive inhibitor of the M. tuberculosis homologue of AMACR (MCR) and showed about a 6-fold increase in binding affinity $\left(K_{\mathrm{i}}=16.9 \mu \mathrm{M} v\right.$ s. $K_{\mathrm{m}}=106$ $\mu \mathrm{M})$ compared to ibuprofenoyl-CoA, undoubtedly due to the sidechain of the inhibitor binding to both the $R$ - and $S$ - subsites. ${ }^{149}$

\section{Enhancing acidity of the $\alpha$-proton and alternative substrates}

A number of racemases/epimerases have alternative substrates which undergo changes in stereochemical configuration $^{8,91,127,164,189}$ or elimination. ${ }^{63,82,120-124,128,161,164}$ Efficiency of inhibition is dependent on concentrations of inhibitor and their catalytic efficiency as substrates $\left(k_{\text {cat }} / K_{\mathrm{m}}\right)$. Alternative substrates are usually competitive inhibitors (for example see ${ }^{127}$ ), which means that inhibition can be overcome by high concentrations of the substrate whose conversion is being inhibited.

Efficient inhibition can be achieved by increasing the acidity of the $\mathrm{C}_{\alpha}-\mathrm{H}$, e.g. by use of trifluoromethyl group (Fig. 6, 47 and 48). ${ }^{136,190}$ The trifluoromethyl group lowers the energy of the enolate intermediate ${ }^{81}$ in the AMACR reaction; ${ }^{136}$ intermediates generally bind tightly to enzymes and more closely resemble the transition states of the reaction. ${ }^{94}$ The presence of a sulfur atom immediately adjacent to the substrate $\mathrm{C}_{\alpha}-\mathrm{H}$ is also an effective strategy for increasing acidity (vide infra, Fig. 29). ${ }^{165}$

\section{Preventing the removal of the $\alpha$-proton}

These types of inhibitors fall into two types: those in which the $\mathrm{C}_{\alpha}-\mathrm{H}$ has been replaced by an alternative group and those with neighbouring groups which decrease the acidity of the $\mathrm{C}_{\alpha}-\mathrm{H}$. A number of different groups have been used to replace the $\mathrm{C}_{\alpha}-\mathrm{H}$ (in addition to the substrate/product analogues with a second side-chain noted above), including fluorine atoms, e.g. 49, ${ }^{191}$ and methylene groups, e.g. $\mathbf{5 0}^{192}$ (Fig. 7).
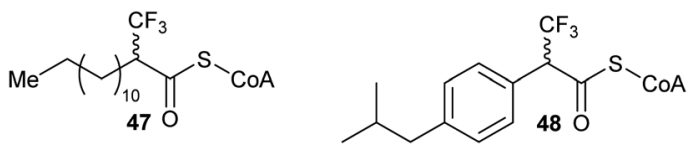

Fig. 6 Representative inhibitors with increased $\mathrm{C}_{\alpha}-\mathrm{H}$ acidity. ${ }^{136,165,190}$
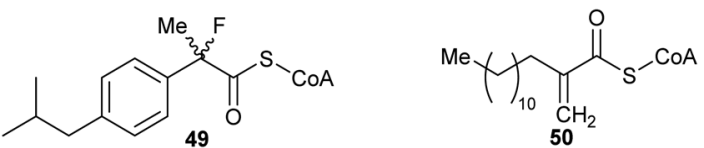

Fig. 7 Representative inhibitors in which the $\mathrm{C}_{\alpha}-\mathrm{H}$ is replaced. ${ }^{191,192}$

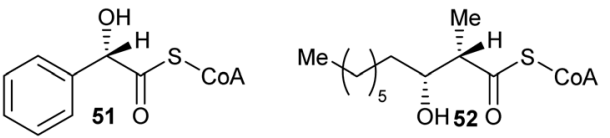

Fig. 8 Representative inhibitors in which the acidity of $\mathrm{C}_{\alpha}-\mathrm{H}$ is decreased. ${ }^{164,191}$

Inhibitors can also have substituents adjacent to the $\mathrm{C}_{\alpha}-\mathrm{H}$, which raise the energy of the deprotonated intermediate, such as hydroxy groups as exemplified by $\mathbf{5 1} 1^{9,164}$ and $52^{164}$ (Fig. 8). Exchange of the $\mathrm{C}_{\alpha}-\mathrm{H}$ was shown not to occur by incorporation studies in ${ }^{2} \mathrm{H}_{2} \mathrm{O}$ and ${ }^{1} \mathrm{H}$ NMR analyses when $\mathbf{5 1}$ and 52 were tested as substrates for AMACR. ${ }^{9,164}$ In all cases, these approaches tend to give rise to moderate inhibitors, as judged by the ratio of $\mathrm{IC}_{50} / K_{\mathrm{m}}$ or $K_{\mathrm{i}} / K_{\mathrm{m}}$ values.

\section{Transition-state and intermediate analogues}

Transition-state analogues are widely recognised as potent drugs. ${ }^{135,193,194}$ This approach has been relatively under-used as a strategy for inhibition of racemases and epimerases, although the few examples show that highly potent inhibitors can be obtained.

An early example is proline racemase, which is inhibited by pyrrole-2-carboxylate $\mathbf{5 3}$ and $\Delta$-pyrroline-2-carboxylate 27 (reviewed in ref. 135) (Fig. 9A). Relatively high concentrations
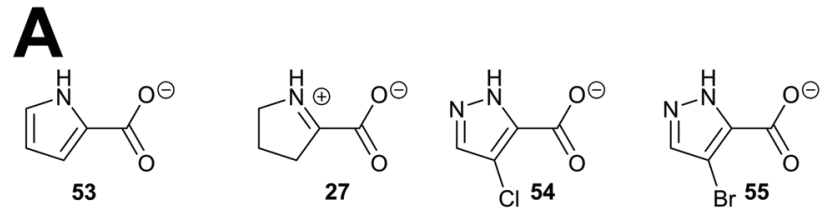

$\log P=-2.41$

$\log P=-3.11$

$\log P=-2.33$

$\log P=-2.20$
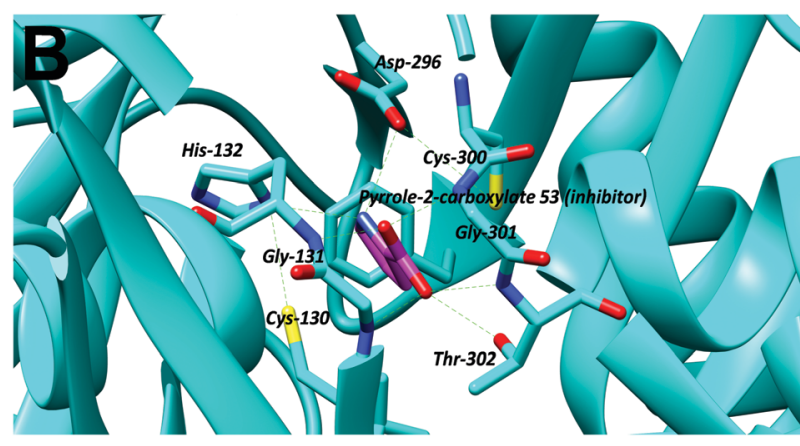

Fig. 9 (A) Structures of proline racemase transition-state analogues. ${ }^{135}$ $\log P$ values were calculated using: https://www.molinspiration.com/ cgi-bin/properties. $\log P, \log _{10}$ (ratio of concentrations of drug in octan1-ol and water at equilibrium); (B) X-ray crystal structure of pyrrole-2carboxylate $\mathbf{5 3}$ bound within the active site of proline racemase from T. cruzi, ${ }^{195}$ showing the catalytic bases Cys-130 and Cys-300. Hydrogen bonds are shown as green dashed lines. 
of these compounds are required for inhibition in vitro of the enzyme (about $10 \times$ that of substrate) and they should be considered as inhibitors in which the $\mathrm{C}_{\alpha}-\mathrm{H}$ is replaced (vide supra). X-ray crystallographic analysis showed that pyrrole-2carboxylate binds within the $T$. cruzi active site (Fig. 9B) between the catalytic bases Cys-130 and Cys-300. ${ }^{195}$ However, despite its relatively low potency, pyrrole-2-carboxylate $\mathbf{5 3}$ reduced invasion of $T$. cruzi in infected mammalian cell models and also reduced differentiation of the parasite from the amastigote form into trypomastigotes. ${ }^{28} \mathrm{~A}$ number of more water-soluble analogues (e.g. 54 and 55) were tested for their ability to inhibit the enzyme but these proved to have lower potency. ${ }^{26}$ Compounds 53, 54 and 55 had similar lipophilicity (calculated $\log P$ values of $-2.41,-2.33$ and -2.20 , respectively) and the loss of inhibitory activity is likely to be related to the difficulties of accommodating the bulky halogen in the highly restricted active site. The halogen atom in $\mathbf{5 4}$ and 55 is also likely to force the carboxylate group out of plane, and this is expected to have a significant impact on binding affinity.

A more recent example of the use of transition-state analogues are the carbamate inhibitors of $\alpha$-methylacyl-CoA racemase (Fig. 10), ${ }^{191}$ which mimic the transition state (or enolate intermediate), giving rise to highly potent inhibition. ${ }^{127,164,191}$ Although the carbamate inhibitor $\mathbf{5 6}$ is by far the most potent AMACR inhibitor reported to date, it has limited utility because acyl-CoAs violate Lipinski guidelines and inhibitors are delivered to cells as the carboxylic acid pro-drug. Unfortunately, the acid pro-drug in this case would be a carbamate 57 which may readily decompose ${ }^{164}$ especially under acidic conditions or in the presence of cellular nucleophiles.

There are several other examples of using analogues of the deprotonated intermediate as inhibitors. For example, the conversion of mandelate by mandelate racemase is proposed to go through an aci-carboxylate intermediate (Fig. 11, 58). ${ }^{196}$ Several mandelate racemase inhibitors of this type have been reported, including the phosphonate inhibitors ${ }^{196,197}$ such as the highly potent inhibitor $59\left(K_{\mathrm{i}}=4.7 \mu \mathrm{M} v s . K_{\mathrm{m}}\right.$ of 1.0 and
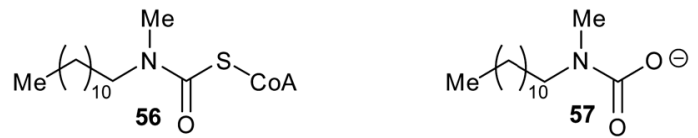

Fig. 10 Structure of the enolate intermediate analogue as an inhibitor of AMACR ${ }^{191}$ and the unstable carbamate pro-drug.

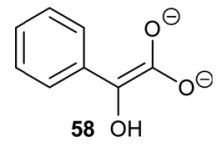<smiles>O=P([O-])([O-])C(O)c1ccccc1</smiles>

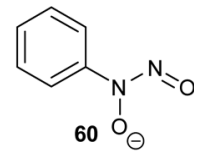<smiles>O=CN(O)c1ccccc1</smiles><smiles>[O-]/N=C(\O)c1ccccc1</smiles>

Fig. 11 Inhibitors of mandelate racemase $(59-62)^{196-198}$ resembling the aci-carboxylate deprotonated intermediate $\mathbf{5 8} .^{196}$
$1.2 \mathrm{mM}$ for $R$ - and $S$-mandelate, respectively). The phosphonate group in 59 possesses two negatively charged oxygen atoms, and hence resembles the aci-carboxylate intermediate $\mathbf{5 8}$. Similarly, cupferron 60 and $N$-hydroxyformanilide 61 also act as analogues of the deprotonated intermediate $\mathbf{5 8}$ because they have an extended planar system of $\mathrm{sp}^{2}$-hybridised atoms, whilst benzohydroxamate 62 is a hydroxamate. Inhibitors 59-62 (Fig. 11) strongly ligate to the metal in the active site of mandelate racemase ( $K_{\mathrm{i}}$ values of $2.7,2.8$ and $9.3 \mu \mathrm{M}$, respectively). ${ }^{198}$

\section{Allosteric inhibition}

Allosteric inhibition arises from inhibitors binding somewhere other than at the enzyme active site. The uncompetitive type of inhibition observed through enzyme kinetics arises from binding of the inhibitor to the enzyme-substrate complex with (almost) no binding to unoccupied enzyme ${ }^{199}$ and, hence, must arise from binding at an allosteric site.

Glutamate racemase is the only racemase/epimerase for which confirmed allosteric inhibitors have been reported. Lundqvist et al. identified an uncompetitive inhibitor 63 during a high-throughput screening campaign on the $H$. pylori enzyme (Fig. 12). ${ }^{200}$ The inhibitor-binding site is remote from the active site. $^{21,200}$ A second cryptic inhibitor-binding site was subsequently identified in the $B$. anthracis enzyme by virtual screening, which led to the identification of pyridine-2,6-dicarboxylate (dipicolinate) 64 as an inhibitor (Fig. 12), with $K_{\mathrm{i}}=1.9 \mathrm{mM}^{25}$ Further studies on 37 showed that inhibitor binding resulted in the active-site $\mathrm{Cys}^{185}$ adopting a conformation in which the $\mathrm{SH}$ group points away from glutamate $\mathrm{C}_{\alpha}-\mathrm{H}^{21}$ It is also noted that some uncompetitive inhibitors of $\alpha$-methylacyl-CoA racemase were recently identified (vide infra, Fig. 15), ${ }^{163}$ implying that they bind to an allosteric site, although the exact binding site has not been confirmed.

\section{Covalent inhibition}

Inhibitors which form a covalent bond to their targets are enjoying a resurgence because of their potential for longlasting effects and strong affinity for the target, amongst other benefits. $^{201-207}$ Indeed, around $30 \%$ of all approved clinical drugs acting on enzymes are covalent inhibitors. ${ }^{202,207}$ Covalent inhibitors can cause either reversible or irreversible inhibition of their target. ${ }^{204-208}$ There is a perception that covalent inhibitors are non-selective and hence are less useful. However, studies

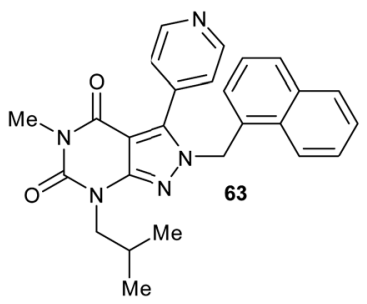<smiles>O=C(O)c1cccc(C(=O)O[Na])n1</smiles>

Fig. 12 Structures of the allosteric inhibitors $63(H$. pylori glutamate racemase) ${ }^{200}$ and pyridine-2,6-dicarboxylate 64 (B. anthracis glutamate racemase). ${ }^{25}$ The ionisation state of $\mathbf{6 4}$ which is shown is that used in the virtual screen. 
have shown that high selectivity for the target enzyme can be achieved. ${ }^{203-210}$ Modification of the substituents around the electrophile can also further enhance selectivity, ${ }^{210-212}$ especially for electrophiles modifying cysteine residues ${ }^{212-215}$ (which are the catalytic bases in many cofactor-independent amino-acid racemases and epimerases ${ }^{5,18,20,22}$ ). Electrophilic properties can be predicted using the 'electrophilicity index'. ${ }^{209}$

Covalent inhibition of racemases and epimerases has been previously investigated. Both diaminopimelate epimerase $\mathrm{e}^{20,124}$ and $\alpha$-methylacyl-CoA racemase ${ }^{127,152}$ have been shown to be inhibited by non-specific protein-modification agents. In each case, these are cysteine-reactive compounds such as iodoacetamide, ebselen (2-phenyl-1,2-benzoisoselenazol-3(2H)-one) and ebselen oxide. It is also noted that mandelate racemase undergoes covalent inhibition by 3-hydroxypyruvate because of formation of an imine between the inhibitor and Lys-166, one of the active-site bases. ${ }^{216}$ There have also been several attempts to design irreversible inhibitors rationally, most notably the aziridine inhibitors of diaminopimelate epimerase. ${ }^{20,124,217,218}$ A recent example of rational covalent inhibitor design is seen with $O$-ureidoserine racemase (which interconverts $S$ - and $R$ - $O$-ureidoserine 65), which is irreversibly inhibited by oxiranes $R$ - and $S$-66 to give covalent adducts (Scheme 10). ${ }^{46}$

An irreversible inhibitor of $B$. subtilis glutamate racemase was also identified by virtual screening (vide infra), ${ }^{23,24}$ and was proposed to bind close to the catalytic cysteine residues. ${ }^{22}$ The inhibitor is proposed to modify irreversibly one of these thiols by conjugate addition (a.k.a. Michael addition). ${ }^{202,205,206}$ The hit compound 67a and several analogues 67b-67d (Scheme 11A) were subsequently shown to be irreversible inhibitors. ${ }^{22}$ Compounds 67a and 67c proved to be non-saturating inhibitors. In contrast, 67b and 67d displayed saturating inhibition, consistent with modification of active site residues. Further experiments showed
A
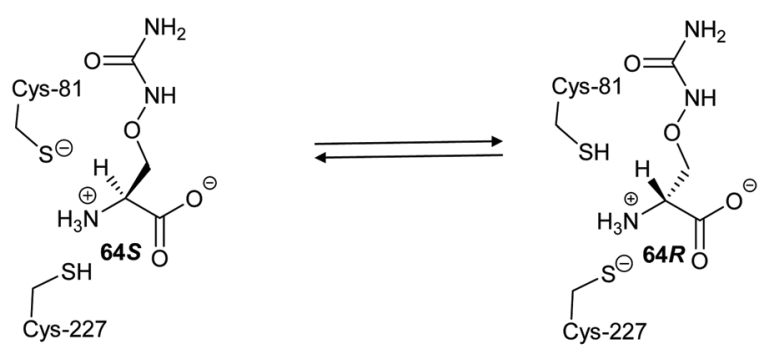

B

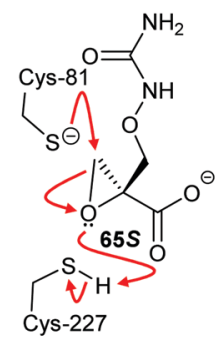

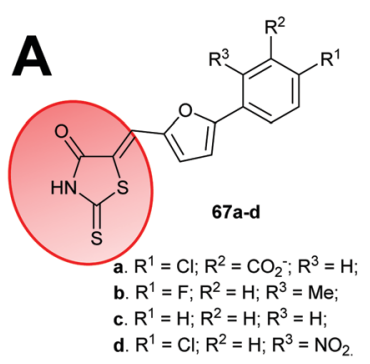

B
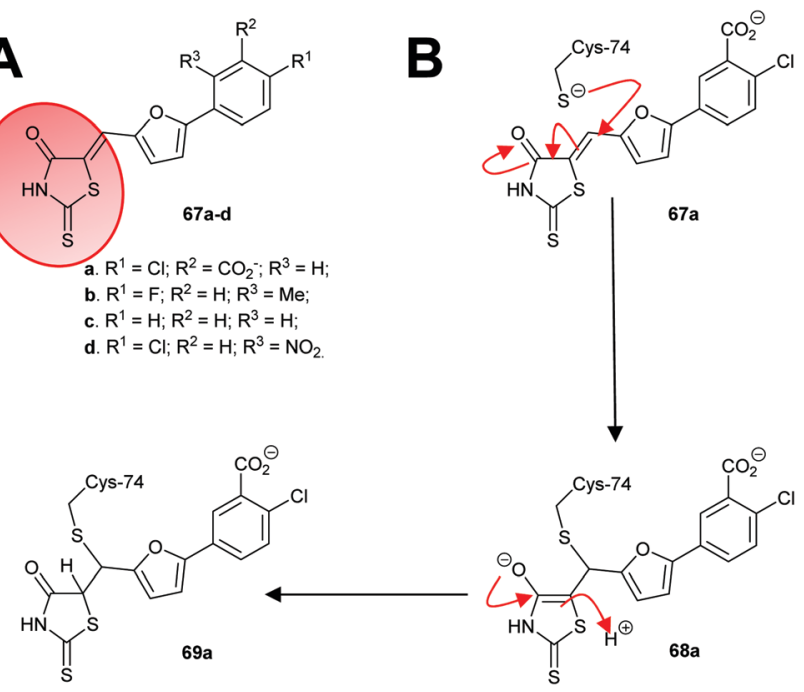

Scheme 11 (A) Structures of irreversible inhibitors of $B$. subtilis glutamate racemase..$^{22}$ The rhodanine motif is highlighted in red; $(B)$ inactivation of glutamate racemase by 68 a by 1,4 -conjugate addition.

that inhibition was reversible, consistent with a reversible conjugate addition via enolate 68a to give the product 69a (Scheme 11B). Mass spectrometric analysis of wild-type and $\mathrm{C} 74 \mathrm{~A}$ mutant glutamate racemase following incubation with 67a confirmed modification of Cys-74, one of the active-site bases. Compound 67a was unreactive with 2-mercaptoethanol under the assay conditions, ${ }^{22}$ showing that conjugate addition to thiols only occurred in the presence of the high nucleophilic Cys-74 in the enzyme active site. The rhodanine warhead (Scheme 11A) is recognised as a common motif found in panassay interference compounds (PAINs), which give rise to false positive or intractable leads in high-throughput screening campaigns. ${ }^{219}$ These rhodanine glutamate racemase inhibitors showed activity against various bacterial strains, including various methicillin-resistant $S$. aureus strains. ${ }^{22}$

In a second study, 3-chloroalanine 70 ( $\beta$-chloroalanine; a poor inhibitor of PLP-dependent alanine racemase ${ }^{134}$ ) was shown to irreversibly inactivate glutamate racemase from M. tuberculosis. ${ }^{134}$ Non-saturating kinetics where observed for the $S$-isomer with a second-order rate constant of $2.7 \mathrm{M}^{-1} \mathrm{~s}^{-1}$. Mass spectrometric analysis of peptides showed that 3-chloro$S$-alanine (70S) reacted at Cys-185, while 3-chloro- $R$-alanine (70R) reacted at Cys-74. In the glutamate racemase reaction, $R$-glutamate is deprotonated by Cys-74 whilst $S$-glutamate is deprotonated by Cys-185 during enantiomerisation, i.e. the active-site Cys acting as an acid is derivatised by 3-chloroalanine $\mathbf{7 0 .}$

The authors proposed ${ }^{134}$ that the adduct was a pyruvate derivative, based on the observation that pyruvate $\mathbf{7 1}$ was generated upon treatment of the enzyme with 3-chloroalanine 70 but their proposed mechanism is very unlikely. Two more likely mechanisms can be envisaged (Scheme 12, pathways A and B) based on the observed increase in mass of $\sim 87 \mathrm{Da}$. In pathway $\mathrm{A}$, removal of the $\mathrm{C}_{\alpha}-\mathrm{H}$ of $70 \mathrm{~S}$ by Cys-74 results in elimination of $\mathrm{HCl}$, yielding the aminoacrylate 

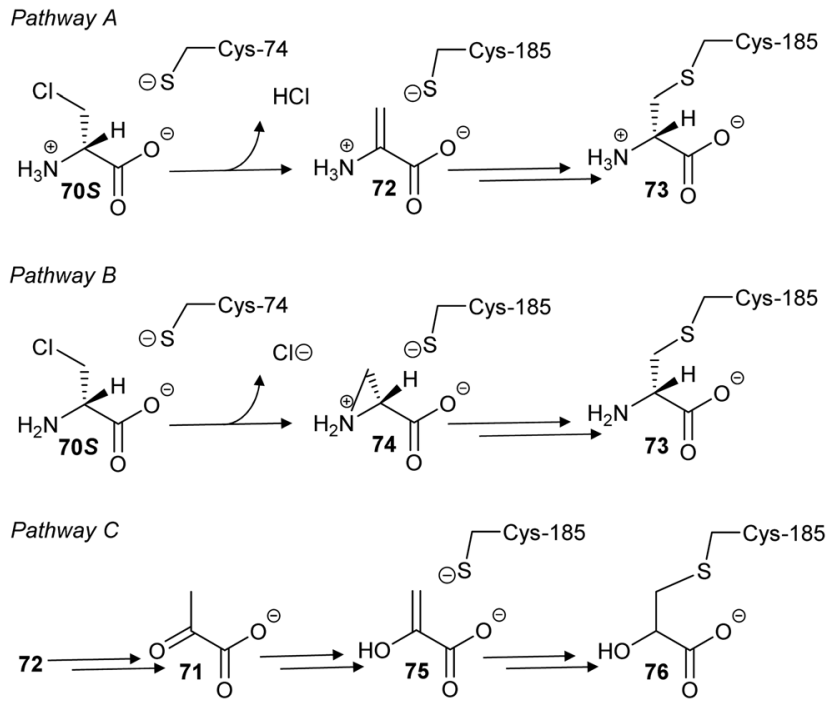

Scheme 12 Proposed mechanisms of glutamate racemase inactivation by 3 -chloro-S-alanine $70 S$ ( $\beta$-chloro-S-alanine).

complex 72. This is followed by conjugate addition of Cys-185 to give 73. However, complex 72 is achiral and non-specific derivatisation of the active site Cys residues might be expected if 72 resulted in alkylation. Pathway B, via the aziridine intermediate $\mathbf{7 4}$, preserves the chirality of reaction and gives rise to the same adduct 73. However, the active site Cys residues are relatively distant from the $\alpha$-amino group, making pathway B less likely. Digestion of the derivatised enzyme and mass spectrometric analysis shows the presence of nitrogen within the enzyme-inhibitor adduct, discounting the possibility that the adduct is a pyruvate derivative (Scheme 12, pathway C). The observed pyruvate $\mathbf{1 7}$ generated in the reaction arises from tautomerisation of aminoacrylate 72 to the imine followed by hydrolysis, i.e. $\mathbf{7 0}$ behaves as a substrate as well as an inhibitor. ${ }^{20}$

Similarly, two covalent inhibitors (77 and 78) of $T$. cruzi proline racemase were identified by virtual screening. ${ }^{26}$ The inhibitors were proposed to modify the active-site cysteine residues ${ }^{26}$ by conjugate addition ${ }^{202,205,206}$ and this was subsequently confirmed by X-ray crystallography. ${ }^{27}$ The active compounds (Scheme 13A) each have a double bond in conjugation with a carboxylate and a ketone $\mathrm{e}^{26,27}$ and X-ray crystallography
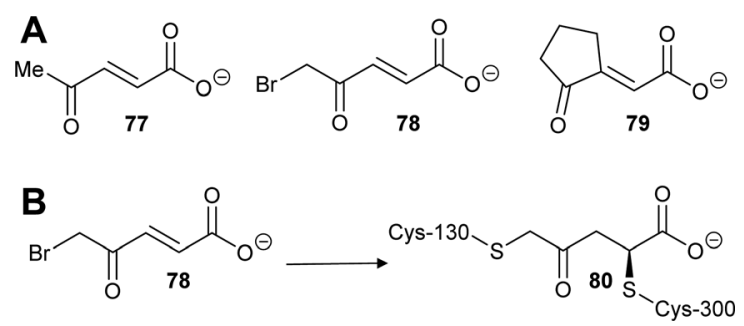

Scheme 13 (A) Structures of highly active covalent inhibitors of proline racemase; $^{26,27}$ (B) Reaction of 78 with catalytic cysteine residues in proline racemase by conjugate addition and $\mathrm{S}_{\mathrm{N}} 2$ reaction to give a cross-linked adduct $80^{27}$ showed that conjugate addition occurred towards the ketone. ${ }^{27}$ This is unsurprising as ketone carbons are more $\delta+$ than carboxylic acids/carboxylates and hence conjugate addition is expected to occur towards the ketone. The most active compound of those subsequently investigated (NG-P27, 79) ${ }^{27}$ was active against $T$. cruzi in infected mammalian cells. It is also notable that one of the original compounds ${ }^{26}$ (5-bromo-4oxopent-2-enoate 78) is divalent and reacts with both active-site cysteine residues, cross-linking the enzyme to give adduct $\mathbf{8 0}$ (Scheme 13B). ${ }^{27}$

\section{Virtual screening and structure-based fragment screening}

Virtual screening of drug targets with a compound library is a well-established method in drug discovery. ${ }^{221-225}$ These approaches can utilise artificial intelligence to optimise the process $^{223}$ or negative design ${ }^{222}$ to remove compounds which are poor prospects.

There are only a few examples of virtual screening being used for identification of inhibitors of racemases/epimerases and all have been for amino-acid racemases. For example, Skariyachan et al. conducted a screen of a virtual natural products library against diaminopimelate epimerase, amongst several other targets, identifying limonin $\mathbf{8 1}$ as a hit (Fig. 13). ${ }^{226}$ Limonin 81 and several other hits showed dose-dependent activity against a clinical strain of multi-drug resistant Acinetobacter baumannii.

Studies on B. subtilis glutamate racemase used ab initio quantum mechanics/molecular mechanics to probe transition states in the reaction. ${ }^{23} \mathrm{~A}$ strong correlation between computational and experimentally determined binding of known inhibitors was observed. The same $\operatorname{study}^{23}$ used a enzymatic transition state conformation in a virtual screen of over one million compounds followed by experimental testing. Although no tight-binding inhibitors were identified, several common motifs for competitive inhibitors were identified. A subsequent virtual screening study on the same enzyme ${ }^{24}$ identified several competitive inhibitors such as $\mathbf{6 4}$ and $\mathbf{8 2}$, with the two most potent inhibitors, 83 and $\mathbf{8 4}$, having $K_{\mathrm{i}}$ values of 59 and $42 \mu \mathrm{M}$ (Fig. 14).

Virtual screening has also been used against proline racemase from T. cruzi, the causative agent of Chagas disease (vide supra). ${ }^{26}$ Proline racemase without a ligand exists in an 'open' conformation. Upon binding of an inhibitor, a 'closed' conformation is adopted, such that a very restricted active site is produced, which prevents design of inhibitors using standard

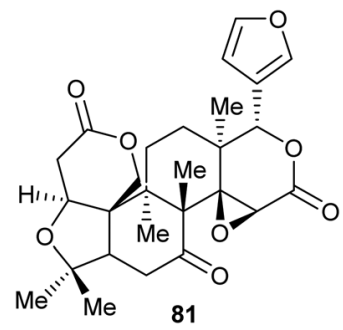

Fig. 13 Structure of limonin $\mathbf{8 1} .^{226}$ 
<smiles></smiles><smiles>O=C([O-])c1cccc(S(=O)(=O)[O-])c1</smiles><smiles>O=S(=O)([O-])c1ccc(O)c(S(=O)(=O)[O-])c1</smiles>

$K_{\mathrm{i}}=59 \mu \mathrm{M}$

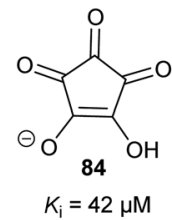

Fig. 14 Representative inhibitors of $B$. subtilis glutamate racemase identified using virtual high-throughput screening. ${ }^{23,24}$ The inhibitor ionisation state shown are those that were used in the virtual screen.

approaches. The virtual screening study generated forty-nine intermediate conformations en route from the 'open' to 'closed' conformations. Four of these conformations were used in virtual screens of 31000 compounds. These screens led to the identification of covalent inhibitors (vide supra, Scheme 13), which showed dose-dependent activity against $T$. cruzi in infected mammalian cells. ${ }^{26,27}$

\section{High-throughput screening and related approaches}

High-throughput screening is an under-utilised approach to discovering inhibitors of racemases and epimerases. Highthroughput screening offers a number of advantages, including the possibility of discovering inhibitors which are not competitive (which is the mode of inhibition often observed for activesite-directed inhibitors). ${ }^{227}$

Several different in vitro assays have been used in discovery campaigns. Release of tritium $\left({ }^{3} \mathrm{H}^{+}\right)$from a radiolabelled substrate into solvent was used in a screen of $\sim 5000$ compounds against human $\alpha$-methylacyl-CoA racemase (AMACR). ${ }^{152}$ Crucially, the assay requires several steps, including chromatographic separation of residual (acyl-CoA) substrate from tritiated water product. Therefore, this assay is not ideally suited for high-throughput or fragment-screening campaigns. This study $^{152}$ identified a number of non-specific protein-modifying and degrading agents, such as ebselen, ebselen oxide and Rose Bengal. ${ }^{127,152}$

A subsequent high-throughput screen on human $\mathrm{AMACR}^{163}$ made use of an eliminating substrate 37 (vide supra, Scheme 9) producing 2,4-dinitrophenoxide 38. ${ }^{127}$ Conveniently, this allowed identification of inhibitors based on absorbance changes over the time course in a continuous assay. The screen identified a series of mixed competitive and uncompetitive pyrazoloquinolines, e.g. 85, and pyrazolopyrimidines, e.g. 86 (Fig. 15). The use of a chromogenic substrate $^{127}$ allows real-time monitoring of the enzymatic reaction but substrates of this type can only be used with a few racemases/epimerases.

Two studies have made use of high-throughput screens with coupling enzymes. The first study, by Lundqvist et al., conducted a high-throughput screen of 385861 compounds against $H$. pylori glutamate racemase. ${ }^{200}$ No details of the actual
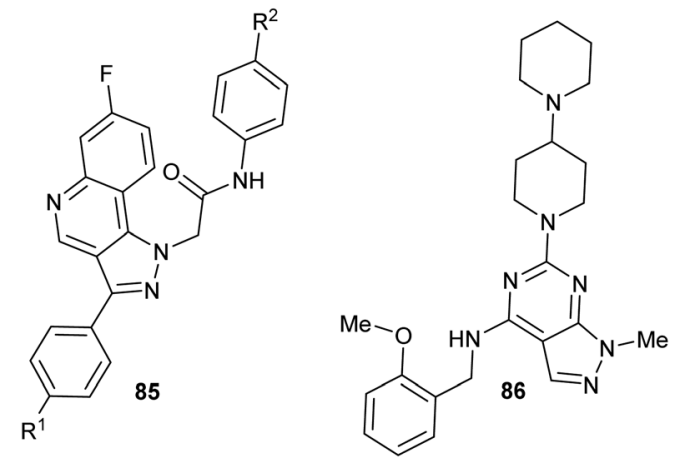

Fig. 15 Representative structures of pyrazoloquinoline and pyrazolopyrimidine AMACR inhibitors. ${ }^{163} 85 a, R^{1}=R^{2}=H$, uncompetitive inhibition, $K_{\mathrm{i}}=4.8 \pm 0.7 \mu \mathrm{M} ; \mathbf{8 5 b}, \mathrm{R}^{1}=\mathrm{R}^{2}=\mathrm{F}$, mixed competitive inhibition, $K_{\mathrm{i}}=2.4 \pm 0.9 \mu \mathrm{M} ; 86$, uncompetitive inhibition, $K_{\mathrm{i}}=4.6 \pm 0.4 \mu \mathrm{M}$.

screen are given but the authors used two different assays for assessing identified inhibitor activity: conversion of $S$ - to $R$-glutamate was coupled to UDP- $N$-acetyl-muramic acidalanine: $R$-glutamate ligase (MurD) and purine nucleoside phosphorylase with monitoring of the reaction at $360 \mathrm{~nm}$. In the second assay, conversion of $R$ - to $S$-glutamate was coupled to $S$-glutamate dehydrogenase with spectrophotometric monitoring of conversion of $\mathrm{NAD}^{+}$to NADH. These screens led to the identification of an uncompetitive inhibitor (vide supra Fig. 12, 63), which was subsequently shown to exert its effect by changing the conformation of the catalytic base, Cys-185, such that it points away from the glutamate substrate $\mathrm{C}_{\alpha}-\mathrm{H}$.

In a second example ${ }^{228}$ of a coupled assay, dTDP-6-deoxy-Dxylo-4-hexopyranosid-4-ulose 3,5-epimerase (RmlC) was coupled to the subsequent enzyme in the biosynthetic pathway, which is $\mathrm{NADP}^{+}$-dependent, with activity being followed by decreasing fluorescence of NADPH at $460 \mathrm{~nm}$. This led to the identification of a series of inhibitors, including some with potency in the $\mathrm{nM}$ range e.g. 87 (Fig. 16). ${ }^{228}$ Use of coupling enzymes, such as in these examples, is a standard approach in high-throughput and fragment-screening campaigns ${ }^{227}$ (vide infra), although it is always necessary to check if the hits are inhibiting the desired target or the coupling enzyme.

Racemases used in biotechnological applications have been assayed in several different ways, typically using oxidase enzymes of various types. These assays could be adapted for high-throughput screening for inhibitors. For example, mutant mandelate racemases were assayed using mandelate dehydrogenase, which uses $\mathrm{NAD}^{+}$. Conveniently, the ketoacid product

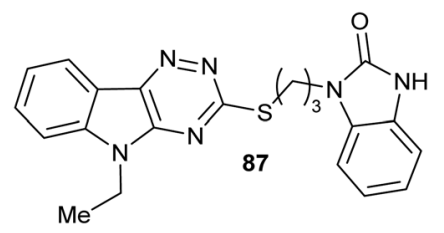

Fig. 16 Structure of the most potent hit $\mathbf{8 7}$ identified by high-throughput screening inhibiting RmlC. $\mathbf{6 1}$ is a fully reversible, competitive inhibitor with $\mathrm{IC}_{50}=200 \mathrm{nM}{ }^{228}$ 
<smiles>CCCC(NC(C)=O)C(=O)O[Na]</smiles>

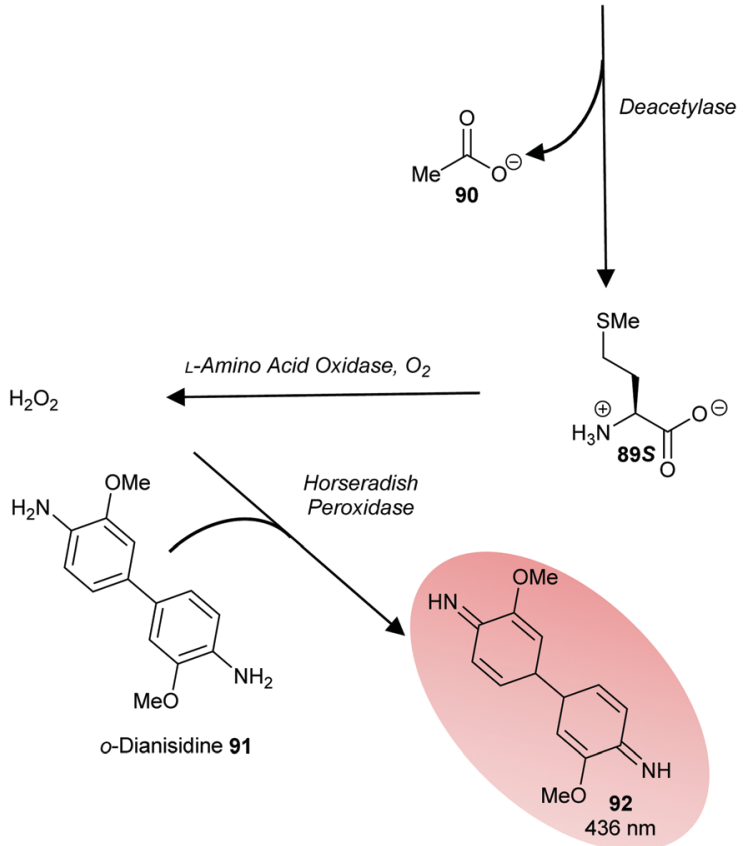

Scheme 14 Continuous assay of $\mathrm{N}$-acetyl-amino acid racemases using a three-enzyme coupling system to give a coloured product 92 absorbing at $436 \mathrm{~nm}^{181}$

can be assayed using 2,4-dinitrophenylhydrazine (2,4-DNPH) at alkaline $\mathrm{pH}$ with the final 2,4-dinitrophenylhydrazone product absorbing at $450 \mathrm{~nm} .{ }^{54}$ Ketoacids are also be produced by the action of amino-acid racemases and epimerases on amino-acid hydroxamate and other eliminating substrates ${ }^{82,128}$ (vide supra, Schemes 3, 4, 6 and 7). Alternatively, the NAD(P)H product from dehydrogenases can be assayed using diaphorases ${ }^{23,125}$ or by direct monitoring of absorbance or fluorescence.

Similarly, hydrogen peroxide is produced by several oxidative enzymes, including D-amino-acid oxidase, which can be conveniently assayed using horseradish peroxidase. ${ }^{174,229}$ Notably, an assay based on D-amino-acid oxidase/horseradish peroxidase was used to evaluate rationally designed inhibitors of proline racemase ${ }^{26}$ and in the high-throughput screening of alanine racemase. ${ }^{230}$ Similarly, a continuous assay for $\mathrm{N}$ acetylamino-acid racemases was developed using the $R$ - substrate $\mathbf{8 8 R}$ (Scheme 14). ${ }^{181}$ A stereoselective deacetylase was used to convert the $S$ - product $\mathbf{8 8 S}$ to the corresponding $S$-amino acid $89 S$ and acetate 90 . L-Amino acid oxidase was used to produce $\mathrm{H}_{2} \mathrm{O}_{2}$ from $89 \mathrm{~S}$, which was quantified by the horseradish peroxidase-catalysed oxidation of dianisidine $\mathbf{9 0}$ to give the coloured oxidation product $\mathbf{9 1}$.

In additional, several racemases/epimerases eliminate $\mathrm{HF}$ from fluorine-containing substrates (vide supra, Scheme 8), ${ }^{120,121}$ which could potentially be assayed using fluoride sensors, although this can be challenging in aqueous systems. ${ }^{161}$ Finally, microscale, medium-throughput polarimetric assays offer the possibility of direct observation of the change in chirality ${ }^{142}$ during screening.

\section{Inhibitors of racemases and epimerases}

Racemases and epimerases play pivotal roles in metabolism and are excellent drug targets. The following is a survey of recent advances in drug development, focussing on recently reported small-molecule inhibitors. Inhibition of many aminoacid racemases/epimerases has been the subject of a recent excellent review ${ }^{20}$ and readers are referred to this and the above sections for details of studies on inhibition of diaminopimelate racemase, ${ }^{20,124,217,218,226}$ proline racemase, ${ }^{26,27,135,188}$ hydroxyproline epimerase ${ }^{20}$ aspartate racemase ${ }^{20}$ serine racemase ${ }^{188}$ isoleucine epimerase ${ }^{20}$ and $O$-ureidoserine racemase. ${ }^{46}$ Studies on inhibition of mandelate racemase r1,139,196-198,216 $^{\text {are }}$ detailed in the section on inhibition strategies above. There have been no reported studies on inhibition of EcL-DER, RacX, YgeA, McyF, YcjG or $N$-acetylmannoseamine-6-phosphate 2-epimerase or $\mathrm{N}$-acetylamino-acid or $\mathrm{N}$-succinylamino-acid racemases since 2015 .

\section{PLP-dependent racemases}

Alanine racemase. Alanine racemase is involved in cyclosporine biosynthesis ${ }^{179}$ and is a well-established antibacterial drug target. ${ }^{18,20}$ The enzyme has been the subject of extensive inhibitor studies, ${ }^{231,232}$ including the early studies with 3-fluoroalanine and 3-chloroalanine noted above. ${ }^{132}$ Other inhibitors include several peptide and halogen-containing peptides, phosphonic acid derivatives (fosfalin) and various halovinylglycines and thiadiazolidinones. ${ }^{231,232}$

An important inhibitor of alanine racemase is D-cycloserine, a natural product used in the treatment of drug resistant tuberculosis. ${ }^{233,234}$ It is notable that the biosynthetic pathway for D-cycloserine contains a reaction catalysed by a racemase, $O$-ureidoserine racemase ${ }^{46}$ (vide supra, Scheme 10A). D-Cycloserine 93 is a relatively non-specific antibiotic and targets M. tuberculosis alanine racemase and D-Ala-D-Ala ligase. ${ }^{233,234}$ Inhibition of alanine racemase is proposed to occur by formation of the external aldimine $\mathbf{9 4}$ followed by reversible rearrangement to the ketimine 95 and isoxazole 96 (Scheme 15). ${ }^{233}$ Stereoselective isotope exchange with solvent is observed when the reaction is carried out in ${ }^{2} \mathrm{H}_{2} \mathrm{O}$, with D-cycloserine 93 incorporating deuterium at the $\alpha$-position without a change in stereochemical configuration. Deuteration appears to arise by exchange of the $\alpha$-proton. Incubations of alanine racemase with $\mathrm{D}$-cycloserine $\mathbf{9 3}$ also result in the formation of isoxazole $97 . .^{233}$ The authors propose a complex rearrangement of the keto tautomer of $\mathbf{9 6}$ but this seems unlikely. A simpler explanation is that alanine racemase catalyses hydrolysis of aldimine 94 using a hydrogen-bonded water molecule, to form the linear aldimine $\mathbf{9 8}$ directly. This could undergo imine exchange to form $\mathbf{9 9}$ but a more likely scenario is that $\mathbf{9 7}$ is released from 98 which uses its hydroxylamine to form the aldimine complex 99 directly (the $\mathrm{p} K_{\mathrm{a}}$ for the conjugate acid of 


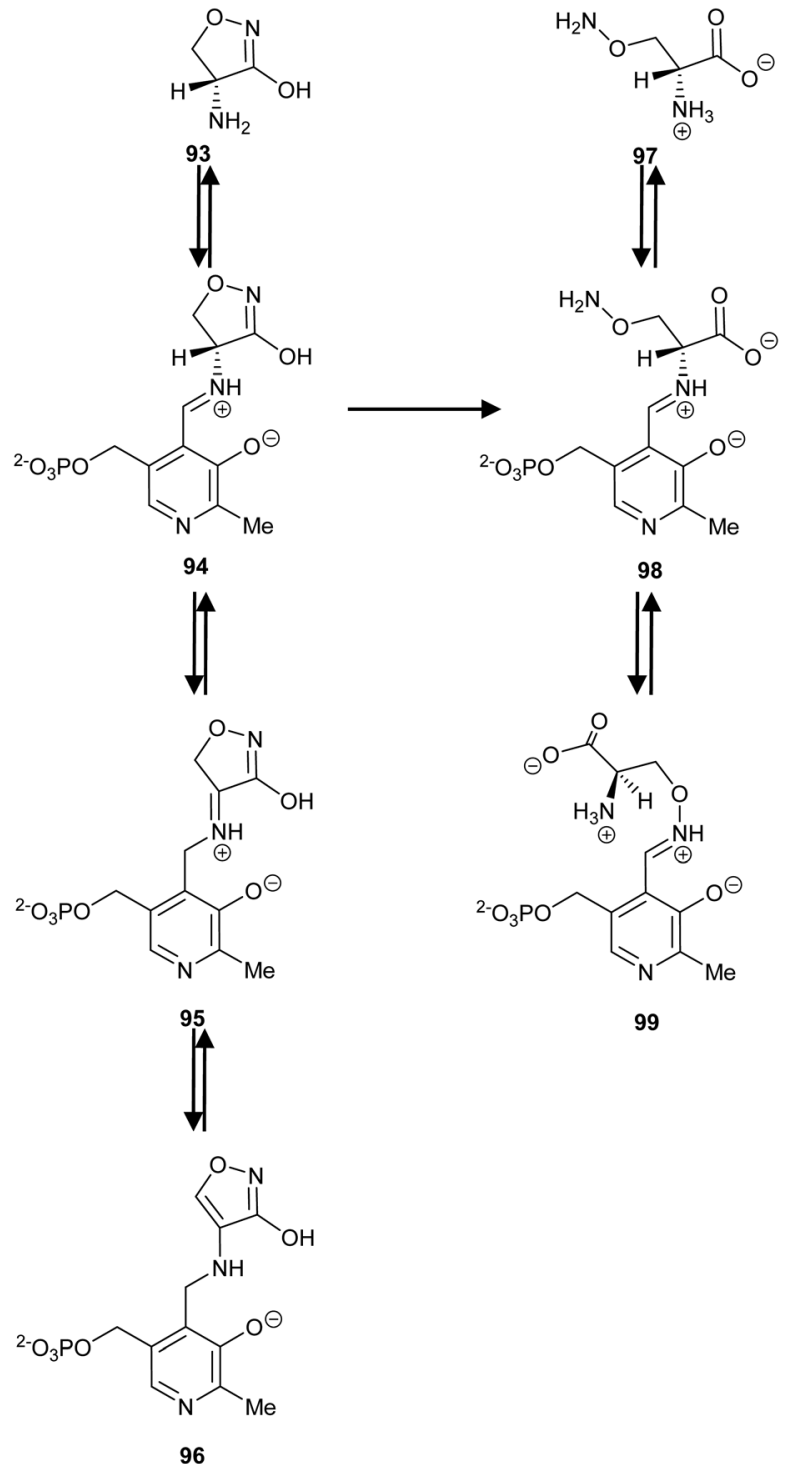

Scheme 15 Inhibition of alanine racemase by D-cycloserine 93 . Note that 96 was proposed to be directly converted into $99^{233}$ but it is more likely that $\mathbf{9 4}$ undergoes hydrolysis to form $\mathbf{9 8}$, which releases $\mathbf{9 7}$. This directly forms two different external aldimines, $\mathbf{9 8}$ or $\mathbf{9 9}$, respectively (see text for details).

the $\alpha-\mathrm{NH}_{2}$ and $\gamma-\mathrm{O}-\mathrm{NH}_{2}$ groups are 9.14 and $3.16,{ }^{235}$ respectively, and, hence, the $\gamma-\mathrm{O}-\mathrm{NH}_{2}$ group will be uncharged at neutral $\mathrm{pH}$ ). Thus, D-cycloserine 93 is both a substrate (undergoing $\alpha$-proton exchange and hydrolysis) and an irreversible inhibitor of alanine racemase, consistent with the observation that $M$. tuberculosis alanine racemase is not fully inhibited even by high concentrations of 93.

A series of tetrazole-peptide derivatives were also designed and synthesised as inhibitors of alanine racemase in bacterial cells (Fig. 17). ${ }^{236}$ The tetrazole group is a well-established bioisostere of the carboxylate group, ${ }^{236}$ and hence 5-(1-aminoethyl)tetrazole $\mathbf{1 0 0}$ should behave as an analogue of alanine. $S$ - and $R$-5-(1-aminoethyl)tetrazole 100 (AET) were inactive when tested against a series of Gram-negative and -positive

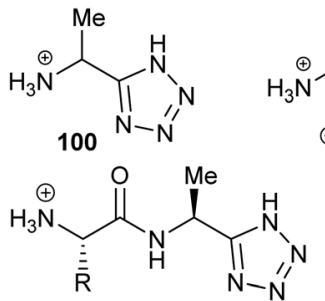

103a, $R=$ Me-; 103b, $R=$ n-propyl-;

103c, $R=$ iso-butyl-; 103d, $R=$ Phenylmethyl-

Fig. 17 Structures of 5-(1-aminoethyl)tetrazole 100, fosfalin 101, alafosfalin 102, and dipeptide analogues 103a-d and tripeptide analogue $104{ }^{236}$

bacteria $^{236}$ but this is unsurprising as it is known that alanine is imported into bacterial cells as an oligopeptide. Indeed, fosfalin $\mathbf{1 0 1}$ is delivered to bacterial cells as a "dipeptide" alafosfalin 102. ${ }^{231,236}$

Therefore, a series of di- and tripeptide derivatives were synthesised and tested. ${ }^{236}$ The $S S$-Ala-Ala analogue 103a was active against several Gram-negative species, whilst the $S S$-norvalene-AET 103b, $S S$-Leu-AET 103c and $S S$-Phe-AET 103d analogues were active against several Gram-positive species. The SSS-Ala-Ala-AET analogue 104 showed similar activity to 103a. $N$-Succinyl derivatives of these peptide analogues were largely inactive. It was not determined if $S$ - and $R$-5(1-aminoethyl)tetrazole $\mathbf{1 0 0}$ or any of the peptide analogues were inhibitors of alanine racemase and hence the mechanism of antibacterial activity has not been confirmed.

High-throughput screening of small-molecule and fungal extract libraries against Aeromonas hydrophila alanine racemase has also been performed. This screen identified several previously unknown inhibitors (Fig. 18) of moderate potency $\left(\mathrm{IC}_{50}=6.6\right.$ to $\left.18.5 \mu \mathrm{M}\right)$, including homogentisic acid 105 and hydroxyquinone $106 .{ }^{230} \mathrm{D}$-Cycloserine 93 (the control inhibitor) had an $\mathrm{IC}_{50}$ of $5.4 \mu \mathrm{M}$ under the conditions used in this screen. Kinetic analysis showed that homogentisic acid 105 was a competitive inhibitor $\left(K_{\mathrm{i}}=51.7 \mu \mathrm{M}\right)$ whilst hydroxyquinone 106 was a non-competitive inhibitor $\left(K_{\mathrm{i}}=212 \mu \mathrm{M}\right)$. These two compounds showed antibacterial activity against $A$. hydrophila, a Gram-negative anaerobic pathogen. Anabellamide 107 was a potent inhibitor of alanine racemase in vitro $\left(\mathrm{IC}_{50}=6.6 \mu \mathrm{M}\right)$ but was inactive in cellular assays (Fig. 18).

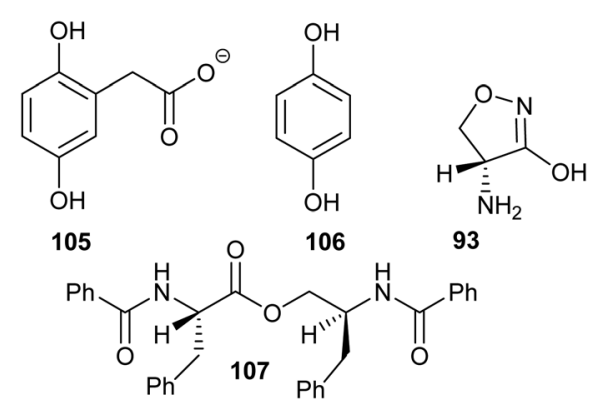

Fig. 18 Structures of alanine racemase inhibitors identified by highthroughput screening. ${ }^{230}$ Abbreviation used: Ph, phenyl. 
Isoleucine 2-epimerase. Isoleucine 2-epimerase is a novel anti-bacterial drug target. There are only two studies on the inhibition of isoleucine 2-epimerase. ${ }^{180,189}$ Mutaguchi et al. noted, in their original characterisation of the enzyme, that it was inhibited by non-specific inhibitors of other PLPdependent enzymes, such as hydroxylamine, aminooxyacetate and phenylhydrazine. ${ }^{180}$ The effect of hydroxylamine was reversed upon dialysis and addition of PLP to the buffer, providing good evidence that the enzyme is a PLP-dependent epimerase.

Subsequently, a study investigating inhibition of Lactobacillus buchneri isoleucine 2-epimerase by substrate/product analogues was reported. ${ }^{189}$ Two groups of inhibitors (Fig. 19) were investigated, based on the structure of the substrate $S$-isoleucine $\mathbf{1 0 8 .}$ These inhibitors fell into two classes: those with a single modified sidechain (109-111); and those with dual sidechains (112), which are similar to the substrate-product analogues that inhibit other racemases and epimerases. ${ }^{139,149,150,174,188,197,198}$ The $2 R$ - and $2 S$ - enantiomers of $\mathbf{1 0 9}$ were substrates of the enzyme, although these are converted with an efficiency of only $\sim 50 \%$ to $80 \%$ of that of the natural substrates (as judged by $k_{\text {cat }} / K_{\mathrm{m}}$ values ${ }^{180,189}$ ) and, hence, would not be very effective competitive inhibitors. On the other hand, 110 which possesses an additional methyl group on the sidechain was not a substrate but instead behaved as a pure competitive inhibitor $\left(K_{\mathrm{i}}\right.$ values of 1.5 and $2.9 \mathrm{mM}$ for the $2 R$ and $2 S$ enantiomers, respectively). Compound 111 which has a cyclic sidechain was also an alternative substrate and was converted with very similar efficiencies to 109 (as judged by $k_{\text {cat }} / K_{\mathrm{m}}$ values). The synthesised compounds with dual sidechains (112, $n=1,2$ and 3) were rather poor inhibitors, although potency increased with increasing size and hydrophobicity of the sidechain $\left(K_{\mathrm{i}}=144,19\right.$ and $11 \mathrm{mM}$, respectively).

Serine racemase. Serine racemase catalyses the formation of $R$-serine from $S$-serine as well as the elimination of water. ${ }^{69}$ $R$-Serine binds to the $N$-methyl-D-aspartate (NMDA) receptor glycine-binding site. The NMDA receptor is associated with several neurological diseases, including Alzheimer's disease, amyotrophic lateral sclerosis, Huntington's disease, Parkinson's disease, epilepsy and eye disease, amongst others, and psychiatric diseases such as schizophrenia, and depression..$^{35,237-241}$ Hence, inhibition of serine racemase is of interest as a strategy for the manipulation of levels of $R$-serine.
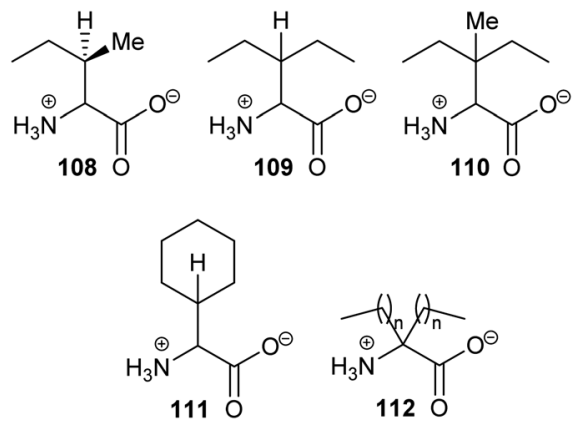

Fig. 19 structures of isoleucine 108 and inhibitors of isoleucine 2-epimerase. ${ }^{189}$ For 112, $n=1,2$ and 3 .<smiles>CC(=O)NC(=O)NNC(=O)Cc1cccs1</smiles><smiles>CCOC(=O)NC(=O)NNC(=O)Cc1ccccc1</smiles><smiles>Cc1ccc(/C=C/S(=O)(=O)NCC(=O)Nc2ccc(OCC3=CC=CCC3)cc2)cc1</smiles>

115

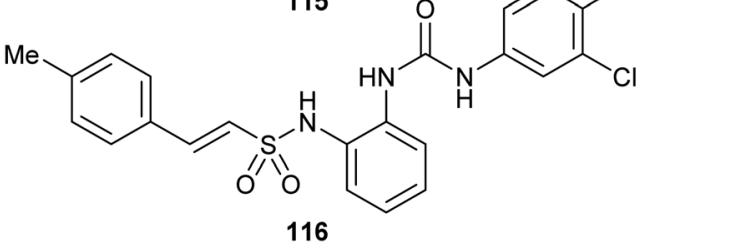

Fig. 20 Structures of inhibitors of serine racemase. 239,245

A large number of studies have appeared on the biological and pathological role of serine racemase in the last five years $^{35,69,129,241-244}$ but only one study has reported synthesis and evaluation of inhibitors. ${ }^{239}$ This study $^{239}$ elaborated a potent hit (Fig. 20, 113) identified in a previous virtual screen. ${ }^{245}$ of the synthesised compounds, five showed potent inhibition of serine racemase in vitro. Two of these compounds were similar in structure to the original hit and $\mathrm{IC}_{50}$ values were determined for the three other compounds (140, 270 and $280 \mu \mathrm{M}$ for 114, 115 and 116, respectively). This compares to an $\mathrm{IC}_{50}$ value of $770 \mu \mathrm{M}$ for malonate, a standard inhibitor. Further studies showed 114 reduced NDMA receptor activation by $\sim 1$.4-fold, consistent with engagement of the target in vivo.

\section{Cofactor-independent racemases and epimerases}

Glutamate racemase (MurI). Glutamate racemase catalyses the interconversion of $S$ - and $R$-glutamate. $R$-Glutamate is a key component of the bacterial cell wall ${ }^{17}$ and the enzyme is an important drug target. Readers are also referred to the review on amino-acid racemases ${ }^{20}$ and the previous section for details of substrate/product analogues, ${ }^{175}$ allosteric inhibitors, ${ }^{21,25,200}$ covalent inhibitors, ${ }^{22-24,134}$ high-throughput screening ${ }^{200}$ and virtual screening. ${ }^{23-25}$

Malapati et al. have reported a series of medium-throughput screening studies on $M$. tuberculosis glutamate racemase using thermal-shift assays (Fig. 21). ${ }^{246-248}$ Structure-activity relationship (SAR) studies led to inhibitors 117-119 with low $\mu \mathrm{M} \mathrm{IC}_{50}$ values. Non-competitive inhibition was assigned based on the observed changes within the thermal shift assay, although this was not confirmed by enzyme activity assays. Docking studies suggested that these compounds bound to an allosteric binding site.

In addition, Duvall et al. reported phenotypic screening of a diversity-orientated synthetic collection ( $\sim 100000$ compounds) 


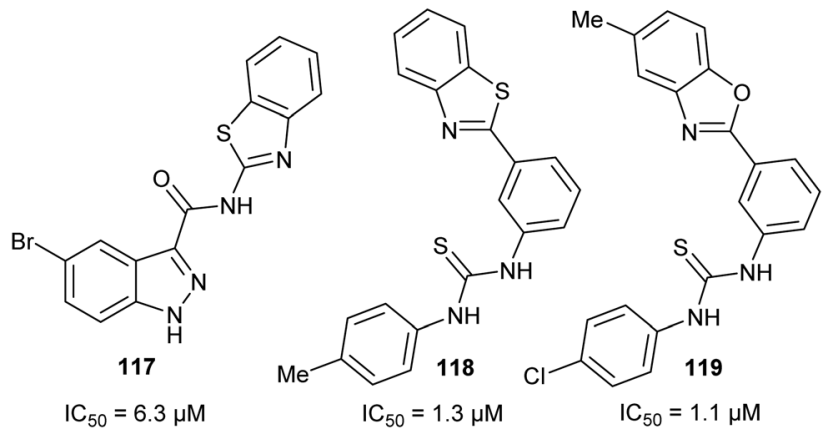

Fig. 21 Structures of leads reported by Malapati et al. ${ }^{246-248}$

against Clostridium difficile and other bacterial strains under anaerobic conditions. ${ }^{249}$ One of the hits (BRD0761, Fig. 22, 120) showed minimum inhibitory concentrations of $0.06-0.25 \mu \mathrm{g} \mathrm{mL}^{-1}$ $(0.13-0.55 \mu \mathrm{M})$ against various $C$. difficile strains, with much higher MIC values against other anaerobes, while its epimer BRD3141 121 was also active (Fig. 22). BRD0761 inhibited uptake of $\left[{ }^{14} \mathrm{C}\right]-N$-acetylglucosamine into bacteria in a dose-dependent manner, suggesting that it targeted bacterial cell wall biosynthesis. The target was identified from resistance mutants as glutamate racemase and a binding model was produced based on the X-ray crystal structure of $H$. pylori enzyme. Dosing of mice with $\mathbf{1 2 0}$ protected them from $C$. difficile infection.

UDP-N-acetylglucosamine 2-epimerase. UDP- $N$-acetylglucosamine 2-epimerase is one of the first enzymes in the teichoic acid biosynthetic pathway, ${ }^{250}$ which is required for the integrity of the bacterial cell wall. In addition, Zika virus uses 2,3-linked sialic acid residues to enter mammalian cells and CRISPR-Cas9 knock-out of this enzyme reduces viral infection. ${ }^{251}$ The use of $\mathrm{N}$-acetylmannosamine analogues as inhibitors is especially favourable, as $\mathrm{N}$-acetylmannosamine is used solely for biosynthesis of sialic acid; in contrast, UDP- $N$-acetylglucosamine is also used in the biosynthesis of other glycans ${ }^{252}$ and analogues are likely to suffer from lack of selectivity.

A series of $N$-acetylglucosamines and $N$-acetylmannosamines, some with modified UDP moieties, have been previously developed as inhibitors but had modest potency (reviewed in ref. 253). Nieto-Garcia et al., reported a series of inhibitors in which the C6 hydroxy group was replaced with sulfur or selenium (Fig. 23). ${ }^{253}$ The diselenide inhibitor 122 proved to be highly potent $\left(\mathrm{IC}_{50}=8.5 \mu \mathrm{M}\right)$ compared to the other inhibitors $\left(\mathrm{IC}_{50}\right.$ values of 1.9 to $\left.>10 \mathrm{mM}\right)$. The dimeric
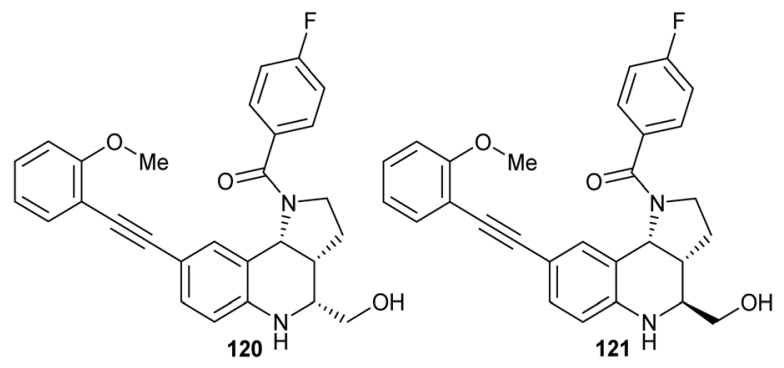

Fig. 22 Structures of BRD0761 120 and BRD3141 121.249
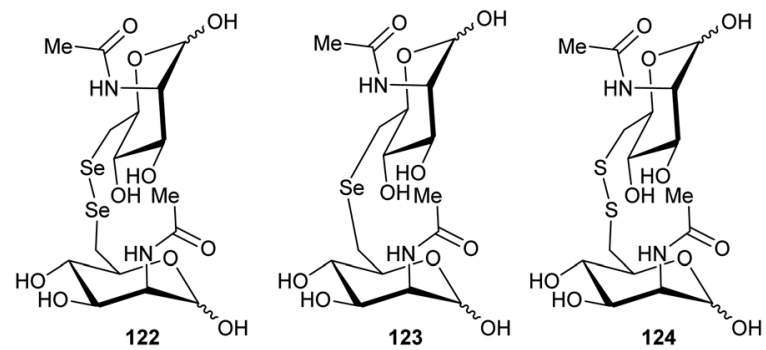

Fig. 23 Structures of (di)selenide and disulfide inhibitors of UDP-Nacetylglucosamine 2-epimerase $/ \mathrm{N}$-acetylmannosamine kinase. ${ }^{253}$

monoselenide inhibitor 123 was much less potent $\left(\mathrm{IC}_{50}=3.0 \mathrm{mM}\right)$. The corresponding disulfide analogue $\mathbf{1 2 4}$ was also much less active than $122\left(\mathrm{IC}_{50}=4.2 \mathrm{mM}\right)$, showing the importance of the diselenide unit for potent inhibition. The much higher potency of 122 compared to the other inhibitors could be due to bond length or flexibility of the linker. ${ }^{253}$ Small-molecule diselenide bonds have been reported as having a bond length of $2.29 \AA \AA^{254}$ while disulfide bonds (in proteins) have a corresponding bond length of $2.05 \AA^{255}$ It has also been suggested that van der Waals interactions and hydrogen bonding potential may also be important in determining inhibitory potency. ${ }^{253}$ Diselenide $\mathbf{1 2 2}$ was a competitive inhibitor with a $K_{\mathrm{i}}$ value of $15.7 \mu \mathrm{M} .^{253}$

Hinderlich et al. reported a high-throughput screening campaign using a library of 41536 compounds and a luciferase assay to measure ATP depletion. ${ }^{252}$ The $N$-acetylmannosamine substrate was used at $33 \mu \mathrm{M}$, close to its $K_{\mathrm{m}}$ value, with an average $Z^{\prime}$ value (a measure of the ability of the assay to discriminate between a hit and random noise ${ }^{227,256}$ ) of 0.78 . Compounds were screened at $13 \mu \mathrm{M}$, yielding 252 hits of which 174 were analysed using dose-response curves, yielding 46 inhibitors with $\mathrm{IC}_{50}<33 \mu \mathrm{M}$. Further analysis and counterscreening against yeast hexokinase yielded several leads 125128 (Fig. 24). The $\mathrm{IC}_{50}$ values did not significantly change with changing concentrations of ATP, suggesting that they were noncompetitive. Modelling studies suggested that 125, 126 and 128 bound in the $N$-acetylmannosamine-binding site in the closed form of the enzyme, although $\mathbf{1 2 7}$ was larger than the available site, suggesting it might be bound to the open conformation. ${ }^{252}$
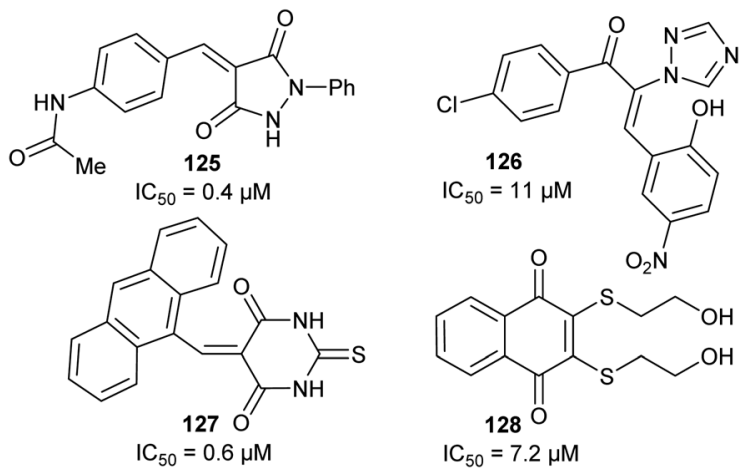

Fig. 24 Structures of UDP-N-acetylglucosamine 2-epimerase/Nacetylmannosamine kinase inhibitors. ${ }^{252}$ 
<smiles>O=C([O-])c1cc(C(F)(F)F)ccn1</smiles>

$\mathrm{IC}_{50}=900 \mu \mathrm{M}$

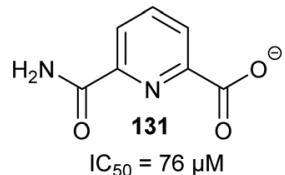

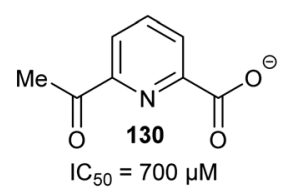

Fig. 25 Structure of hit 129 and derived inhibitors 130 and $131 .{ }^{257}$

UDP- $N$-acetylglucosamine epimerase/ $N$-acetylmannosamine kinase is also one of only two racemases or epimerases to be subjected to a fragment-screening campaign. ${ }^{257}$ A library of 281 fluorinated fragments were screened at $50 \mu \mathrm{M}$ using ${ }^{19} \mathrm{~F}$ NMR and binding of inhibitor was confirmed by competition with $N$-acetylmannosamine and ATP, yielding 23 hits. Of these, compound $\mathbf{1 2 9}$ was also shown to inhibit in a coupled enzyme assay and so was chosen for development. Analogues of $\mathbf{1 2 9}$ were screened, leading to identification of $\mathbf{1 3 0}$ which was optimised to 131 (Fig. 25). Modelling of the binding of the inhibitor suggested that $\mathbf{1 3 1}$ bound to the active-site $\mathrm{Mg}^{2+}$ used in the kinase reaction, near the catalytic site. However, these compounds were not developed into more potent leads.

dTDP-4-keto-6-deoxyglucose 3,5-epimerase (RmlC). dTDP-4keto-6-deoxyglucose 3,5-epimerase ( $\mathrm{RmlC}$ ) is involved in biosynthesis of $\mathrm{L}$-rhamnose in $M$. tuberculosis and other bacteria. ${ }^{111,228}$ L-Rhamnose is biosynthesised from D-glucose6-phosphate in a four-step pathway. The third step of this pathway is epimerisation at both carbons C3 and C5 of the 4-ketosugar moiety catalysed by $\mathrm{RmlC}$, followed by reduction of the keto group by $\mathrm{RmID}$ in the final step. ${ }^{111}$ Because L-Rhamnose is essential for the integrity of the bacterial cell wall, RmlC and the other enzymes in the pathway are drug targets. ${ }^{258-260} \mathrm{RmlC}$ is also responsible for activation of the virulence factor in the marine pathogen Vibrio vulnificus. ${ }^{261}$

Several inhibitors of RmlC have been previously characterised (including the high-throughput screening inhibitors noted above; ${ }^{228}$ vide supra, Fig. 16), although many have limited aqueous solubility. ${ }^{259}$ van der Beek et al. conducted a fragmentscreening campaign with a commercial library using bio-layer interferometry. ${ }^{259} \mathrm{~A}$ library of $\sim 1000$ fragments was screened at $200 \mu \mathrm{M}$ with twelve hits. Of these, seven compounds showed dose-dependent enzyme inhibition and inhibited bacterial growth. Three hits (Fig. 26, 132-134) with diverse structures inhibited both RmlB (the preceding enzyme in the biosynthetic pathway) and RmlC.

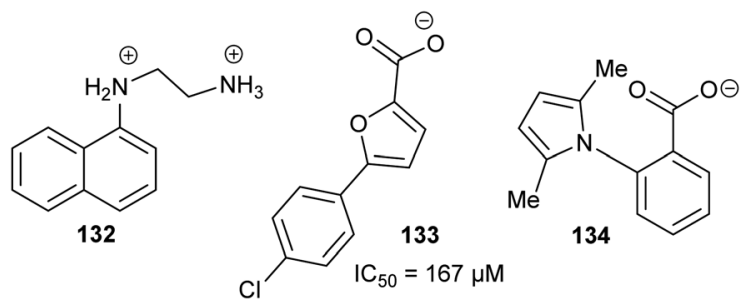

Fig. 26 Structures of fragment screening hits active against $\mathrm{RmIC}^{259}$
Sasikala et al. also conducted a virtual screen of RmlC and identified several potential inhibitors of the Vibrio vulnificus enzyme (also known as WbpP). ${ }^{261}$ However, none of these compounds were confirmed as hits in biochemical or biophysical screens.

$\alpha$-Methylacyl-CoA racemase. $\alpha$-Methylacyl-CoA racemase (AMACR; P504S) is a metabolic enzyme involved in the degradation of branched-chain fatty acids and the activation of ibuprofen and related drugs. ${ }^{6,7}$ Levels of the AMACR protein are increased in prostate cancer and many other cancers and the reader is referred to previous reviews on the subject. ${ }^{6,7}$ The M9V single-nucleotide polymorphism (SNP) is well known to increase risk of prostate cancer (reviewed in ref. 7) but recent analysis showed interaction of this SNP with SNPs in serine/ threonine kinase AKT1 which are also involved in prostate cancer. ${ }^{262}$ Levels of AMACR protein have also been shown to be downregulated by microRNA miR200, resulting in decreased proliferation and migration of prostate cancer cells. ${ }^{263}$ Interestingly, a recent epidemiological study showed that AMACR levels were diminished in men with prostate cancer who supplemented their diet with extracts from cruciferous vegetables, such as broccoli, which contains the isothiocyanate compound, sulforaphane. ${ }^{264}$ AMACR levels are also increased in glioblastoma ${ }^{265,266}$ and high AMACR levels are correlated with poor prognosis for patients. ${ }^{265}$ Hence, AMACR is a potentially a novel biomarker for glioblastoma. ${ }^{265}$ siRNA knock-down of AMACR levels led to reduced proliferation of glioblastoma cells. ${ }^{265}$ Increased AMACR levels are thought to indicate an increase in fatty acid $\beta$-oxidation, in a similar way to that observed in prostate cancer. ${ }^{266}$

AMACR has been the subject of several previous inhibitor studies as well as structural studies on the M. tuberculosis homologue (MCR), with literature up to the end of 2012 having been previously reviewed. ${ }^{6,7}$ Following on from previous reports ${ }^{136}$ Carnell et al. reported a series of acyl-CoA inhibitors with modified cores. ${ }^{191}$ The reported several new inhibitors (Fig. 27) including ( \pm )- $\alpha$-fluoroibuprofenoyl-CoA 49 (in which the $\mathrm{C}_{\alpha}-\mathrm{H}$ was replaced by fluorine), a chloro derivative 135 , and $N$-dodecanoyl- $R$-alanyl-CoA 136. Inhibitor 49 replaces the $\mathrm{C}_{\alpha}-\mathrm{H}$ with a $\mathrm{C}_{\alpha}-\mathrm{F}$, effectively removing the $\alpha$-proton. Substitution of
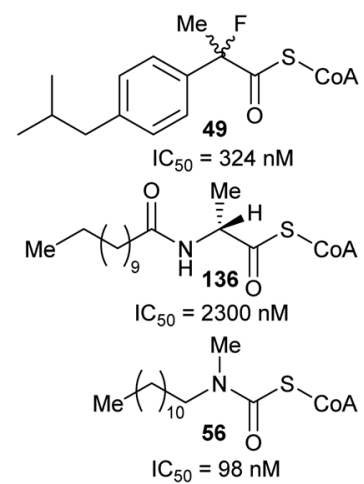
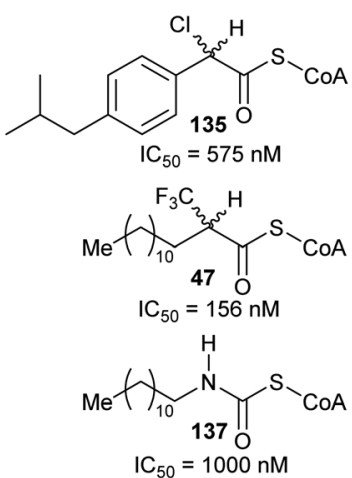

Fig. 27 Structures of rationally designed AMACR inhibitors reported by Carnell et al. ${ }^{191}$ 
hydrogen with fluorine is commonly used in drug design because of the similar atomic radii $(1.10 v s .1 .35 \AA),{ }^{267}$ bond lengths to carbon (1.08 to 1.11 vs. 1.26 to $1.41 \AA)^{267}$ and the high C-F bond energies (typically $>456 \mathrm{~kJ} \mathrm{~mol}^{-1}$ ). ${ }^{138,268}$ Inhibitors 135 and 136 are expected to form the enolate intermediate more easily, ${ }^{191}$ although this was not actually proven. Model studies suggest the $\mathrm{C}_{\alpha}-\mathrm{H} \mathrm{p} K_{\mathrm{a}}$ for 136 should be $\sim 14.5^{-}$ $16.5^{86,191}$ compared to a $\mathrm{C}_{\alpha}-\mathrm{H}$ p $K_{\mathrm{a}}$ of $\sim 21$ for standard acyl-CoA esters. ${ }^{86,88}$ Inhibitors 49 and 135 had IC $_{50}$ values of 324 and $570 \mathrm{nM}^{191} \mathrm{~N}$-Dodecanoyl- $R$-alanyl-CoA 136 was less potent, with an $\mathrm{IC}_{50}$ value of $2300 \mathrm{nM}$, which is probably be due to lower stabilisation of the negatively charged intermediate. ${ }^{191}$ The known inhibitor $( \pm)$-2-trifluoromethyltetradecanoyl-CoA ${ }^{136}$ 47 had an $\mathrm{IC}_{50}$ of $156 \mathrm{nM} .{ }^{191}$ Significantly, two potent carbamate inhibitors 56 and $\mathbf{1 3 7}$ as analogues of the intermediate enolate were reported $\left(\mathrm{IC}_{50}=98\right.$ and $\left.1000 \mathrm{nM}\right)$. Later studies $^{127,164}$ showed that the carbamate inhibitor 56 was highly potent compared to other inhibitors $\left(\mathrm{IC}_{50}=\sim 0.4 \mathrm{nM}\right.$ using the colorimetric assay ${ }^{127}$ ).

Also following on from the Carnell et al. study in $2007,{ }^{136}$ Festuccia et al. ${ }^{190}$ reported the synthesis and testing of trifluoroibuprofenoyl-CoA (Fig. 28, 48). Limited kinetic analysis suggested non-competitive inhibition by this compound with a $K_{\mathrm{i}}=1.7 \mu \mathrm{M}$. This result is notable because non-competitive inhibition of enzymes is rather rare (reviewed in ref. 227) and this is the only example of a non-competitive inhibitor reported for AMACR (and one of only a few for racemases/epimerases in general). Non-competitive inhibition is inconsistent with the inhibitor acting as an alternative substrate but instead arises through allosteric inhibition, stabilisation of an inactive conformation or covalent modification of the target. ${ }^{227}$ The basis for inhibition of AMACR by trifluoroibuprofenoyl-CoA is unclear, although elimination of fluoride is not reported. Treatment of cultured androgen-dependent and -independent prostate cancer cells with the pro-drug trifluoroibuprofen (Fig. 28, 138) resulted in arrest at $\mathrm{G} 2 / \mathrm{M}$ in the cell cycle and a host of other changes, including induction of apoptosis. ${ }^{190}$ Tumour growth in androgen-dependent and -independent prostate cancer xenograft mouse models was also significantly reduced by treatment with this agent. ${ }^{190}$

The advent of the AMACR colorimetric assay (vide supra, Scheme 9) ${ }^{127}$ has enabled much more thorough testing of inhibitors than had been previously possible, including determination of $\mathrm{IC}_{50}$ and $K_{\mathrm{i}}$ values and of reversibility of inhibition. This also enabled the first structure-activity relationship studies to be conducted. The first studies ${ }^{127,164}$ looked at a series of known AMACR inhibitors and substrates. A second study ${ }^{165}$ looked at a focussed series of 2-(arylthio)propanoyl-CoA inhibitors;

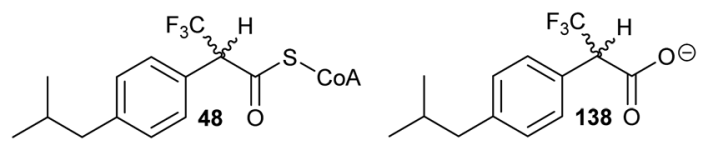

Fig. 28 Structures of trifluoroibuprofenoyl-CoA 48 and the trifluoroibuprofen pro-drug 138 . $^{190}$

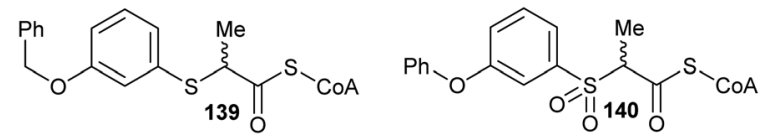

Fig. 29 Structure of the most potent 2-(arylthio)propanoyl-CoA inhibitor 139 and the poorly active 2-(arylsulfonyl)propanoyl-CoA 140 of human AMACR. ${ }^{165}$

the presence of the side-chain sulfur atom resulted in increased acidity of the $\mathrm{C}_{\alpha}-\mathrm{H}$ (previous studies on straight-chain acyl-CoAs and their 3-thia analogues showed that the presence of the sulfur reduces the $\mathrm{p} K_{\mathrm{a}}$ of the $\mathrm{C}_{\alpha}-\mathrm{H}$ to $\sim 15-16.5,{ }^{269,270}$ compared to $\sim 21$ for the corresponding acyl-CoA ${ }^{86,88}$ ). Many of these 2-(arylthio)propanoyl-CoA inhibitors were equipotent to fenoprofenoyl-CoA but optimisation of the inhibitor side-chain resulted in increased potency, e.g. 139, $\mathrm{IC}_{50}=22.3 \mathrm{nM} .{ }^{165} \mathrm{~A} 2$-(arylsulfonyl)propanoyl-CoA inhibitor 140 was also synthesised in the hope that the presence of the sulfonyl group would further increase $\mathrm{C}_{\alpha}-\mathrm{H}$ acidity but this proved to be a poor inhibitor (Fig. 29). ${ }^{165}$

Plotting pIC $_{50}$ values for all inhibitors ${ }^{127,164,165}$ characterised by the AMACR colorimetric assay ${ }^{127}$ against calculated $\log P$ values (Fig. 30) showed that inhibitor potency was positively correlated with $\log P$. The 2-(arylsulfonyl)propanoyl-CoA inhibitor 140 was highly hydrophilic, ${ }^{165}$ suggesting that this was the reason for its unexpected low potency. Although the 2-(arylthio)propanoyl-CoA inhibitors, such as 139, were highly potent in enzyme assays in vitro $\left(\mathrm{IC}_{50}=22-520 \mathrm{nM}\right)$, the carboxylic acid pro-drugs did not show any appreciable inhibition of androgen-dependent or -independent prostate cancer cells, ${ }^{165}$ possibly due to oxidation of the inhibitor pro-drug sulfur to the sulfoxide or sulfone.

Since the last review, ${ }^{7}$ two studies featuring rational design of inhibitors for the M. tuberculosis AMACR homologue, MCR, have been published. The first study ${ }^{149}$ describes the synthesis and testing of several substrate/product acyl-CoA inhibitors

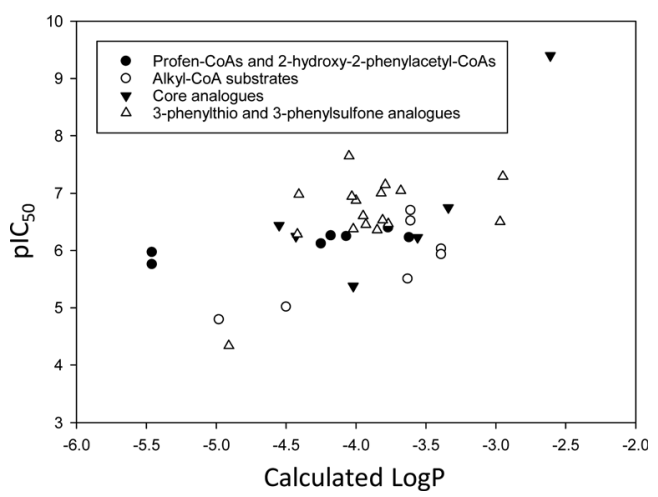

Fig. 30 Potency of acyl-COA inhibitors of AMACR, as measured by $\mathrm{plC}_{50}$ as a function of calculated $\log P$ values. Inhibitors are as follows (with compound numbers from the original papers in parentheses): Ibuprofenoyl-CoA and analogues (5-11), ${ }^{164}$ straight-chain acyl-CoAs and other substrates (12-14 and 18-21); ${ }^{164}$ inhibitors with modified acyl-CoA cores $(4,22-26) ;{ }^{164}$ and 2-arylthiapropanoyl-CoAs and 2-arylsulfonylpropanoyl-CoA $(\mathbf{7 a}-\mathbf{7 n}, \mathbf{1 0 b}){ }^{165} \log P$ values were calculated using: https://www.molinspiration.com/cgi-bin/properties. $\log P$, $\log _{10}$ (ratio of concentrations of drug in octan-1-ol and water at equilibrium); $\mathrm{plC}_{50}$, $-\log _{10} \mid C_{50}$. 


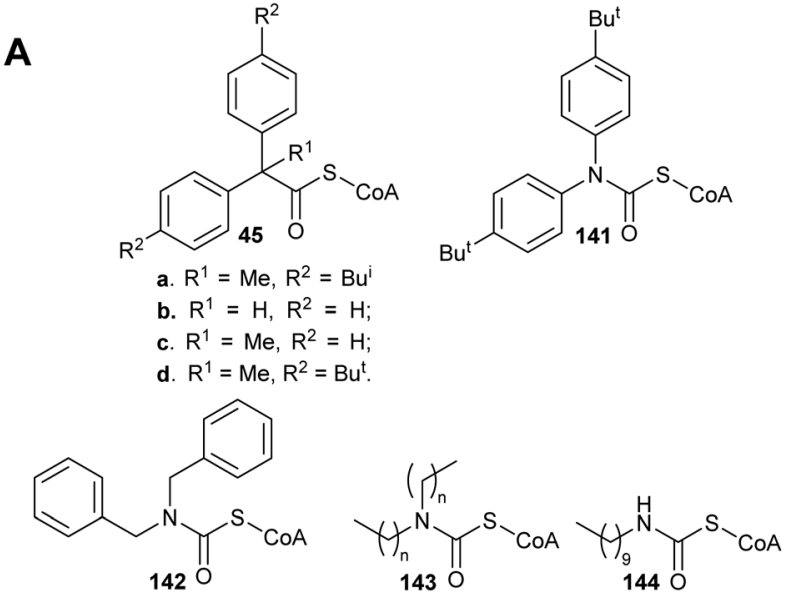

B

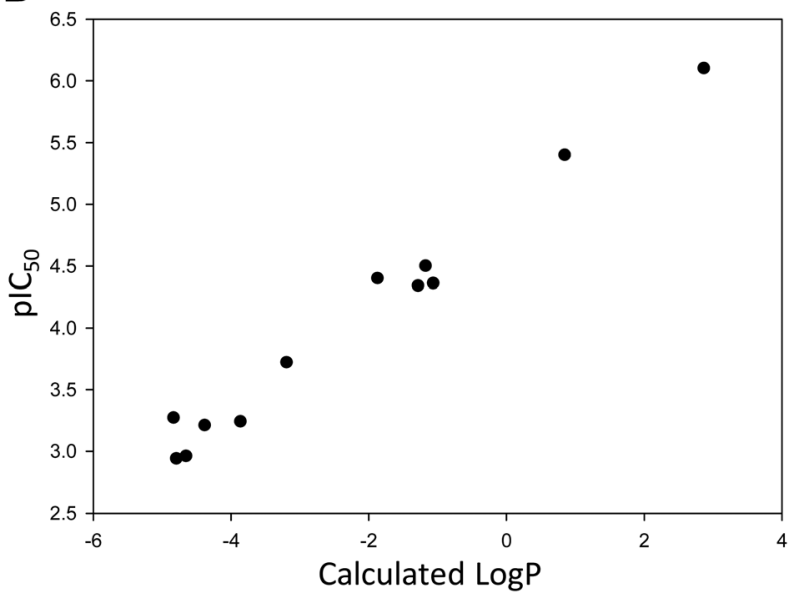

Fig. 31 (A) Structures of substrate-product analogues ${ }^{149,150}$ inhibiting the M. tuberculosis homologue of AMACR (MCR). For $143, n=3,5,7,9$ or 11 ; (B) acyl-CoA inhibitor potency as measured by $\mathrm{plC}_{50}$ as a function of calculated $\log P$ values. $\log P$ values were calculated using: https://www. molinspiration.com/cgi-bin/properties. $\log P, \log _{10}$ (ratio of concentrations of drug in octan-1-ol and water at equilibrium); $\mathrm{pl}_{50},-\log _{10} \mid \mathrm{C}_{50}$.

(vide supra), in which the $\alpha$-proton is replaced by a second sidechain in the inhibitor. The presence of the second sidechain increases potency of inhibition by $\sim 6$-fold, although the measured absolute potency is relatively modest (e.g. 16.9 cf. $106 \mu \mathrm{M}$ for 45a $v s$. ibuprofenoyl-CoA). One of these inhibitors (Fig. 31A, 45b) has a $\alpha$-proton in place of the $\alpha$-methyl group and, as predicted, this does not undergo enzyme-catalysed exchange with solvent consistent with the $\alpha$-proton being located in the methylbinding site of the enzyme. The study is also notable in that several carboxylic acid precursors are also inhibitors, albeit with $\mathrm{IC}_{50}$ values in the $\mathrm{mM}$ range. ${ }^{149}$ Similar to the above AMACR inhibitors (vide supra, Fig. 30), potency of inhibition of MCR is also related to calculated $\log P$ values (Fig. 31).

Following from the observation that carbamate analogues are highly potent AMACR inhibitors, ${ }^{127,164,191}$ Pal et al. ${ }^{150}$ synthesised and tested carbamate analogues 141-144 of their substrate/product inhibitors against MCR (Fig. 31A). ${ }^{149}$ Inhibition is reported to be competitive, although the Lineweaver-Burk plots for some analogues, e.g. $143(n=5)$, suggested mixed competitive inhibition. Surprisingly, several of these analogues show irreversible inhibition, in marked contrast to the carbamate AMACR inhibitors which are fully reversible. ${ }^{127,164}$ Inhibitors with long alkyl chains ( $n=9$ and 11) show saturating loss of activity with maximum $k_{\text {inact }}$ values of $\sim 0.4 \mathrm{~min}^{-1}$ consistent with being active-site directed. Analogues with less lipophilic side-chains $(\mathbf{1 4 3}, n=3)$ or a single sidechain (144) showed a non-saturating loss of enzymatic activity with a rate constant of $0.016-0.04 \mathrm{~min}^{-1} \cdot{ }^{150}$ Inhibition was not reversed upon dialysis but no protein modification was observed by mass spectrometry. This observation is consistent with either non-covalent slow-binding inhibition, resulting in a long-lived enzyme-inhibitor complex, or irreversible inhibition resulting in a covalent modification of the protein, which is labile under mass spectrometric conditions.

Identification of AMACR inhibitors by high-throughput screening has also been reported. ${ }^{163}$ Unlike the previous study, ${ }^{152}$ the identified inhibitors were not non-specific protein modification agents. ${ }^{163}$ A number of pyrazoloquinolines and pyrazolopyrimidines were identified (vide supra, Fig. 15, 85a, 85b and 86), and some structure-activity relationships were observed. ${ }^{163}$ The identified inhibitors displayed either mixed competitive or uncompetitive inhibition. The latter is a rare type of inhibition and arises from binding of inhibitor to the enzyme-substrate complex.

\section{Conclusions}

Racemases and epimerases occupy a unique position in metabolism, in that they are the only major class of enzymes which can use substrates with both configurations at a chiral centre. Because of this, many racemases and epimerases are excellent drug targets and several have been extensively investigated as such, e.g. glutamate racemase..$^{20-25,134,175,200,249}$ Use of inhibitors with the same configuration as the less abundant substrate (often $\mathrm{D}^{-}$or $R$-enantiomer) potentially offers additional benefits in that these isomers may be less prone to off-target binding and may have reduced drug metabolism, with consequent reductions in toxicities and longer durations of action.

However, efforts to develop drugs targeted against racemases and epimerases have been largely limited to rational design campaigns, with the few notable exceptions detailed above. Development of inhibitors which are alternative substrates has met with limited success, in part because several of the effective inhibitors are rapidly depleted in vivo whilst the effects of less effective inhibitors are readily overcome by the physiological substrate. Moreover, these inhibitors are necessarily chiral and there had been a move away from chiral drugs towards drugs with fewer $\mathrm{sp}^{3}$ carbons. ${ }^{227}$ This is despite a growing realisation that the attrition rate is higher for 'flatter' drugs $^{271,272}$ and that licenced drugs have a higher average proportion of $\mathrm{sp}^{3}$ centres than molecules published in The Journal of Medicinal Chemistry. ${ }^{273}$ Consequently there has been a more recent move towards structures with a higher proportion of $\mathrm{sp}^{3}$ and chiral centres. ${ }^{274}$ Similarly, racemase/epimerase 
inhibitors in which the $\mathrm{C}_{\alpha}-\mathrm{H}$ is replaced or where deprotonation is made more difficult tend not to be highly potent. The use of substrate-product analogues as inhibitors has also met with variable success. This strategy tends to work relatively well for racemases and epimerases in which large changes in substrate side-chain position occur during the reaction. Enzymes catalysing reactions resulting in limited changes in side-chain position and/ or with small or sterically hindered active sites tend to be poorly inhibited by this type of compound.

There are relatively few developed inhibitors which are analogues of the transition state/deprotonated intermediate, perhaps because the early inhibitors developed against proline racemase were not highly effective and one of these inhibitors was an unstable imine. ${ }^{135}$ Some covalent inhibitors have been developed by rational design or identified by screening techniques. $^{20,22-24,26,27,46,124,134,217,218}$ There has been renewed interest in the development of covalent inhibitors in recent years, prompted by a number of covalent drugs coming into clinical use. ${ }^{201,205,207,208}$ Covalent drugs acting on racemases and epimerases have all been directed against enzymes using active-site cysteine thiols ${ }^{20,22-24,26,27,46,124,134,217,218}$ (amino-acid racemases and epimerases). Covalently reacting drugs containing electrophiles reacting with other active-site bases ${ }^{205,208}$ have been under-explored. Both transition-state analogues ${ }^{135,193,194}$ and covalent inhibitors ${ }^{201,204-206,208}$ offer the potential for high potency and long duration of action and are potentially fertile ground for the future development of inhibitors.

Screening approaches ${ }^{227}$ have also been under-used to identify novel inhibitors. There are only five high-throughput screening campaigns in the literature ${ }^{152,163,200,228,252}$ and only two fragment-screening campaigns. ${ }^{257,259}$ Almost all racemases and epimerases catalyse reversible reactions and this places restriction on these assays but these can be overcome by using an elimination substrate or irreversible coupling enzyme (see section on enzyme assays for examples). The use of coupling enzymes also enables assays based on fluorescence or absorbance to be used, which are readily adaptable to highthroughput screening formats. ${ }^{27}$ Direct assaying of racemase or epimerase activity may also be possible using fluorescence anisotropy to monitor ligand binding. ${ }^{227}$

Fragment screening using assays of enzyme activity ${ }^{227,275-279}$ or biophysical techniques ${ }^{275-280}$ (particularly X-ray crystallography ${ }^{274-277,279-281}$ ) hold significant promise, although the different screening techniques have advantages and disadvantages $^{280}$ and different tendencies towards false positive and negative results. ${ }^{279}$ There is also a balance to be struck between fragment complexity and affinity to maximise chances of success. ${ }^{279}$ Screening of fragment libraries for direct identification of inhibitors is particularly appealing for enzymes with small, enclosed active sites, e.g. proline racemase, ${ }^{26,27}$ as the amino-acid substrates are small fragments themselves $\left(M_{\mathrm{w}}=89-204 \mathrm{Da}\right)$. There have been a number of studies on the screening of small fragments (which will generally have low affinity ${ }^{279}$ ), including one using virtual screening initially to triage compounds which resulted in a $40 \%$ hit rate for a very small fragment library (fifteen compounds). ${ }^{282}$ Similarly, fragment-based screening holds promise for development of inhibitors of enzymes with larger active sites, ${ }^{227,275-280}$ although there are challenges associated with identification of different fragments which bind simultaneously and also in the elaboration of fragment hits into leads. ${ }^{274,283}$

It is important that inhibitors produced by rational design, identified by screening and other approaches are fully characterised to determine if covalent modification of the target is occurring. There are examples of rationally designed racemase inhibitors intended to be reversible which appear to exert their effects by covalent modification of the racemase target. ${ }^{150}$ Several inhibitors identified by screening approaches ${ }^{239,252,259}$ could also potentially inhibit their targets by covalent modification. Unselective modification of off-target proteins or other biological molecules could give rise to significant toxicities. ${ }^{201-205,207-209,215}$ Therefore, it is important to balance this potential draw-back with the advantages of covalent inhibition.

\section{Abbreviations used}

\begin{tabular}{|c|c|}
\hline AET & 5-(1-Aminoethyl)tetrazole \\
\hline AMACR & $\begin{array}{l}\text { Human } \alpha \text {-methylacyl-CoA racemase } \\
\text { (a.k.a. P504S) spliced variant } 1 \mathrm{~A}\end{array}$ \\
\hline DprE & Decaprenylphosphoryl- $\beta$-D-ribose epimerase \\
\hline EcL-DER & E. coli $\mathrm{L}$-aspartate/L-glutamate racemase \\
\hline IAM 12614 & $\begin{array}{l}\text { L. aggregata cis-3-hydroxy-S-proline racemase/ } \\
\text { dehydratase }\end{array}$ \\
\hline MCR & $\alpha$-Methylacyl-CoA racemase from $M$. tuberculosis \\
\hline McyF & Microcystis aeruginosa aspartate racemase \\
\hline MMP0739 & Aspartate/glutamate racemase from \\
\hline & Methanococcus maripaludis \\
\hline $\mathrm{Ph}$ & phenyl \\
\hline $\mathrm{pIC}_{50}$ & $-\log _{10}\left(\mathrm{IC}_{50}\right)$ \\
\hline PLP & Pyridoxal 5'-phosphate \\
\hline $\operatorname{RacX}$ & $\begin{array}{l}\text { B. subtilis arginine, lysine and ornithine } \\
\text { racemase }\end{array}$ \\
\hline RmlC & $\begin{array}{l}\text { Deoxythymidine diphosphate-4-keto-6- } \\
\text { deoxyglucose 3,5-epimerase }\end{array}$ \\
\hline YgeA & E. coli homoserine racemase \\
\hline YcjG & $\begin{array}{l}\text { E. coli alanyl dipeptide epimerase. } \\
\text { Standard one- and three-letter amino-acid codes } \\
\text { are used. }\end{array}$ \\
\hline
\end{tabular}

\section{Conflicts of interest}

There are no conflicts of interest to declare.

\section{Acknowledgements}

The authors have been funded by Prostate Cancer UK (grants S10-03 and PG14-009), LifeArc, Biochemical Society Summer Vacation Studentships, the Cancer Research @ Bath network and a Bath-Shandong Undergraduate Exchange Studentship. TDJ wishes to thank the Royal Society for a Wolfson Research Merit Award and the Open Research Fund of the School of 
Chemistry and Chemical Engineering, Henan Normal University for support (2020ZD01). Diagrams in Schemes 9B and C have been reproduced from Yevglevskis et al., $2017^{127}$ with permission from the Royal Society of Chemistry.

\section{Notes and references}

1 N. Fujii, T. Takata, N. Fujii, K. Aki and H. Sakaue, Biochim. Biophys. Acta, Proteins Proteomics, 2018, 1866, 840-847.

2 J. Sasabe and M. Suzuki, Keio J. Med., 2019, 68, 1-16.

3 R. S. Cahn, C. Ingold and V. Prelog, Angew. Chem., Int. Ed. Engl., 1966, 5, 385-415.

4 A. Ballard, S. Narduolo, H. O. Ahmad, D. A. Cosgrove, A. G. Leach and N. J. Buurma, Expert Opin. Drug Discovery, 2019, 14, 527-539.

5 A. Ballard, S. Narduolo, H. O. Ahmed, N. I. Keymer, N. Asaad, D. A. Cosgrove, N. J. Buurma and A. G. Leach, Chem. - Eur. J., 2020, 26, 3661-3687.

6 M. D. Lloyd, D. J. Darley, A. S. Wierzbicki and M. D. Threadgill, FEBS J., 2008, 275, 1089-1102.

7 M. D. Lloyd, M. Yevglevskis, G. L. Lee, P. J. Wood, M. D. Threadgill and T. J. Woodman, Prog. Lipid Res., 2013, 52, 220-230.

8 T. J. Woodman, P. J. Wood, A. S. Thompson, T. J. Hutchings, G. R. Steel, P. Jiao, M. D. Threadgill and M. D. Lloyd, Chem. Commun., 2011, 47, 7332-7334.

9 M. Yevglevskis, C. R. Bowskill, C. C. Y. Chan, J. H.-J. Heng, M. D. Threadgill, T. J. Woodman and M. D. Lloyd, Org. Biomol. Chem., 2014, 12, 6737-6744.

10 L.-B. Gao, J.-Z. Wang, T.-W. Yao and S. Zeng, Chirality, 2012, 24, 86-95.

11 T. Poiger, M. D. Müller, H.-R. Buser and I. J. Buerge, J. Agric. Food Chem., 2015, 63, 2583-2590.

12 H.-R. Buser and M. D. Müller, Environ. Sci. Technol., 1997, 31, 1960-1967.

13 M. D. Müller and H.-R. Buser, Environ. Sci. Technol., 1997, 31, 1953-1959.

14 Y. Ogasawara and T. Dairi, Front. Microbiol., 2018, 9, 156.

15 S. A. Cochrane and C. T. Lohans, Eur. J. Med. Chem., 2020, 194, 112262.

16 T. Do, J. E. Page and S. Walker, J. Biol. Chem., 2020, 295, 3347-3361.

17 A. J. F. Egan, J. Errington and W. Vollmer, Nat. Rev. Microbiol., 2020, 18, 446-460.

18 S. L. Bearne, Chem. - Eur. J., 2020, 26, 10367-10390.

19 R. V. Chikhale, M. A. Barmade, P. R. Murumkar and M. R. Yadav, J. Med. Chem., 2018, 61, 8563-8593.

20 C. Fischer, Y. C. Ahn and J. C. Vederas, Nat. Prod. Rep., 2019, 36, 1687-1705.

21 K. R. Witkin, N. R. Vance, C. Caldwell, Q. Li, L. Yu and M. A. Spies, ChemMedChem, 2020, 15, 376-384.

22 N. R. Vance, K. R. Witkin, P. W. Rooney, Y. Li, M. Pope and M. A. Spies, ChemMedChem, 2018, 13, 2514-2521.

23 M. A. Spies, J. G. Reese, D. Dodd, K. L. Pankow, S. R. Blanke and J. Baudry, J. Am. Chem. Soc., 2009, 131, 5274-5284.
24 K. L. Whalen, K. L. Pankow, S. R. Blanke and M. A. Spies, ACS Med. Chem. Lett., 2010, 1, 9-13.

25 K. L. Whalen, K. B. Tussey, S. R. Blanke and M. A. Spies, J. Phys. Chem. B, 2011, 115, 3416-3424.

26 A. Berneman, L. Montout, S. Goyard, N. Chamond, A. Cosson, S. d'Archivio, N. Gouault, P. Uriac, A. Blondel and P. Minoprio, PLoS One, 2013, 8, e60955.

27 P. de Aguiar Amaral, D. Autheman, G. Dias de Melo, N. Gouault, J.-F. Cupif, S. Goyard, P. Dutra, N. Coatnoan, A. Cosson, D. Monet, F. Saul, A. Haouz, P. Uriac, A. Blondel and P. Minoprio, PLoS Neglected Trop. Dis., 2018, 12, e0006853.

28 L. Coutinho, M. Alves Ferreira, A. Cosson, M. Meuser Batista, D. da Gama Jaén Batista, P. Minoprio, W. M. Degrave, A. Berneman and M. de Nazaré Correia Soeiro, Mem. Inst. Oswaldo Cruz, 2009, 104, 1055-1062.

29 S. Zha, S. Ferdinandusse, S. Denis, R. J. Wanders, C. M. Ewing, J. Luo, A. M. De Marzo and W. B. Isaacs, Cancer Res., 2003, 63, 7365-7376.

30 R. Inoue, K. Hashimoto, T. Harai and H. Mori, J. Neurosci., 2008, 28, 14486-14491.

31 C.-H. Chang, C.-H. Lin and H.-Y. Lane, Int. J. Mol. Sci., 2020, 21, 2676.

32 W. J. Griffiths and Y.-Q. Wang, Prostaglandins Other Lipid Mediators, 2020, 147, 106381.

33 M. Y. S. Hooi and R. J. W. Truscott, Age, 2011, 33, 131-141.

34 H. Jiang, J. Fang, B. Wu, G. Yin, L. Sun, J. Qu, S. W. Barger and S. Wu, J. Neuroinflammation, 2011, 8, 119.

35 A. Steliga, P. Kowiański, E. Czuba, M. Waśkow, J. Moryś and G. Lietzau, Transl. Stroke Res., 2019, 11, 553-579.

36 K. R. Baker, H. H. Sigurðardóttir, B. Jana and L. Guardabassi, Antimicrob. Agents Chemother., 2017, 61, e01773-e01716.

37 S. Ferdinandusse, S. Denis, P. T. Clayton, A. Graham, J. E. Rees, J. T. Allen, B. N. McLean, A. Y. Brown, P. Vreken, H. R. Waterham and R. J. A. Wanders, Nat. Genet., 2000, 24, 188-191.

38 C. M. Dobson, A. Gradinger, N. Longo, X. Wu, D. Leclerc, J. Lerner-Ellis, M. Lemieux, C. Belair, D. Watkins, D. S. Rosenblatt and R. A. Gravel, Mol. Genet. Metab., 2006, 88, 327-333.

39 M. Andréasson, R. H. Zetterström, U. von Döbeln, A. Wedell and P. Svenningsson, Int. J. Mol. Sci., 2019, 20, 2631.

40 N. F. Liachko, A. D. Saxton, P. J. McMillan, T. J. Strovas, C. D. Keene, T. D. Bird and B. C. Kraemer, PLoS Genet., 2019, 15, e1008526.

41 A. P. Gomes, D. Ilter, V. Low, J. E. Endress, J. FernandezGarcia, A. Rosenzweig, T. Schild, D. Broekaert, A. Ahmed, M. Planque, I. Elia, J. Han, C. Kinzig, E. Mullarky, A. P. Mutvei, J. Asara, R. de Cabo, L. C. Cantley, N. Dephoure, S. M. Fendt and J. Blenis, Nature, 2020, 585, 283-287.

42 K. M. Hodge-Hanson, A. Zoino and D. M. Downs, J. Bacteriol., 2018, 200, e00751-e00717.

43 D. Kreuzmann, R. Horstkorte, G. Kohla, C. Kannicht, D. Bennmann, A. Thate and K. Bork, ChemBioChem, 2017, 18, 1188-1193. 
44 S.-C. Chen, C.-H. Huang, S.-J. Lai, C. S. Yang, T.-H. Hsiao, C.-H. Lin, P.-K. Fu, T. P. Ko and Y. Chen, Sci. Rep., 2016, 6, 23274.

45 R. Singh and R. Arya, Mol. Neurobiol., 2016, 53, 3088-3101. 46 Y.-C. Ahn, C. Fischer, M. J. van Belkum and J. C. Vederas, Org. Biomol. Chem., 2018, 16, 1126-1133.

47 A. S. Murkin and M. E. Tanner, J. Org. Chem., 2002, 67, 8389-8394.

48 M. M. Musa, Chirality, 2020, 32, 147-157.

49 S. Martínez-Rodríguez, P. Soriano-Maldonado and J. A. Gavira, Biochim. Biophys. Acta, Proteins Proteomics, 2020, 1868, 140377.

50 J. F. Rocha, A. F. Pina, S. F. Sousa and N. M. F. S. A. Cerqueira, Catal. Sci. Technol., 2019, 9, 4864-4876.

51 Y. Zhang, Y. Zhang and O. Ramström, Catal. Rev.: Sci. Eng., 2020, 62, 66-95.

52 R. B. Hamed, J. R. Gomez-Castellanos, D. S. Froese, E. Krysztofinska, W. W. Yue and C. J. Schofield, ChemBioChem, 2016, 17, 471-473.

53 A. Tøndervik, G. Klinkenberg, F. L. Aachmann, B. I. G. Svanem, H. Ertesvåg, T. E. Ellingsen, S. Valla, G. SkjåkBraek and H. Sletta, Biomacromolecules, 2013, 14, 2657-2666.

54 C. Yang, L. Ye, J. Gu, X. Yang, A. Li and H.-W. Yu, Appl. Microbiol. Biotechnol., 2017, 101, 1063-1072.

55 R. Ushimaru, Z. Chen, H. Zhao, P.-H. Fan and H.-W. Liu, Angew. Chem., Int. Ed., 2020, 59, 3558-3562.

56 A. Benjdia, A. Guillot, P. Ruffié, J. Leprince and O. Berteau, Nat. Chem., 2017, 9, 698-707.

57 S. W. Fuchs, G. Lackner, B. I. Morinaka, Y. Morishita, T. Asai, S. Riniker and J. Piel, Angew. Chem., Int. Ed., 2016, 55, 12330-12333.

58 F. Kudo, S. Hoshi, T. Kawashima, T. Kamachi and T. Eguchi, J. Am. Chem. Soc., 2014, 136, 13909-13915.

59 B. I. Morinaka, A. L. Vagstad and J. Piel, in Marine Enzymes and Specialized Metabolism, Pt A, ed. B. S. Moore, 2018, vol. 604, pp. 237-257.

60 A. L. Vagstad, T. Kuranaga, S. Püntener, V. R. Pattabiraman, J. W. Bode and J. Piel, Angew. Chem., Int. Ed., 2019, 58, 2246-2250.

61 S. T. M. Allard, M. F. Giraud and J. H. Naismith, Cell. Mol. Life Sci., 2001, 58, 1650-1665.

62 J. A. Rankin, R. C. Mauban, M. Fellner, B. Desguin, J. McCracken, J. Hu, S. A. Varganov and R. P. Hausinger, Biochemistry, 2018, 57, 3244-3251.

63 M. E. Tanner, Acc. Chem. Res., 2002, 35, 237-246.

64 M. Alfano and C. Cavazza, Protein Sci., 2020, 29, 1071-1089.

65 M. Brecik, I. Centarova, R. Mukherjee, G. S. Kolly, S. Huszar, A. Bobovska, E. Kilacskova, V. Mokosova, Z. Svetlikova, M. Sarkan, J. Neres, J. Kordulakova, S. T. Cole and K. Mikusova, ACS Chem. Biol., 2015, 10, 1631-1636.

66 G. Degiacomi, J. M. Belardinelli, M. R. Pasca, E. De Rossi, G. Riccardi and L. R. Chiarelli, Appl. Sci., 2020, 10, 623.

67 J. Gawad and C. Bonde, Chem. Cent. J., 2018, 12, 72.

68 G. Riccardi, M. R. Pasca, L. R. Chiarelli, G. Manina, A. Mattevi and C. Binda, Appl. Microbiol. Biotechnol., 2013, 97, 8841-8848.
69 J. Liang, Q. Han, Y. Tan, H. Z. Ding and J. Y. Li, Front. Mol. Biosci., 2019, 6, 4.

70 M. D. Toney, Biochim. Biophys. Acta, Proteins Proteomics, 2011, 1814, 1407-1418.

71 S. L. Bearne, Biochim. Biophys. Acta, Proteins Proteomics, 2017, 1865, 619-630.

72 M. E. Glasner, D. P. Truong and B. C. Morse, FEBS J., 2020, 287, 1323-1342.

73 J. Q. Fuller and P. F. Leadlay, Biochem. J., 1983, 213, 643-650.

74 V. M. Powers, C. W. Koo, G. L. Kenyon, J. A. Gerlt and J. W. Kozarich, Biochemistry, 1991, 30, 9255-9263.

75 B. Mitra, A. T. Kallarakal, J. W. Kozarich, J. A. Gerlt, J. G. Clifton, G. A. Petsko and G. L. Kenyon, Biochemistry, 1995, 34, 2777-2787.

76 A. Rubinstein and D. T. Major, J. Am. Chem. Soc., 2009, 131, 8513-8521.

77 G. J. Cardinal and R. H. Abeles, Biochemistry, 1968, 7, 3970-3978.

78 K. A. Gallo, M. E. Tanner and J. R. Knowles, Biochemistry, 1993, 32, 3991-3997.

79 D. J. Darley, D. S. Butler, S. J. Prideaux, T. W. Thornton, A. D. Wilson, T. J. Woodman, M. D. Threadgill and M. D. Lloyd, Org. Biomol. Chem., 2009, 7, 543-552.

80 D. J. Darley, D. S. Butler, S. J. Prideaux, T. W. Thornton, A. D. Wilson, T. J. Woodman, M. D. Threadgill and M. D. Lloyd, Org. Biomol. Chem., 2009, 7, 5272.

81 S. Sharma, P. Bhaumik, W. Schmitz, R. Venkatesan, J. K. Hiltunen, E. Conzelmann, A. H. Juffer and R. K. Wierenga, J. Phys. Chem. B, 2012, 116, 3619-3629.

82 M. E. Tanner, K. A. Gallo and J. R. Knowles, Biochemistry, 1993, 32, 3998-4006.

83 S. Glavas and M. E. Tanner, Biochemistry, 1999, 38, 4106-4113.

84 R. J. Stern, T.-Y. Lee, T.-J. Lee, W. Yan, M. S. Scherman, V. D. Vissa, S.-K. Kim, B. L. Wanner and M. R. McNeil, Microbiology, 1999, 145, 663-671.

85 H. C. Dunathan, Proc. Natl. Acad. Sci. U. S. A., 1966, 55, 712-716.

86 T. L. Amyes and J. P. Richard, Synlett, 2017, 1407-1421.

87 M. A. Spies and M. D. Toney, Biochemistry, 2003, 42, 5099-5107.

88 J. P. Richard and T. L. Amyes, Curr. Opin. Chem. Biol., 2001, 5, 626-633.

89 G. Williams, E. P. Maziarz, T. L. Amyes, T. D. Wood and J. P. Richard, Biochemistry, 2003, 42, 8354-8361.

90 A. A. McCarthy, H. M. Baker, S. C. Shewry, M. L. Patchett and E. N. Baker, Structure, 2001, 9, 637-646.

91 M. Nagar, A. Narmandakh, Y. Khalak and S. L. Bearne, Biochemistry, 2011, 50, 8846-8852.

92 J. A. Gerlt, G. L. Kenyon, J. W. Kozarich, D. J. Neidhart, G. A. Petsko and V. M. Powers, Curr. Opin. Struct. Biol., 1992, 2, 736-742.

93 J. Crugeiras, A. Rios, E. Riveiros, T. L. Amyes and J. P. Richard, J. Am. Chem. Soc., 2008, 130, 2041-2050.

94 T. L. Amyes and J. P. Richard, Biochemistry, 2013, 52, 2021-2035. 
95 P. Bhaumik, W. Schmitz, A. Hassinen, J. K. Hiltunen, E. Conzelmann and R. K. Wierenga, J. Mol. Biol., 2007, 367, 1145-1161.

96 M. C. Pélissier, C. Sebban-Kreuzer, F. Guerlesquin, J. A. Brannigan, Y. Bourne and F. Vincent, J. Biol. Chem., 2014, 289, 35215-35224.

97 J. P. Richard, T. L. Amyes, B. Goryanova and X. Zhai, Curr. Opin. Chem. Biol., 2014, 21, 1-10.

98 H.-Y. Sagong and K.-J. Kim, Sci. Rep., 2017, 7, 42318.

99 A. Watanabe, T. Yoshimura, B. Mikami, H. Hayashi, H. Kagamiyama and N. Esaki, J. Biol. Chem., 2002, 277, 19166-19172.

100 F. Ding, J. M. Smith and H. Wang, J. Org. Chem., 2009, 74, 2679-2691.

101 M. D. Toney, Front. Bioengin. Biotechnol., 2019, 7, 25.

102 E. A. T. Ringia, J. B. Garrett, J. B. Thoden, H. M. Holden, I. Rayment and J. A. Gerlt, Biochemistry, 2004, 43, 224-229.

103 J. B. Thoden, E. A. T. Ringia, J. B. Garrett, J. A. Gerlt, H. M. Holden and I. Rayment, Biochemistry, 2004, 43, 5716-5727.

104 S. Baxter, S. Royer, G. Grogan, F. Brown, K. E. Holt-Tiffin, I. N. Taylor, I. G. Fotheringham and D. J. Campopiano, J. Am. Chem. Soc., 2012, 134, 19310-19313.

105 S. N. Ruzheinikov, M. A. Taal, S. E. Sedelnikova, P. J. Baker and D. W. Rice, Structure, 2005, 13, 1707-1713.

106 J. P. Richard and T. L. Amyes, Bioorg. Chem., 2004, 32, 354-366. 107 C. W. Koo and J. S. Blanchard, Biochemistry, 1999, 38, 4416-4422.

108 J.-W. Ahn, J. H. Chang and K.-J. Kim, FEBS Lett., 2015, 589, 3842-3847.

109 X. Liu, F. Gao, Y. Ma, S. Liu, Y. Cui, Z. Yuan and X. Kang, FEBS Lett., 2016, 590, 1262-1269.

110 W. F. Visser, N. M. Verhoeven-Duif and T. J. de Koning, J. Biol. Chem., 2012, 287, 21654-21662.

111 D. K. Dhaked, M. B. Divya and L. Guruprasad, Prog. Biophys. Mol. Biol., 2019, 145, 52-64.

112 X. Li, Q.-C. Zheng and H.-X. Zhang, Int. J. Quantum Chem., 2012, 112, 619-624.

113 S. Scheiner, Struct. Chem., 2019, 30, 1119-1128.

114 S. Scheiner, T. Kar and Y. L. Gu, J. Biol. Chem., 2001, 276, 9832-9837.

115 S. Scheiner, Isr. J. Chem., 2009, 49, 139-147.

116 U. M. Babu and R. B. Johnston, Biochem. Biophys. Res. Commun., 1974, 58, 460-466.

117 S. D. Heck, W. S. Faraci, P. R. Kelbaugh, N. A. Saccomano, P. F. Thadeio and R. A. Volkmann, Proc. Natl. Acad. Sci. U. S. A., 1996, 93, 4036-4039.

118 A. Wiese, M. Pietzsch, C. Syldatk, R. Mattes and J. Altenbuchner, J. Biotechnol., 2000, 80, 217-230.

119 X. S. Zhang, R. Kumar, M. W. Vetting, S. W. Zhao, M. P. Jacobson, S. C. Almo and J. A. Gerlt, J. Am. Chem. Soc., 2015, 137, 1388-1391.

120 M. Yevglevskis, G. L. Lee, M. D. Threadgill, T. J. Woodman and M. D. Lloyd, Chem. Commun., 2014, 50, 14164-14166.

121 M. H. Gelb, Y. Lin, M. A. Pickard, Y. Song and J. C. Vederas, J. Am. Chem. Soc., 1990, 112, 4932-4942.
122 D. T. Lin, V. M. Powers, L. J. Reynolds, C. P. Whitman, J. W. Kozarich and G. L. Kenyon, J. Am. Chem. Soc., 1988, 110, 323-324.

123 J. A. Landro, A. T. Kallarakal, S. C. Ransom, J. A. Gerlt, J. W. Kozarich, D. J. Neidhart and G. L. Kenyon, Biochemistry, 1991, 30, 9274-9281.

124 R. J. Cox, A. Sutherland and J. C. Vederas, Bioorg. Med. Chem., 2000, 8, 843-871.

125 H. Zhou, D. M. Z. Schmidt, J. A. Gerlt and W. A. van der Donk, ChemBioChem, 2003, 4, 1206-1215.

126 K. Oki, F. S. Lee and S. L. Mayo, Protein Eng., Des. Sel., 2019, 32, 261-270.

127 M. Yevglevskis, G. L. Lee, A. Nathubhai, Y. D. Petrova, T. D. James, M. D. Threadgill, T. J. Woodman and M. D. Lloyd, Chem. Commun., 2017, 53, 5087-5090.

128 S. Glavas and M. E. Tanner, Bioorg. Med. Chem. Lett., 1997, 7, 2265-2270.

129 D. L. Graham, M. L. Beio, D. L. Nelson and D. B. Berkowitz, Front. Mol. Biosci., 2019, 6, 8.

130 M. Marchetti, S. Bruno, B. Campanini, S. Bettati, A. Peracchi and A. Mozzarelli, Amino Acids, 2015, 47, 163-173.

131 D. L. Nelson, G. A. Applegate, M. L. Beio, D. L. Graham and D. B. Berkowitz, J. Biol. Chem., 2017, 292, 13986-14002.

132 E. Wang and C. Walsh, Biochemistry, 1978, 17, 1313-1321.

133 H. Wolosker, Biochim. Biophys. Acta, Proteins Proteomics, 2011, 1814, 1558-1566.

134 G. A. Prosser, A. Rodenburg, H. Khoury, C. de Chiara, S. Howell, A. P. Snijders and L. P. S. de Carvalho, Antimicrob. Agents Chemother., 2016, 60, 6091-6099.

135 G. B. Evans, V. L. Schramm and P. C. Tyler, MedChemComm, 2018, 9, 1983-1993.

136 A. J. Carnell, I. Hale, S. Denis, R. J. A. Wanders, W. B. Isaacs, B. A. Wilson and S. Ferdinandusse, J. Med. Chem., 2007, 50, 2700-2707.

137 J. R. Mohrig, Acc. Chem. Res., 2013, 46, 1407-1416.

138 Y. Pan, ACS Med. Chem. Lett., 2019, 10, 1016-1019.

139 F. Siddiqi, J. R. Bourque, H. Jiang, M. Gardner, M. St Maurice, C. Blouin and S. L. Bearne, Biochemistry, 2005, 44, 9013-9021.

140 S.-Y. Choi, N. Esaki, T. Yoshimura and K. Soda, J. Biochem., 1992, 112, 139-142.

141 S. Sawada, Y. Tanaka, S. Hayashi, M. Ryu, T. Hasegawa, Y. Yamamoto, N. Esaki, K. Soda and S. Takahashi, Biosci., Biotechnol., Biochem., 1994, 58, 807-811.

142 D. L. Schonfeld and U. T. Bornscheuer, Anal. Chem., 2004, 76, 1184-1188.

143 H. Stecher, A. Hermetter and K. Faber, Biotechnol. Tech., 1998, 12, 257-261.

144 T. L. Thaler, P. R. Gibbs, R. P. Trebino and A. S. Bommarius, Astrobiology, 2006, 6, 901-910.

145 T. Yamauchi, S.-Y. Choi, H. Okada, M. Yohda, H. Kumagai, N. Esaki and K. Soda, J. Biol. Chem., 1992, 267, 18361-18364.

146 D. Ouazia and S. L. Bearne, Anal. Biochem., 2010, 398, 45-51. 
147 X. Z. Wang, C. C. Chen, T. Shen and J. Y. Zhang, PeerJ, 2019, 7, 8300.

148 K. A. Gallo and J. R. Knowles, Biochemistry, 1993, 32, 3981-3990.

149 M. Pal, M. Khanal, R. Marko, S. Thirumalairajan and S. L. Bearne, Chem. Commun., 2016, 52, 2740-2743.

150 M. Pal, N. M. Easton, H. Yaphe and S. L. Bearne, Bioorg. Chem., 2018, 77, 640-650.

151 M. D. Olp, K. S. Kalous and B. C. Smith, BMC Bioinf., 2020, 21, 186.

152 B. A. P. Wilson, H. Wang, B. A. Nacev, R. C. Mease, J. O. Liu, M. G. Pomper and W. B. Isaacs, Mol. Cancer Ther., 2011, 10, 825-838.

153 C. Kumar-Sinha, R. B. Shah, B. Laxman, S. A. Tomlins, J. Harwood, W. Schmitz, E. Conzelmann, M. G. Sanda, J. T. Wei, M. A. Rubin and A. M. Chinnaiyan, Am. J. Pathol., 2004, 164, 787-793.

154 P. F. Leadlay and J. Q. Fuller, Biochem. J., 1983, 213, 635-642.

155 T. L. Amyes and J. P. Richard, in Measurement and Analysis of Kinetic Isotope Effects, ed. M. E. Harris and V. E. Anderson, 2017, vol. 596, pp. 163-177.

156 P. L. Fernandez and A. S. Murkin, Molecules, 2020, 25, 1933.

157 C. I. F. Watt, J. Phys. Org. Chem., 2010, 23, 561-571.

158 K. Y. Wong, Y. Q. Xu and L. Xu, Biochim. Biophys. Acta, Proteins Proteomics, 2015, 1854, 1782-1794.

159 M. Katane, K. Nakayama, T. Kawata, Y. Yokoyama, Y. Matsui, Y. Kaneko, S. Matsuda, Y. Saitoh, T. Miyamoto, M. Sekine and H. Homma, J. Pharm. Biomed. Anal., 2015, 116, 109-115.

160 P. P. VanVeldhoven, K. Croes, M. Casteels and G. P. Mannaerts, Biochim. Biophys. Acta, 1997, 1347, 62-68.

161 M. Yevglevskis, G. L. Lee, J. Sun, S. Zhou, X. Sun, G. KociokKöhn, T. D. James, T. J. Woodman and M. D. Lloyd, Org. Biomol. Chem., 2016, 14, 612-622.

162 L. K. P. Lam, L. D. Arnold, T. H. Kalantar, J. G. Kelland, P. M. Lanebell, M. M. Palcic, M. A. Pickard and J. C. Vederas, J. Biol. Chem., 1988, 263, 11814-11819.

163 Y. D. Petrova, K. Wadda, A. Nathubhai, M. Yevglevskis, P. J. Mitchell, T. D. James, M. D. Threadgill, T. J. Woodman and M. D. Lloyd, Bioorg. Chem., 2019, 92, 103264.

164 M. Yevglevskis, G. L. Lee, A. Nathubhai, Y. D. Petrova, T. D. James, M. D. Threadgill, T. J. Woodman and M. D. Lloyd, Bioorg. Chem., 2018, 79, 145-154.

165 M. Yevglevskis, A. Nathubhai, K. Wadda, G. L. Lee, S. AlRawi, T. Jiao, P. J. Mitchell, T. D. James, M. D. Threadgill, T. J. Woodman and M. D. Lloyd, Bioorg. Chem., 2019, 92, 103263.

166 J. Mackie, H. Kumar and S. L. Bearne, FEBS Lett., 2018, 592, 3399-3413.

167 V. Usha, L. G. Dover, D. L. Roper and G. S. Besra, FEMS Microbiol. Lett., 2008, 280, 57-63.

168 T. Miyamoto, M. Katane, Y. Saitoh, M. Sekine and H. Homma, Amino Acids, 2017, 49, 1885-1894.

169 M. G. Snider, B. S. Temple and R. Wolfenden, J. Phys. Org. Chem., 2004, 17, 586-591.
170 M. St Maurice and S. L. Bearne, Biochemistry, 2002, 41, 4048-4058.

171 M. L. Harty, A. N. Sharma and S. L. Bearne, Metallomics, 2019, 11, 707-723.

172 G. Gadda and P. Sobrado, Biochemistry, 2018, 57, 3445-3453.

173 M. Nagar, H. Kumar and S. L. Bearne, Protein Eng., Des. Sel., 2018, 31, 135-145.

174 A. Ohtaki, Y. Nakano, R. Iizuka, T. Arakawa, K. Yamada, M. Odaka and M. Yohda, Proteins: Struct., Funct., Bioinf., 2008, 70, 1167-1174.

175 M. Pal and S. L. Bearne, Bioorg. Med. Chem. Lett., 2014, 24, 1432-1436.

176 P. B. Le Calvez, C. J. Scott and M. E. Migaud, J. Enzym. Inhib. Med. Chem., 2009, 24, 1291-1318.

177 Y. Okubo, K. Yokoigawa, N. Esaki, K. Soda and H. Kawai, Biochem. Biophys. Res. Commun., 1999, 256, 333-340.

178 T. Nomura, I. Yamamoto, F. Morishita, Y. Furukawa and O. Matsushima, J. Exp. Zool., 2001, 289, 1-9.

179 M. L. di Salvo, R. Florio, A. Paiardini, M. Vivoli, S. D'Aguanno and R. Contestabile, Archives Biochem. Biophys., 2013, 529, 55-65.

180 Y. Mutaguchi, T. Ohmori, T. Wakamatsu, K. Doi and T. Ohshima, J. Bacteriol., 2013, 195, 5207-5215.

181 G. Sánchez-Carrón, T. Fleming, K. E. Holt-Tiffin and D. J. Campopiano, Anal. Chem., 2015, 87, 3923-3928.

182 D. Odokonyero, A. W. McMillan, U. A. Ramagopal, R. Toro, D. P. Truong, M. Z. Zhu, M. S. Lopez, B. Somiari, M. Herman, A. Aziz, J. B. Bonanno, K. G. Hull, S. K. Burley, D. Romo, S. C. Almo and M. E. Glasner, Biochemistry, 2018, 57, 3676-3689.

183 A. M. Brizendine, D. Odokonyero, A. W. McMillan, M. Z. Zhu, K. Hull, D. Romo and M. E. Glasner, Biochem. Biophys. Res. Commun., 2014, 450, 679-684.

184 A. Sakai, D. F. Xiang, C. F. Xu, L. Song, W. S. Yew, F. M. Raushel and J. A. Gerlt, Biochemistry, 2006, 45, 4455-4462.

185 A. W. McMillan, M. S. Lopez, M. Z. Zhu, B. C. Morse, I. C. Yeo, J. Amos, K. Hull, D. Romo and M. E. Glasner, Biochemistry, 2014, 53, 4434-4444.

186 D. Odokonyero, A. Sakai, Y. Patskovsky, V. N. Malashkevich, A. A. Fedorov, J. B. Bonanno, E. V. Fedorov, R. Toro, R. Agarwal, C. X. Wang, N. D. S. Ozerova, W. S. Yew, J. M. Sauder, S. Swaminathan, S. K. Burley, S. C. Almo and M. E. Glasner, Proc. Natl. Acad. Sci. U. S. A., 2014, 111, 8535-8540.

187 D. D. Cao, C. P. Zhang, K. Zhou, Y. L. Jiang, X. F. Tan, J. Xie, Y. M. Ren, Y. X. Chen, C. Z. Zhou and W. T. Hou, Biochem. Biophys. Res. Commun., 2019, 514, 1108-1114.

188 M. Harty, M. Nagar, L. Atkinson, C. M. LeGay, D. J. Derksen and S. L. Bearne, Bioorg. Med. Chem. Lett., 2014, 24, 390-393.

189 N. T. Sorbara, J. W. M. MacMillan, G. D. McCluskey and S. L. Bearne, Org. Biomol. Chem., 2019, 17, 8618-8627.

190 C. Festuccia, G. L. Gravina, A. Mancini, P. Muzi, E. Di Cesare, R. Kirk, M. Smith, S. Hughes, R. Gibson, L.-Y. Lian, 
E. Ricevuto and A. J. Carnell, Anti-Cancer Agents Med. Chem., 2014, 14, 1031-1041.

191 A. J. Carnell, R. Kirk, M. Smith, S. McKenna, L.-Y. Lian and R. Gibson, ChemMedChem, 2013, 8, 1643-1647.

192 A. Morgenroth, E. A. Urusova, C. Dinger, E. Al-Momani, T. Kull, G. Glatting, H. Frauendorf, O. Jahn, F. M. Mottaghy, S. N. Reske and B. D. Zlatopolskiy, Chem. Eur. J., 2011, 17, 10144-10150.

193 V. L. Schramm, Acc. Chem. Res., 2015, 48, 1032-1039.

194 V. L. Schramm, Chem. Rev., 2018, 118, 11194-11258.

195 A. Buschiazzo, M. Goytia, F. Schaeffer, W. Degrave, W. Shepard, C. Gregoire, N. Chamond, A. Cosson, A. Berneman, N. Coatnoan, P. M. Alzari and P. Minoprio, Proc. Natl. Acad. Sci. U. S. A., 2006, 103, 1705-1710.

196 M. Nagar and S. L. Bearne, Biochemistry, 2015, 54, 6743-6752.

197 M. Nagar, A. D. Lietzan, M. St Maurice and S. L. Bearne, Biochemistry, 2014, 53, 1169-1178.

198 A. D. Lietzan, M. Nagar, E. A. Pellmann, J. R. Bourque, S. L. Bearne and M. St Maurice, Biochemistry, 2012, 51, 1160-1170.

199 S. M. Buker, P. A. Boriack-Sjodin and R. A. Copeland, SLAS Discovery, 2019, 24, 515-522.

200 T. Lundqvist, S. L. Fisher, G. Kern, R. H. A. Folmer, Y. F. Xue, D. T. Newton, T. A. Keating, R. A. Alm and B. L. M. de Jonge, Nature, 2007, 447, 817-822.

201 J. Singh, R. C. Petter, T. A. Baillie and A. Whitty, Nat. Rev. Drug Discovery, 2011, 10, 307-317.

202 M. H. Johansson, Mini-Rev. Med. Chem., 2012, 12, 1330-1344.

203 A. K. Ghosh, I. Samanta, A. Mondal and W. R. Liu, ChemMedChem, 2019, 14, 889-906.

204 A. Tuley and W. Fast, Biochemistry, 2018, 57, 3326-3337.

205 S. Ray and A. S. Murkin, Biochemistry, 2019, 58, 5234-5244.

206 S. E. Dalton and S. Campos, ChemBioChem, 2020, 21, 1080-1100.

207 F. Sutanto, M. Konstantinidou and A. Dömling, RSC Med. Chem., 2020, 11, 876-884.

208 M. Gehringer and S. A. Laufer, J. Med. Chem., 2019, 62, 5673-5724.

209 M. R. Hermann, A. Pautsch, M. A. Grundl, A. Weber and C. S. Tautermann, J. Comput.-Aided Mol. Des., 2021, 35, 531-539.

210 T. E. Speltz and R. E. Moellering, Nat. Chem., 2020, 12, 885-887.

211 C. Jöst, C. Nitsche, T. Scholz, L. Roux and C. D. Klein, J. Med. Chem., 2014, 57, 7590-7599.

212 H. Johansson, Y. C. I. Tsai, K. Fantom, C. W. Chung, S. Kumper, L. Martino, D. A. Thomas, H. C. Eberl, M. Muelbaier, D. House and K. Rittinger, J. Am. Chem. Soc., 2019, 141, 2703-2712.

213 D. McShan, S. Kathman, B. Lowe, Z. Y. Xu, J. Zhan, A. Statsyuk and I. V. Ogungbe, Bioorg. Med. Chem. Lett., 2015, 25, 4509-4512.

214 S. G. Kathman, I. Span, A. T. Smith, Z. Y. Xu, J. Zhan, A. C. Rosenzweig and A. V. Statsyuk, J. Am. Chem. Soc., 2015, 137, 12442-12445.
215 S. G. Kathman, Z. Y. Xu and A. V. Statsyuk, J. Med. Chem., 2014, 57, 4969-4974.

216 M. Nagar, B. N. Wyatt, M. St Maurice and S. L. Bearne, Biochemistry, 2015, 54, 2747-2757.

217 B. Pillai, M. M. Cherney, C. M. Diaper, A. Sutherland, J. S. Blanchard, J. C. Vederas and M. N. G. James, Proc. Natl. Acad. Sci. U. S. A., 2006, 103, 8668-8673.

218 B. Pillai, V. A. Moorthie, M. J. van Belkum, S. L. Marcus, M. M. Cherney, C. M. Diaper, J. C. Vederas and M. N. G. James, J. Mol. Biol., 2009, 385, 580-594.

219 J. B. Baell and J. W. M. Nissink, ACS Chem. Biol., 2018, 13, 36-44.

220 B. S. Axelsson, H. G. Floss, S. Lee, A. Saeed, P. A. Spencer and D. W. Young, J. Chem. Soc., Perkin Trans. 1, 1994, 2137-2142.

221 X. C. Yan, J. M. Sanders, Y.-D. Gao, M. Tudor, A. M. Haidle, D. J. Klein, A. Converso, C. A. Lesburg, Y. Zang and H. B. Wood, J. Chem. Inform. Model., 2020, 60, 4144-4152.

222 Z.-Y. Yang, J.-H. He, A.-P. Lu, T.-J. Hou and D.-S. Cao, J. Med. Chem., 2020, 63, 4411-4429.

223 X. Yang, Y. Wang, R. Byrne, G. Schneider and S. Yang, Chem. Rev., 2019, 119, 10520-10594.

224 A. Kumar and K. Y. J. Zhang, Methods, 2015, 71, 26-37.

225 N. Weill, E. Therrien, V. Campagna-Slater and N. Moitessier, Curr. Pharm. Des., 2014, 20, 3338-3359.

226 S. Skariyachan, M. Manjunath and N. Bachappanavar, J. Biomol. Struct. Dyn., 2019, 37, 1146-1169.

227 M. D. Lloyd, J. Med. Chem., 2020, 63, 10742-10772.

228 S. Sivendran, V. Jones, D. Sun, Y. Wang, A. E. Grzegorzewicz, M. S. Scherman, A. D. Napper, J. A. McCammon, R. E. Lee, S. L. Diamond and M. McNeil, Bioorg. Med. Chem., 2010, 18, 896-908.

229 S. C. Willies, J. L. White and N. J. Turner, Tetrahedron, 2012, 68, 7564-7567.

230 Y. P. Wang, C. Yang, W. Xue, T. Zhang, X. P. Liu, J. S. Ju, B. H. Zhao and D. Liu, BMC Microbiol., 2017, 17, 122.

231 M. A. Azam and U. Jayaram, J. Enzym. Inhib. Med. Chem., 2016, 31, 517-526.

232 M. Azam and U. Jayaram, J. Enzym. Inhib. Med. Chem., 2018, 33, 726.

233 C. de Chiara, M. Homsak, G. A. Prosser, H. L. Douglas, A. Garza-Garcia, G. Kelly, A. G. Purkiss, E. W. Tate and L. P. S. de Carvalho, Nat. Chem. Biol., 2020, 16, 686-694.

234 W. L. Hong, L. F. Chen and J. P. Xie, Expert Opin. Ther. Targets, 2014, 18, 691-701.

235 A. Boyar and R. E. Marsh, J. Am. Chem. Soc., 1982, 104, 1995-1998.

236 L. A. Kondacs, S. Orenga, R. J. Anderson, E. C. L. Marrs, J. D. Perry and M. Gray, Molecules, 2020, 25, 1315.

237 H. E. Hoffman, J. Jiraskova, M. Ingr, M. Zvelebil and J. Konvalinka, Protein Expression Purif., 2009, 63, 62-67.

238 J. Jirásková-Vaníčková, R. Ettrich, B. Vorlová, H. E. Hoffman, M. Lepšík, P. Jansa and J. Konvalinka, Curr. Drug Targets, 2011, 12, 1037-1055.

239 H. Mori, R. Wada, S. Takahara, Y. Horino, H. Izumi, T. Ishimoto, T. Yoshida, M. Mizuguchi, T. Obita, 
H. Gouda, S. Hirono and N. Toyooka, Bioorg. Med. Chem., 2017, 25, 3736-3745.

240 M. A. B. MacKay, M. Kravtsenyuk, R. Thomas, N. D. Mitchell, S. M. Dursun and G. B. Baker, Front. Psychiatry, 2019, 10, 25.

241 M. J. Wu, Y. M. Liu, H. Zhang, M. L. Lian, J. Chen, H. Y. Jiang, Y. Xu, G. Shan and S. Z. Wu, Exp. Eye Res., 2019, 182, 93-100.

242 F. Marchesani, S. Bruno, G. Paredi, S. Raboni, B. Campanini and A. Mozzarelli, Biochim. Biophys. Acta, Proteins Proteomics, 2018, 1866, 813-821.

243 S. Beltran-Castillo, J. J. Trivino, J. Eugenin and R. von Bernhardi, Biochim. Biophys. Acta, Proteins Proteomics, 2020, 1868, 140447.

244 A. V. Canosa, S. Faggiano, M. Marchetti, S. Armao, S. Bettati, S. Bruno, R. Percudani, B. Campanini and A. Mozzarelli, Sci. Rep., 2018, 8, 9016.

245 H. Mori, R. Wada, J. Li, T. Ishimoto, M. Mizuguchi, T. Obita, H. Gouda, S. Hirono and N. Toyooka, Bioorg. Med. Chem. Lett., 2014, 24, 3732-3735.

246 P. Malapati, V. S. Krishna and S. Dharmarajan, Int. J. Mycobact., 2018, 7, 76-83.

247 P. Malapati, V. S. Krishna, R. Nallangi, N. Meda, R. R. Srilakshmi and D. Sriram, Bioorg. Med. Chem., 2018, 26, 177-190.

248 P. Malapati, V. S. Krishna, R. Nallangi, R. R. Srilakshmi and D. Sriram, Eur. J. Med. Chem., 2018, 145, 23-34.

249 J. R. Duvall, L. Bedard, A. M. Naylor-Olsen, A. L. Manson, J. A. Bittker, W. Sun, M. E. Fitzgerald, Z. He, M. D. Lee, J.-C. Marie, G. Muncipinto, D. Rush, D. Xu, H. Xu, M. Zhang, A. M. Earl, M. A. Palmer, M. A. Foley, J. P. Vacca and C. A. Scherer, ACS Infect. Dis., 2017, 3, 349-359.

250 E. C. de Azevedo and A. S. Nascimento, J. Struct. Biol., 2019, 207, 158-168.

251 C. W. Tan, C. H. H. Hor, S. S. Kwek, H. K. Tee, I. C. Sam, E. L. K. Goh, E. E. Ooi, Y. F. Chan and L. F. Wang, Emerging Microbes Infect., 2019, 8, 426-437.

252 S. Hinderlich, M. Neuenschwander, P. R. Wratil, A. Oder, M. Lisurek, L. D. Nguyen, J. P. von Kries and C. P. R. Hackenberger, ChemBioChem, 2017, 18, 1279-1285.

253 O. Nieto-Garcia, P. R. Wratil, L. D. Nguyen, V. Böhrsch, S. Hinderlich, W. Reutter and C. P. R. Hackenberger, Chem. Sci., 2016, 7, 3928-3933.

254 R. E. Marsh, Acta Crystallogr., 1952, 5, 458-462.

255 M. A. Sun, Y. J. Wang, Q. Zhang, Y. J. Xia, W. Ge and D. J. Guo, BMC Genomics, 2017, 18, 279.

256 J. H. Zhang, T. D. Y. Chung and K. R. Oldenburg, J. Biomol. Screening, 1999, 4, 67-73.

257 J. Aretz, P. R. Wratil, E. C. Wamhoff, H. G. Nguyen, W. Reutter and C. Rademacher, Can. J. Chem., 2016, 94, 920-926.

258 S. L. van der Beek, Y. Le Breton, A. T. Ferenbach, R. N. Chapman, D. M. F. van Aalten, I. Navratilova, G. J. Boons, K. S. McIver, N. M. van Sorge and H. C. Dorfmueller, Mol. Microbiol., 2015, 98, 946-962.
259 S. L. van der Beek, A. Zorzoli, E. Çanak, R. N. Chapman, K. Lucas, B. H. Meyer, D. Evangelopoulos, L. P. S. de Carvalho, G.-J. Boons, H. C. Dorfmueller and N. M. van Sorge, Mol. Microbiol., 2019, 111, 951-964.

260 P. A. Mann, A. Müller, K. A. Wolff, T. Fischmann, H. Wang, P. Reed, Y. Hou, W. J. Li, C. E. Müller, J. Y. Xiao, N. Murgolo, X. W. Sher, T. Mayhood, P. R. Sheth, A. Mirza, M. Labroli, L. Xiao, M. McCoy, C. J. Gill, M. G. Pinho, T. Schneider and T. Roemer, PLoS Pathog., 2016, 12, e1005585.

261 D. Sasikala, J. Jeyakanthan and P. Srinivasan, J. Recept. Signal Transduction, 2016, 36, 515-530.

262 M. de Nóbrega, H. L. Cilião, M. F. de Souza, M. R. de Souza, J. M. Serpeloni, P. E. Fuganti and I. M. de Syllos Cólus, Genet. Mol. Biol., 2020, 43, e20180329.

263 H. Xie, L. Nie, M. Zhang, Z. Su, X. Chen, M. Xu, J. Gong, N. Chen and Q. Zhou, Exp. Ther. Med., 2020, 19, 1806-1816.

264 Z. Zhang, M. Garzotto, E. W. Davis, M. Mori, W. A. Stoller, P. E. Farris, C. P. Wong, L. M. Beaver, G. V. Thomas, D. E. Williams, R. H. Dashwood, D. A. Hendrix, E. Ho and J. Shannon, Nutr. Cancer, 2020, 72, 74-87.

265 H. Lee, M. Kim, S. H. Kim, Q. Tran, G. Kong, C. Kim, S. H. Kwon, J. Park, J. B. Park, S. Park and J. Park, Front. Oncol., 2020, 10, 550673.

266 K. Todorova, S. Hayrabedyan, T. Shamov, M. Karaivanov, A. Kuzmanov, S. Kyurkchiev and I. Kehayov, C. R. Acad. Bulg. Sci., 2007, 60, 1123-1126.

267 J. Mann, Chem. Soc. Rev., 1987, 16, 381-436.

268 B. M. Johnson, Y. Z. Shu, X. L. Zhuo and N. A. Meanwell, J. Med. Chem., 2020, 63, 6315-6386.

269 S. M. Lau, R. K. Brantley and C. Thorpe, Biochemistry, 1988, 27, 5089-5095.

270 P. Vock, S. Engst, M. Eder and S. Ghisla, Biochemistry, 1998, 37, 1848-1860.

271 R. Zhang, P. J. McIntyre, P. M. Collins, D. J. Foley, C. Arter, F. von Delft, R. Bayliss, S. Warriner and A. Nelson, Chem. Eur. J., 2019, 25, 6831-6839.

272 F. Lovering, J. Bikker and C. Humblet, J. Med. Chem., 2009, 52, 6752-6756.

273 W. P. Walters, J. Green, J. R. Weiss and M. A. Murcko, J. Med. Chem., 2011, 54, 6405-6416.

274 F. Giordanetto, C. Jin, L. Willmore, M. Feher and D. E. Shaw, J. Med. Chem., 2019, 62, 3381-3394.

275 D. A. Erlanson, I. J. P. de Esch, W. Jahnke, C. N. Johnson and P. N. Mortenson, J. Med. Chem., 2020, 63, 4430-4444.

276 C. N. Johnson, D. A. Erlanson, W. Jahnke, P. N. Mortenson and D. C. Rees, J. Med. Chem., 2018, 61, 1774-1784.

277 C. N. Johnson, D. A. Erlanson, C. W. Murray and D. C. Rees, J. Med. Chem., 2017, 60, 89-99.

278 P. N. Mortenson, D. A. Erlanson, I. J. P. de Esch, W. Jahnke and C. N. Johnson, J. Med. Chem., 2019, 62, 3857-3872.

279 G. M. Keserü, D. A. Erlanson, G. G. Ferenczy, M. M. Hann, C. W. Murray and S. D. Pickett, J. Med. Chem., 2016, 59, 8189-8206.

280 P. Kirsch, A. M. Hartman, A. K. H. Hirsch and M. Empting, Molecules, 2019, 24, 4309. 
281 M. R. Bentley, O. V. Ilyichova, G. Wang, M. L. Williams, G. Sharma, W. S. Alwan, R. L. Whitehouse, B. Mohanty, P. J. Scammells, B. Heras, J. L. Martin, M. Totsika, B. Capuano, B. C. Doak and M. J. Scanlon, J. Med. Chem., 2020, 63, 6863-6875.
282 S. W. Draxler, M. Bauer, C. Eickmeier, S. Nadal, H. Nar, D. Rangel Rojas, D. Seeliger, M. Zeeb and D. Fiegen, J. Med. Chem., 2020, 63, 5856-5864.

283 A. Bancet, C. Raingeval, T. Lomberget, M. Le Borgne, J.-F. Guichou and I. Krimm, J. Med. Chem., 2020, 63, 11420-11435. 